\title{
DISTRIBUTED OR CENTRALIZED HVAC: A PRACTICAL INVESTIGATION INTO HOUSEHOLD
} HEATING SYSTEMS

\author{
by \\ Morgan James Cunningham \\ B. Eng. , McMaster University (Hamilton, ON), 2012 \\ A thesis \\ presented to Ryerson University \\ in partial fulfillment of the \\ requirements for the degree of \\ Master of Applied Science \\ in the Program of \\ Electrical and Computer Engineering
}

Toronto, Ontario, Canada, 2014

(C) Morgan James Cunningham, 2014 


\section{AUTHOR'S DECLARATION FOR ELECTRONIC SUBMISSION OF THESIS}

I hereby declare that I am the sole author of this thesis. This is a true copy of the thesis, including and required final revisions, as accepted by my examiners.

I hereby authorize Ryerson University to lend this thesis to other institutions or individuals for the purpose of scholarly research.

I further authorize Ryerson University to reproduce this thesis by photocopying or by other means, in total or in part, at the request of other institutions or individuals for the purpose of scholarly research.

I understand that, my thesis may be made electronically available to the public. 


\begin{abstract}
DISTRIBUTED OR CENTRALIZED HVAC: A PRACTICAL INVESTIGATION INTO HOUSEHOLD HEATING SYSTEMS
\end{abstract}

\author{
by \\ Morgan James Cunningham \\ Electrical and Computer Engineering \\ Master of Applied Science \\ Ryerson University, 2014
}

Three main questions pertaining to household heating were and answered through rigorous empirical testing;

- Is it more efficient to keep a house at constant temperature throughout the day, or should the temperature be allowed to dip when unoccupied?

- Is it possible to build a scale-model house with proper thermal ballasting to simulate and verify the first question?

- Can the empirical results be used to verify whether or not steady state models of heat transfer (for simplicity's sake) can provide reasonably accurate results?

It was observed that keeping a house at constant temperature is inefficient and causes over cycling of electro-mechanical equipment. Continuing on, it is possible to build a scale-model house to mimic reality, however, care is needed in the design process if you wish to have similar volumetric time constants. And finally, steady-state models can be implemented to predict energy input, but with a certain degree of error. 


\section{ACKNOWLEDGEMENTS}

First and foremost, I would like to thank one of my mentors, Mr. Wen Chan, for providing me with exceptional guidance throughout my educational journey.

To my colleagues Dr. Ravi Gopal, Dr. Sherman Hon and Mr. Tony Wei who guided me with the development of various modelling and experimental setups, because apparently, not everything can be based on assumptions. Reality and physics eventually begin to ruin scale models, and it's nice to have mentors who can lead you away from making the same mistakes already they have.

To my parents, whose house was my personal laboratory of destruction that fueled my interest in Engineering.

To my friend and classmate, Steven, who convinced me to keep going when I felt like quitting and provided tactical support when required.

And a very special thank you to my supervisor, Dr. Kaamran Raahemifar who took a chance on me and supervised a Masters thesis coming from an industry point-of-view. He has enabled me to think outside the box and never stopped challenging me to do better things along the way. 


\section{TABLE OF CONTENTS}

Author's Declaration $\quad$ ii

Abstract iii

Acknowledgements

Table of Contents $\quad$ v-vi

List of Tables vii

List of Figures $\quad$ viii-ix

List of Appendices $\quad$ X

Chapter 1

1 Introduction 1

Chapter 2

2 Home Heating Systems 4

2.1 Thermostats 6

2.2 Home Insulation $\quad 7$

\section{Chapter 3}

3 Apparatus - Model House Construction 9

3.1 Apparatus - Electrical Heating/Control Hardware 14

3.2 Notes on Circuit Design and Implementation 24

3.3 The Surface Area : Volume Problem - 'Tuning' the house 26

3.4 Model House Limitations and Chapter Summary 29

\section{Chapter 4}

4 Computational Setup $\quad 30$

4.1 Conductive Model 33

4.2 Convective Model 34

\section{Chapter 5}

5 Model Home Experiments $\quad 37$

5.1 Test 1: Constant Temperature with Zoned Heating 38

5.2 Test 2: Constant Temperature with Central Heating Control 40

5.3 Test 3: Occupancy Program with Zoned Heating 41

5.4 Test 4: Occupancy Program with Central Heating Control 42

5.5 A Note on Thermostat Placement $\quad 43$

5.6 Model House - Conclusions 44

5.7 Heating Scheme Tests - Full-Sized House $\quad 45$

5.8 Test \#5 - Fixed Thermostat Set-Point 46

5.9 Test \#6 - Occupancy-Based Thermostat Program 47

5.10 Tuning the Model House: How Did We Do? 47

5.11 Full-Sized House - Conclusions 50 


\section{Chapter 6}

6 Conclusion 52

6.1 To Zone, or Not to Zone?

6.2 Future Work 56

6.3 Model Home Simulation and Control 56

6.4 Improved Mathematical Modelling $\quad 58$

\section{Appendices}

$\begin{array}{lll}\text { Appendix A } & \text { Assorted Tables } & 61\end{array}$

$\begin{array}{lll}\text { Appendix B } & \text { Details of Model House Construction } & 62\end{array}$

$\begin{array}{lll}\text { Appendix C Visual Presentation of Results } & 71\end{array}$

$\begin{array}{ll}\text { References } & 76\end{array}$ 


\section{LIST OF TABLES}

Table 1 - Raw Temperature and Resistance Data of 103JT-75 Thermistor 20

Table 2 - Thermistor Data in Voltage Divider Implementation (Vin =5V) 21

Table 3 - Dimensions Used to Calculate the Inner Surface Area of the Model House 31

Table 4 - Dimensions Used to Calculate the Inner Surface Area of the Full-Sized House 31

Table 5 - Organization of Model House Testing Plan 37

Table 6 - Model House Data from Test 1 with Volume 44

Table 7 - Model House Data from Test 1 with Surface Area 45

Table 8 - Organization of Full-Size House Testing Plan 46

Table 9 - Data Points Used to Solve for the Model House's b/a Factor 49

Table 10 - Data Points Used to Solve for the Full-Sized House's b/a Factor 49

Table 11 - Bill of Materials Required for a 4-Zone HVAC System 55

Table 12 - Sample Occupancy-Based Control Matrix as an Input 57

Table 13 - Densities of Relevant Materials $\quad 61$

Table 14 - Specific Heat Capacities of Relevant Materials 61

Table 15 - Electrical control system bill of materials 63

Table 16 - Dimensional Data of Full-Size House 65

Table 17 - Dimensional Data of Model House with Calculated Concrete Ballasting Data 66 


\section{LIST OF FIGURES}

Figure 1 - Diagram Showing the Tendency for Houses to Have Hot and Cold Spots with Standard Heating Systems

Figure 2 - Diagram of a Standard Passive Forced-Air System

Figure 3 - Diagram of a 2-Zone Forced-Air System 6

Figure 4 - Basement Frame (Upside Down) With Insulated Deck 10

$\begin{array}{ll}\text { Figure } 5 \text { - Wall Frames Showing Insulation } & 10\end{array}$

Figure 6 - Aluminum Wall Structures 11

Figure 7 - Cross Section of Model House Wall 12

Figure 8 - Cross Section of Typical Residential Wall Construction 13

Figure 9 - Cross Section of Model House Roof and Basement 14

Figure 10 - Components of the Heating Modules Found Throughout the Model House 15

Figure 11 - Plan View of the Model House Showing the Location of Thermistors and Heating $\begin{array}{ll}\text { Modules } & 16\end{array}$

Figure 12 - LabJack U3-HV Interface 17

Figure 13 - LabJack CB-15 Expansion Board 17

Figure 14 - Typical installation of thermistors throughout the model house 18

$\begin{array}{ll}\text { Figure } 15 \text { - Voltage Divider with R2 as a Thermistor } & 19\end{array}$

Figure 16 - Resistance-Temperature Trend of 103JT-75 Thermistor 21

Figure 17 - Expected Voltage Values of Thermistor in Voltage Divider Setup (Vin = 5V) 22

Figure 18 - Plot of Parabola Obtained with Solved A, B and C Values Showing the Useable

Region of Voltage 23

Figure 19 - Completed 'Perf' Board Used to Mount Electronics (Relays on Bottom Side) 26

Figure 20 - Steady-State One-Dimensional Heat Transfer 32

Figure 21 - Simplified Model of Convective Heat Transfer 34

Figure 22 - Comparison of Energy Usage: Steady-State Models Versus Empirical Values 36

Figure 23 - Fifteen Minute Sample of Data from Test 1

Figure 24 - Room-by-Room Analysis of Average Temperature and Energy Used in Test 139

Figure 25 - Fifteen Minute Sample of Data from Test 2 Showing Rooms Acting in Unison 40

Figure 26 - Room-by-Room Analysis of Average Temperature and Energy Used in Test 241 Figure 27 - Room-by-Room Analysis of Average Temperature and Energy Used in Test 342 Figure 28 - Room-by-Room Analysis of Average Temperature and Energy Used in Test 443 Figure 29 - Electrical Analogue of the Heat Loss Model 52

Figure 30 - Pictorial of the Finite Difference 2-D Heat Loss Model 59

Figure 31 - Full Schematic of Model House Control/Heating System 64 Figure 32 - The LabView Control Interface Showing Temperature Gauges, Thermostat High and Low Limit Set-Points 
Figure 33 - One Version of the LabView Block Diagram to Automate the Model House 68

Figure 34 - Data Used to Calculate 'b/a' Constant for Model House 69

Figure 35 - HP 34970A and Data Logging Computer Setup Used for Full-Scale Testing 70

Figure 36 - Summary of Energy Input over 8-Hour Duration of Model House Test Cases 72

Figure 37 - Summary of Energy Input and Average Temperature Data over 24-Hour

Duration of All Full-Sized House Test Cases (Note: BTU Converted to kWh) 73

Figure 38 - Test 5: Temperature and Heating Data of the Full-Sized House (Constant

Temperature Scheme)

Figure 39 - Test 6: Temperature and Heating Data of the Full-Sized House (OccupancyBased Temperature Scheme) 


\section{LIST OF APPENDICES}

Appendix A

Assorted Tables

67

Appendix B

Details of Model House Construction

68

Appendix C

Visual Presentation of Results 


\section{Chapter 1}

\section{INTRODUCTION}

\section{Introduction}

The debate surrounding the optimal method to heat a house is one that rages on in hardware stores, product brochures and internet forums alike. The primary question in this debate is: 'Should a house remain at constant temperature throughout the day, or should the temperature be modulated to obtain some level of perceived efficiency to the building owner?' Tied in with that question is another area of interest which asks 'whether or not a property's heating system should be controlled from a centralized thermostat, or from multiple thermostats located around the house with zoned-off heating mechanisms?' When posed with these, a question became obvious; 'Can a model house be built from realistic materials which can deliver the answers?' Additionally, asked myself if some simplified models could be validated against empirical results to suit those who aren't experts at thermodynamics? The questions above were burning inside me, so I made it the focus of this thesis to find the answers.

The home comfort industry seems to think that temperature modulation is the route to pursue; this can be easily determined by a walk through your local big box store where you will most likely be hard-pressed to find a thermostat that isn't programmable. Take the Nest thermostat, for example, which is designed to 'learn' the heating requirements of a household in hopes of saving up to $36.1 \%$ on energy costs [1].The main mechanism behind this thermostat is an occupancy sensor which tracks when people are present and adjusts an active scheduling program in attempt to keep the area at a comfortable temperature when the occupants may be home. 
The next question arises from today's push to incorporate 'smart' technologies into homes to strive for overall energy efficiency. The technology is now available to isolate rooms from each other (in terms of heat/air distribution) and coupled with room-byroom thermostats, allows independent monitoring and control of heating demands in rooms. The most trivial use for this type of scheme arises from the natural convention currents that occur in nature, where hot air masses will always rise to the top of a vessel, leaving colder masses at the bottom (see Figure 1). It is for this reason that, in general, the basements in dwellings will be noticeably cooler than the upper floors. Zoned heating systems are theoretically able to mitigate these temperature gradients by applying heat only where it is necessary as determined by the commanded heat setting in a particular zone [2].

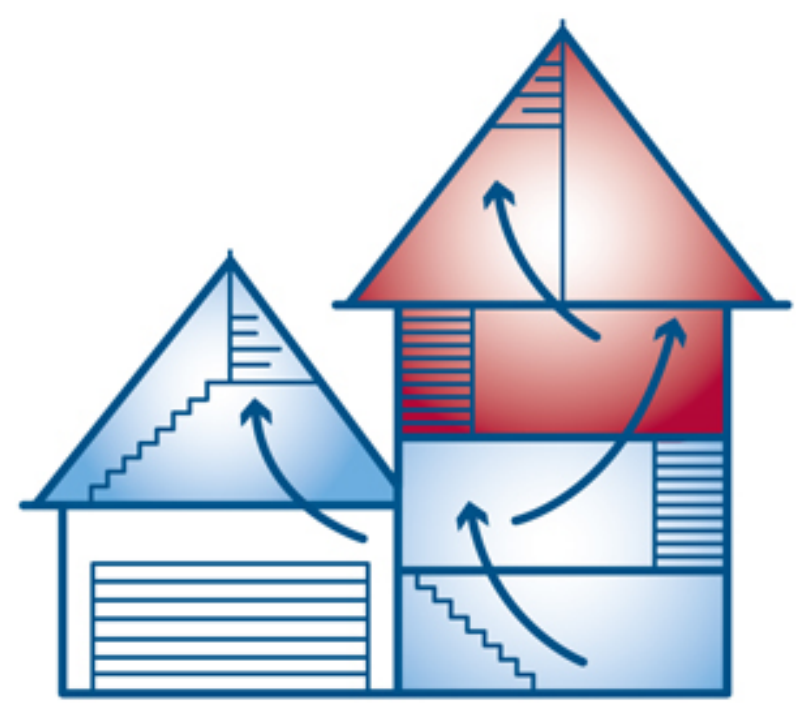

Figure 1 - Diagram Showing the Tendency for Houses to Have Hot and Cold Spots with Standard Heating Systems

The remaining questions were left to be answered upon construction and testing of the model house test bed and were pursued with more of an industry focus. Being able to apply this study directly to the real world is a large motivation for taking a practical approach, with the mathematics taking more of a back seat for guidance purposes. 
The goal was to write this thesis in such a way that many audiences could appreciate various portions of it. As an electrical engineering graduate, there's a lot of emphasis on the electrical hardware/control system side of things. As an electrical engineering graduate who has an elementary knowledge of heat transfer, there's not as much detail into this topic. If you don't happen to be an engineer, or scientific for that matter, then I hope that my descriptions are clear and succinct enough that you can draw your own conclusions about heat loss and efficiency. Ultimately, someone with a little electrical/mechanical knowhow should be able to replicate my research test-bed and end up with results similar to mine. 


\section{Chapter 2}

\section{BACKGROUND TO PROBLEM}

\section{Home Heating Systems}

The principles behind this thesis will be much more understandable with a general overview of how heating systems are typically configured and installed in today's modern houses.

The vast majority of North American houses utilize a central heating system which can vary in terms of its prime heating source and delivery medium. A large number of systems rely on a natural gas burner heating an air-to-air heat exchanger, with a blower which circulates the heated air through metal ducting to heat rooms in a house. Other systems utilize an electric-resistive source to generate the heat, and it is similarly distributed with a blower throughout a house. Conversely, the same two systems mentioned above can also utilize water or glycol as the heat transfer medium utilizing smaller pipes routed throughout a house.

All of these systems have the ability to be controlled from a centralized thermostat, or from multiple thermostats mounted throughout a house to heat only the rooms which require a temperature adjustment. Systems which allow independent control of temperature in different rooms around the house are known as zoned systems. Systems of this nature are popping up more and more with the 'smart home' movement and, in some cases, are being retrofitted into existing dwellings.

Regardless of the heat exchange medium (air, water etc.), zoning is achieved by redirecting or cutting-off the flow of the medium based on readings from zone-by-zone thermostats. The theory behind this system is that only the rooms which require adjustment will be provided to, thus reducing system waste to save on energy. Figure 2 shows the diagram of a passive system where all rooms are tended to at once, determined by the readings of a 
single thermostat. In this case, dampers are manually adjusted by occupants and leave little room for customization.

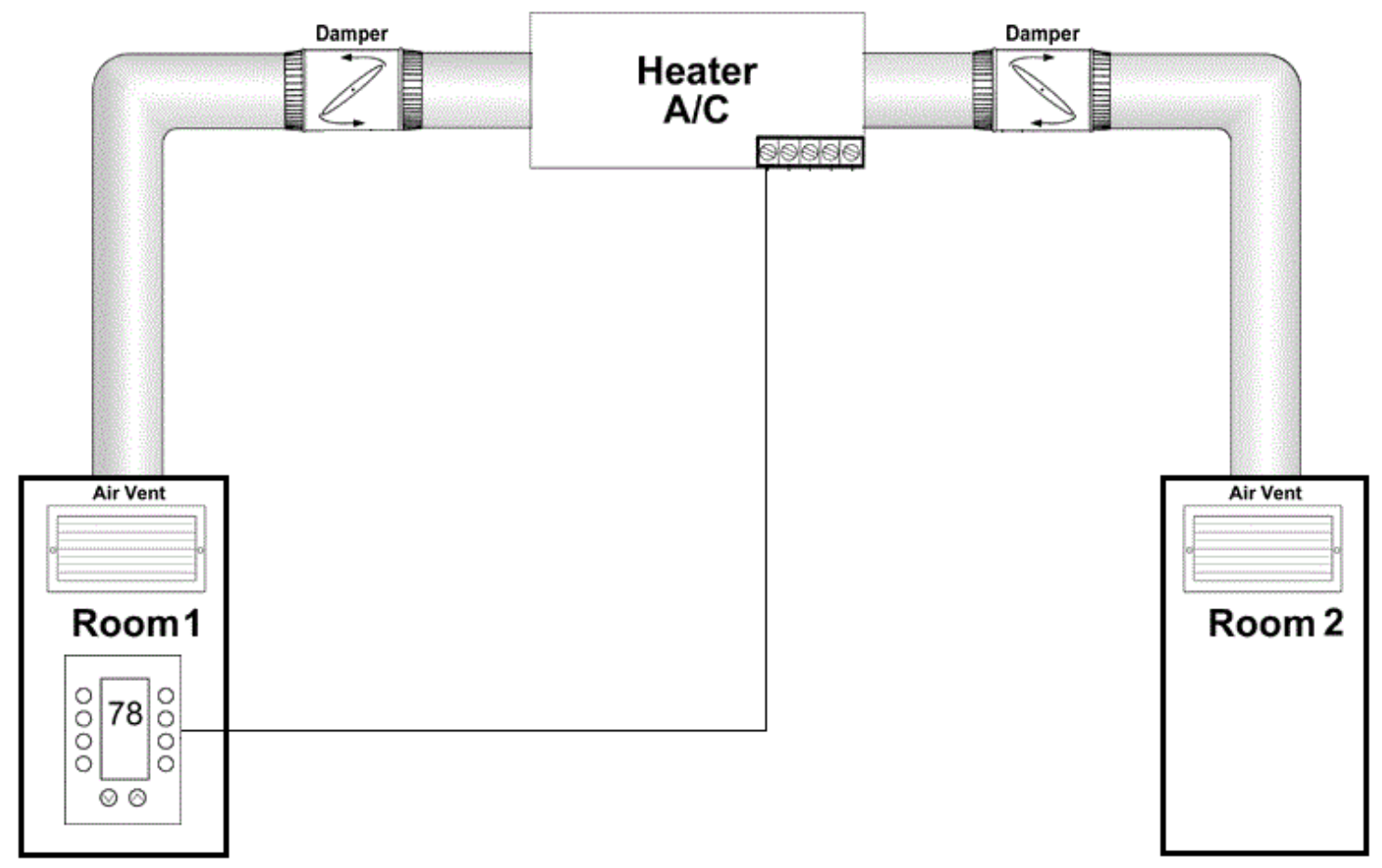

Figure 2 - Diagram of a Standard Passive Forced-Air System (adapted from [3])

Figure 3, on the other hand, shows the setup of a 2-zone system which has activelycontrolled dampers via thermostats in each zone. As a side note, the reader must know that zoned systems typically require bypass valves, or variable-speed fan blowers to discharge or cut back on air flow to compensate for the potential decrease in apparent pipe volume. System manufacturers provide the necessary hardware and guides to accomplish this. 


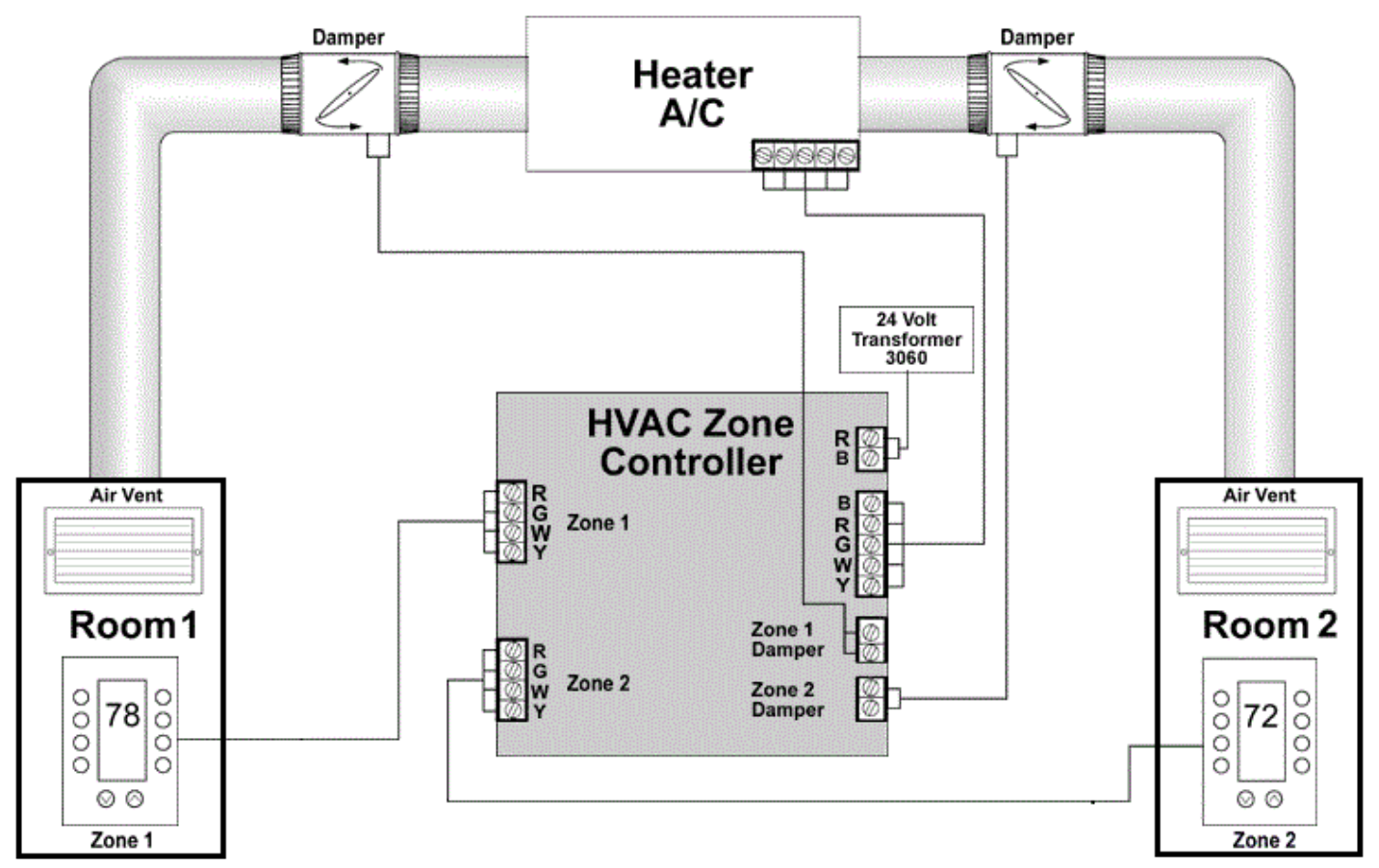

Figure 3 - Diagram of a 2-Zone Forced-Air System [3]

While a zoned system may make more sense on face value because of the potential for energy savings, it does have the disadvantage of being more difficult to retrofit into an existing house due to the need to install control systems in each room as well as dedicated ducts and dampers to independently control. In many cases, home builders will daisy-chain multiple rooms off of one duct run in order to save on material cost (this can reduce the customizability of a system). On top of this is the added cost of control system hardware and the ongoing energy required to power the control system. Having said this, it may make economic sense to install such a system into new home installations and a quick conclusion on this cost will be made later on in the study.

\subsection{Thermostats}

In its simplest form, a thermostat is a device which is used to read and set temperature. These devices are connected to a heating-ventilation-air-conditioning (HVAC) system and activates the desired function (heat, cool) when the ambient room temperature falls outside of the set-point temperature range. Early thermostats utilized bimetallic strips to 
detect temperature, while newer devices are based on semiconductor devices to sense temperature.

Early thermostats were entirely mechanical-based and normally enabled the occupants to set one target temperature only. With the advent of microcontrollers, it became possible to manufacture digital thermostats which could have schedules with variable temperatures programmed into them. With this capability in mind, it is possible to estimate when occupants will be away, active or sleeping and program the temperature according in hopes of saving on energy costs.

An important thing to note is that thermostats are configured with a certain degree of dead band in the range of $1^{\circ} \mathrm{C} / \mathrm{F}$ [4]. A dead band is what amounts to 'slush room' in a set-point to avoid frequent switching of electro-mechanical equipment. So even though a thermostat might be set to hold $25^{\circ} \mathrm{C}$, the ambient temperature may be allowed to fall to $24^{\circ} \mathrm{C}$ before it decides to turn on the equipment. Frequent switching can wear our devices such as; relays, start capacitors and motors.

\subsection{Home Insulation}

Homes and building are typically insulated during their construction to decrease the amount of heat loss a building might experience. Before an interior wall is closed in, interior voids are filled with an insulating material from floor-to-ceiling. There are three main types of insulation used in today's homes: fibreglass (pink), mineral-based (Roxul) and closed-cell spray-in foam. In specialized applications, expanded polystyrene (EPS) maybe be used [5]. Insulations are rated based on their R-value, resistance to heat and fire as well as acoustic damping capabilities. Principal importance to a typical home owner is the R-value, which states how well a type of insulation will keep heat in. R-value can be defined as:

$$
R=\frac{L}{k}
$$


Where $\mathrm{L}$ is the thickness of an insulating material, and $\mathrm{k}$ is the thermal conductivity (a physical property) of the material. Typical insulations will have very low values of thermal conductivity which lead to a high R-value. Although air, on its own, has a smaller thermal conductivity, it tends to exchange more heat than typical thermal insulators due to its gaseous nature and the presence of convection currents in leaky wall spaces. Closed-cell insulations hold onto small pockets of air, limiting its movement, and create an overall effective thermal conductivity that would be much lower than air in a practical implementation [6], [7].

Modern-day house construction, from outside-to-inside, typically consists of brick, plywood, plastic vapour wrap, stud bays (open voids before insulating) and drywall. The stud bays are created due to the nature of the 2" x 4" (actual dimensions: 1.5" x 3.5") wooden boards being used to create a void for insulating material. Walls are insulated from floor-to-ceiling and provide thermal and acoustic regulation. Typical R-values for this application are 12-14 and homeowners willing to go the extra mile can opt for 2" x 6" studs (actual dimensions: 1.5" x 5.5") in their homes during construction to obtain R-values up to 24 for added gains in noise and efficiency. 


\section{Chapter 3}

\section{EXPERIMENTAL SETUP}

\section{Apparatus - Model House Construction}

In order to go through with the study, an experimental apparatus was designed and built to create a miniature heating ecosystem. In its simplest form, the constructed building was based on one-storey of a $6.096 \mathrm{~m} \times 12.192 \mathrm{~m}$ house. The dimensions of this house were scaled down linearly by a factor of 6.667 corresponding to the author's current place of residence in order to keep a realistic floor plan and volumetric area to heat. The dimensions of the model home were set to $0.9144 \mathrm{~m} \times 1.8288 \mathrm{~m}$. This house features 1 master bedroom (dimensions $0.92 \mathrm{~m} \times 0.82 \mathrm{~m} \times 0.3048$ ), 2 smaller bedrooms (dimensions $0.45 \mathrm{~m} \times 0.45 \mathrm{~m} \times 0.30 \mathrm{~m}$ ) and a large central area (dimensions $0.92 \mathrm{~m} \times 0.45 \mathrm{~m} \times 0.30 \mathrm{~m}$ ) to simulate an open-concept kitchen and living room. Because of the quadratic and cubic scaling associated with surface area and room volume, respectively, there was a demand for artificial thermal mass ballasting, which is discussed in more detail later on in Chapter 3.

The house was built out of modern-day building materials such as; pine, plywood, Styrofoam and closed-cell insulation as can be seen in Figure 4 and Figure 5. The only exception made during the construction process was a practical one in which the main frame of the house was constructed out of alloy 6061 aluminum. If the frame had been built to [linear] scale out of wood, the durability and strength of the house would have been compromised seeing as a standard 2" x 4" pine joist would have been machined down by the linear scaling factor of 6.667 to 0.299 " x 0.599 ". The frame provides the main strength component in this implementation and was, therefore, built out of aluminum to deliver high-strength in small dimensions to ensure no damage during experimentation/transportation; see Figure 6. 


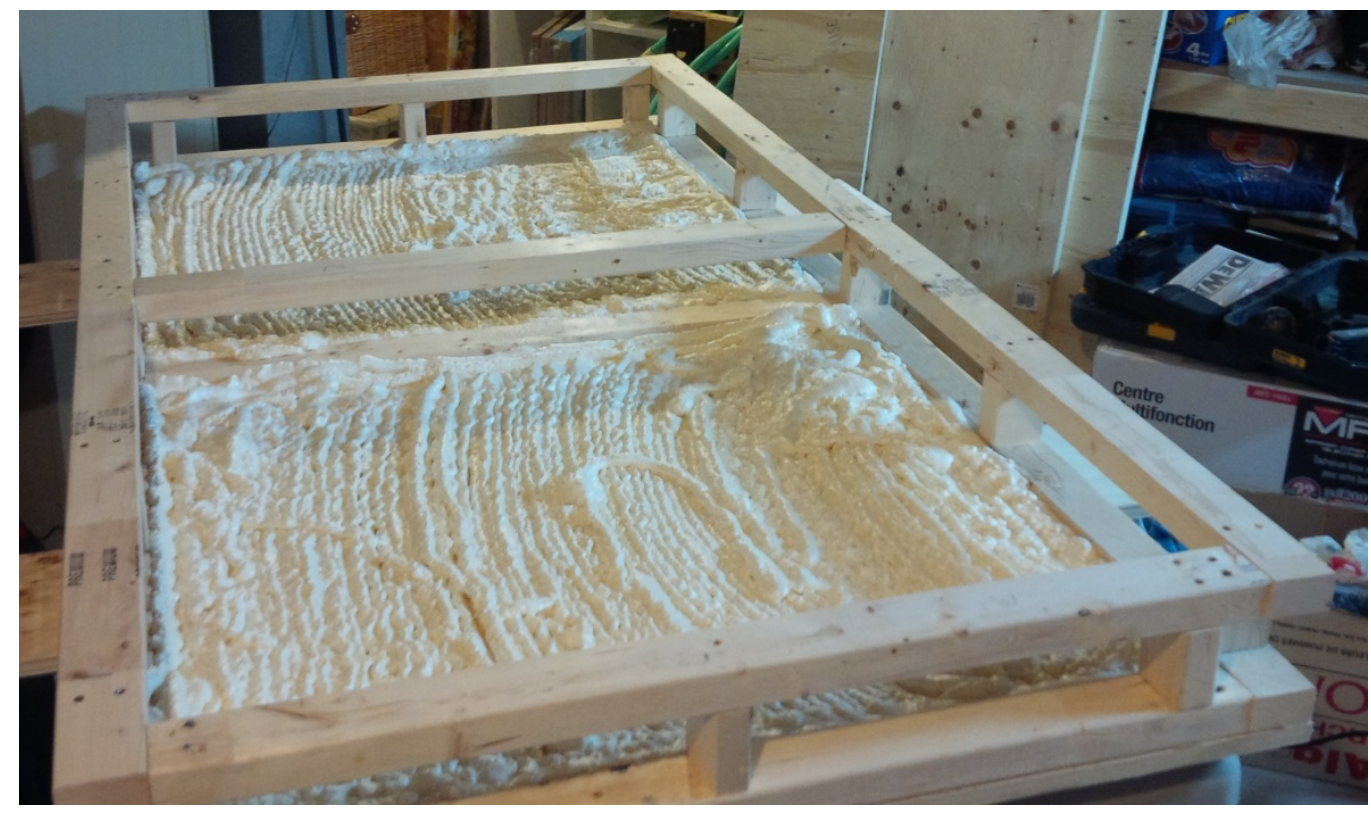

Figure 4 - Basement Frame (Upside Down) With Insulated Deck

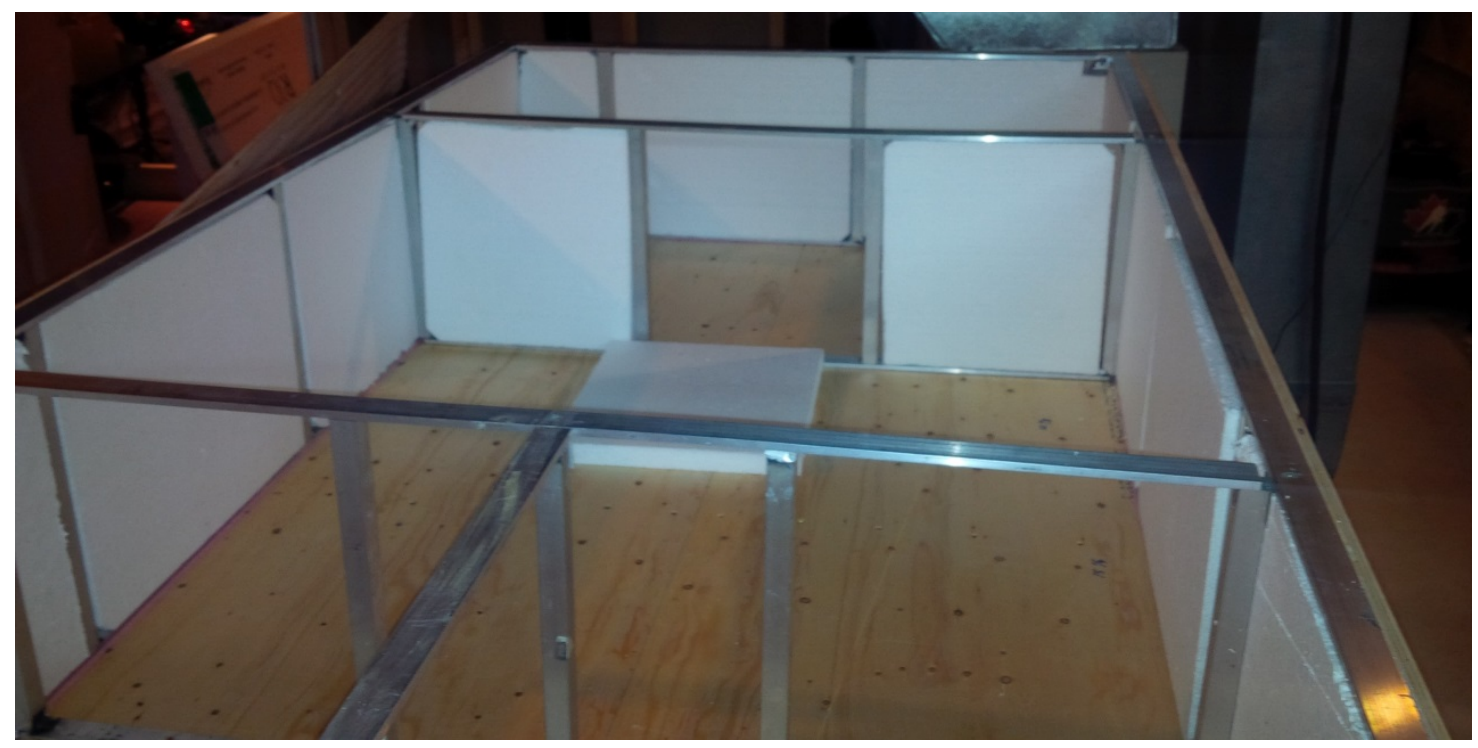

Figure 5 - Wall Frames Showing Insulation

Once the walls were framed and erected, they were insulated using expanded polystyrene foam insulation one inch thick. This thickness of insulation corresponds to an R-Value of 3.75 as seen in Figure 7 which, when scaled up by the linear scaling factor, is approximately equal to the equivalent total R-Value of a modern-day house shown in Figure 8. 
Today's modern houses typically have peaked roofs which should contain an insulation layer up to R60, as in the author's area of residence [8]. The model house's roof and floor was built in a similar manner to ensure that the scaled-down insulation value were substantially more than that of the walls, demonstrated in Figure 9. The hope is that minimal heat will be lost through these two surfaces and that they may be neglected further on in the study.

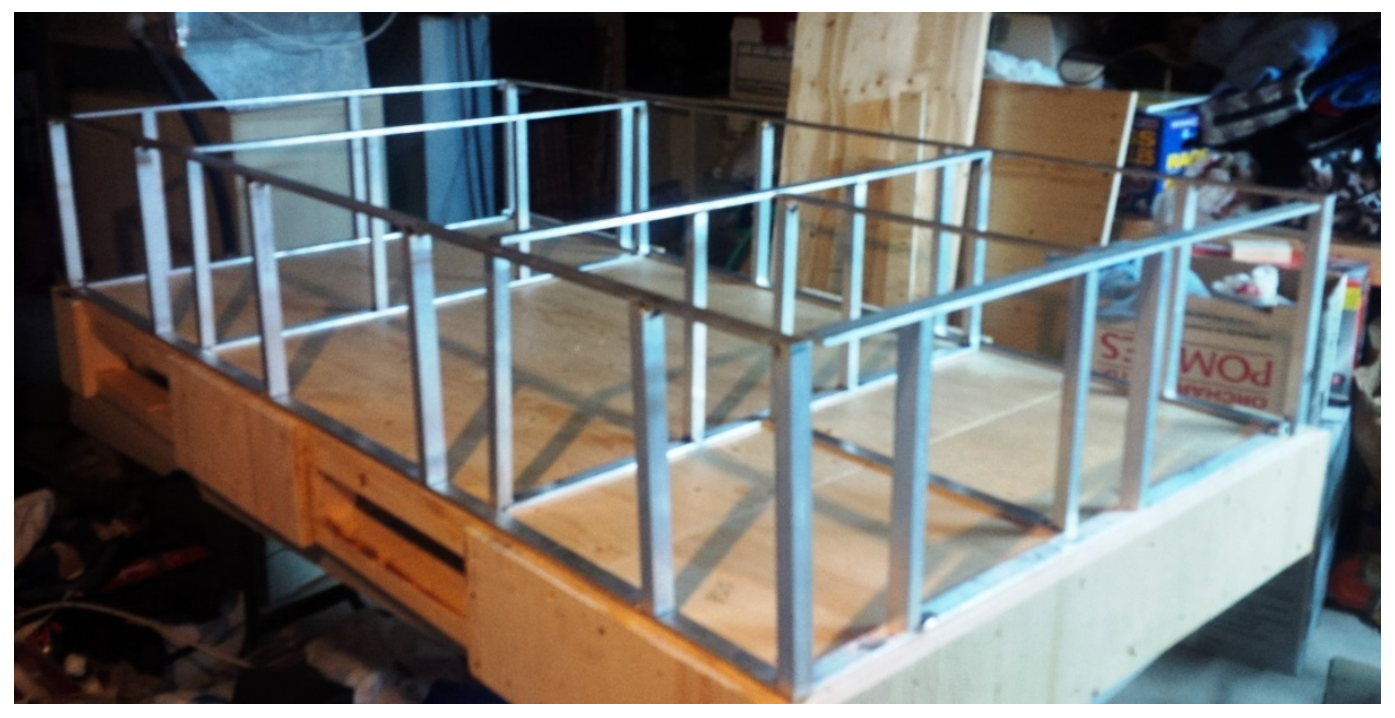

Figure 6 - Aluminum Wall Structures 


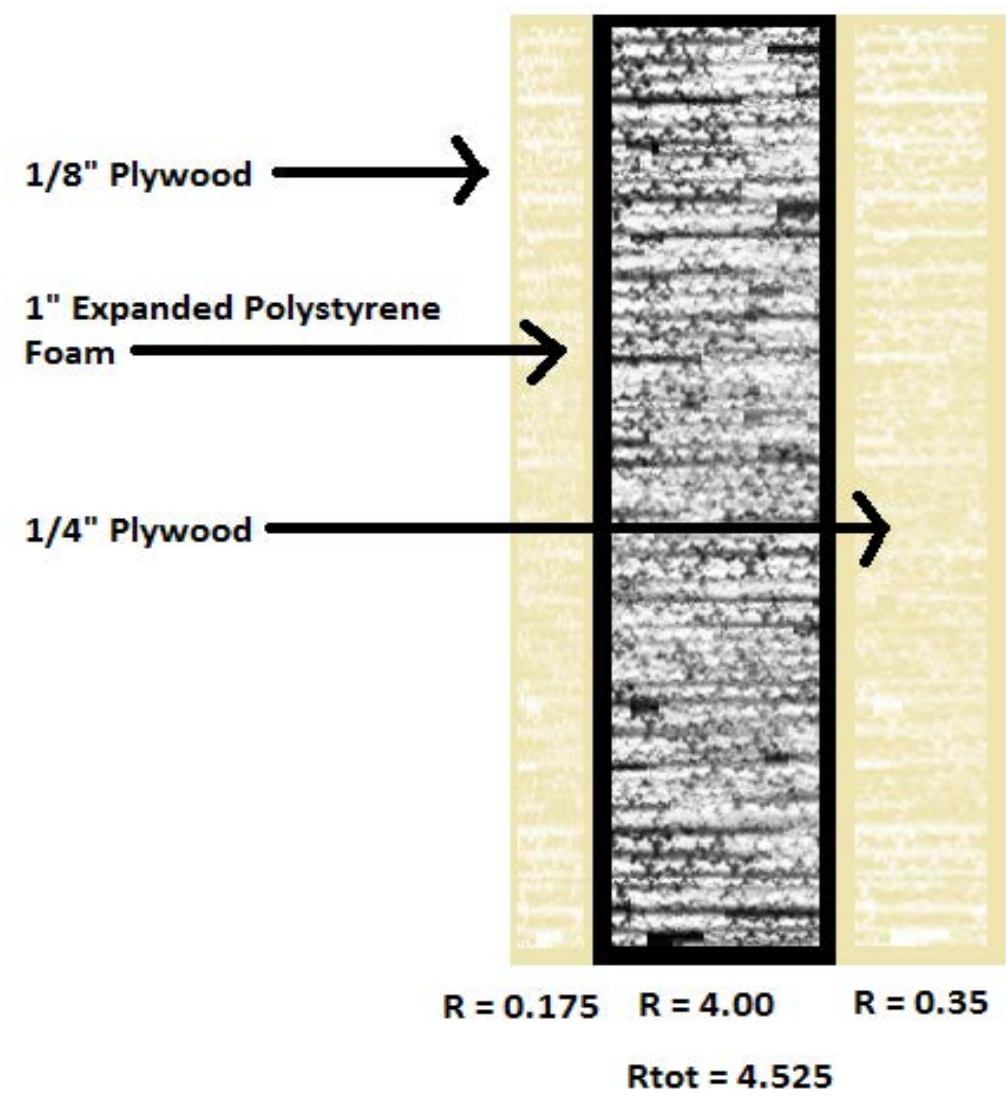

Figure 7 - Cross Section of Model House Wall 


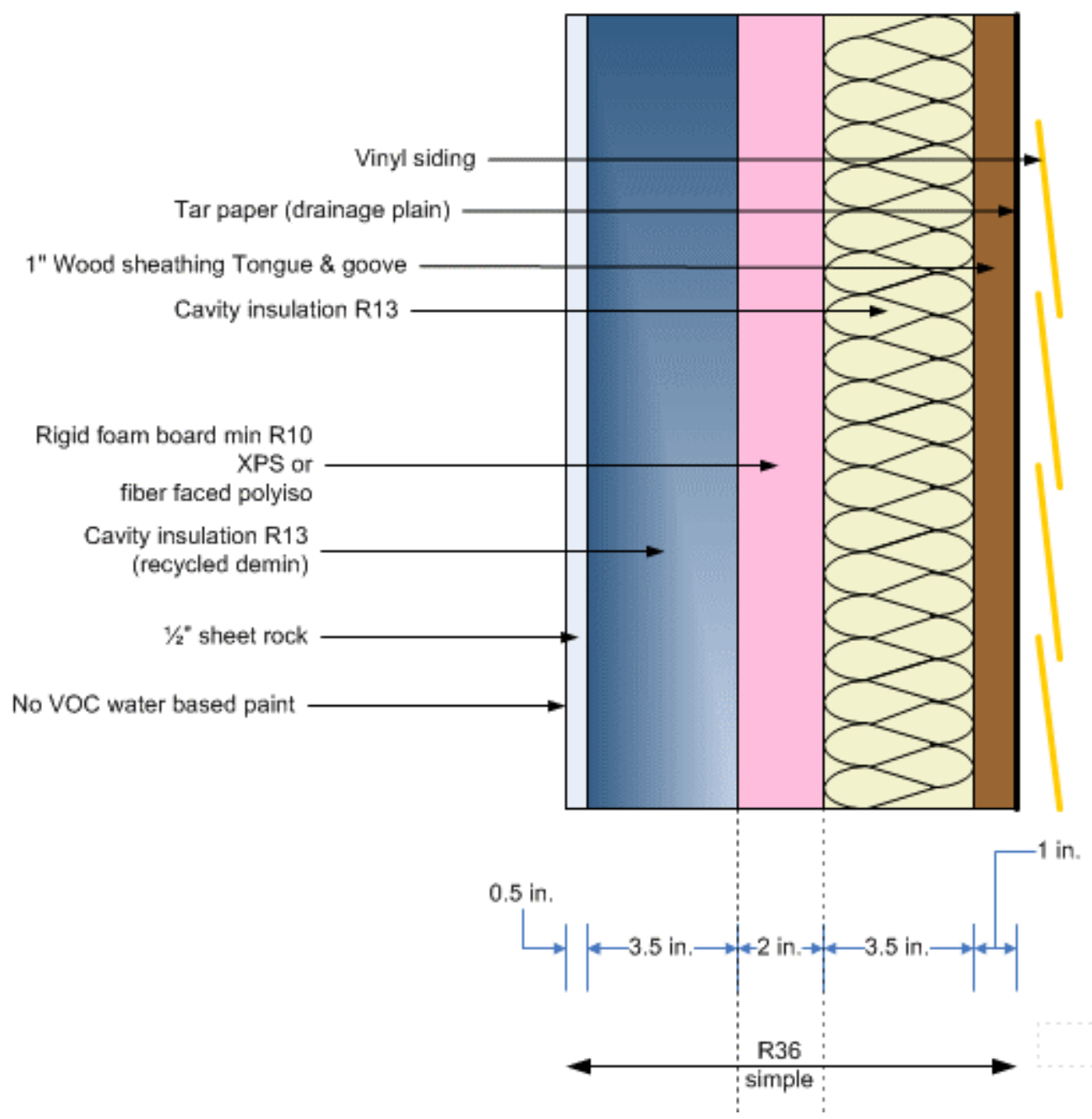

Figure 8 - Cross Section of Typical Residential Wall Construction 


\section{Roof/Attic}

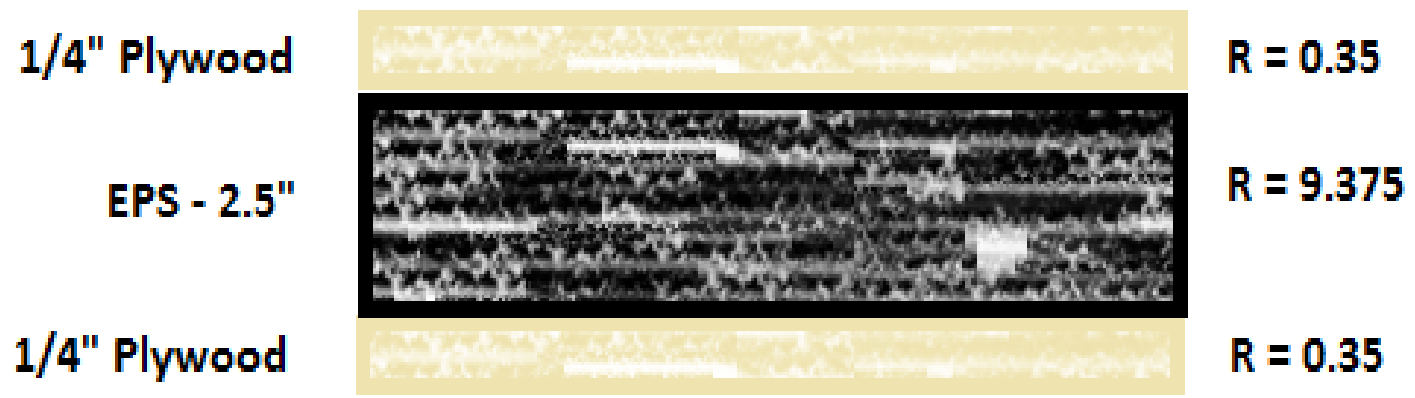

\section{Wallspace}

\section{3/4 Plywood}

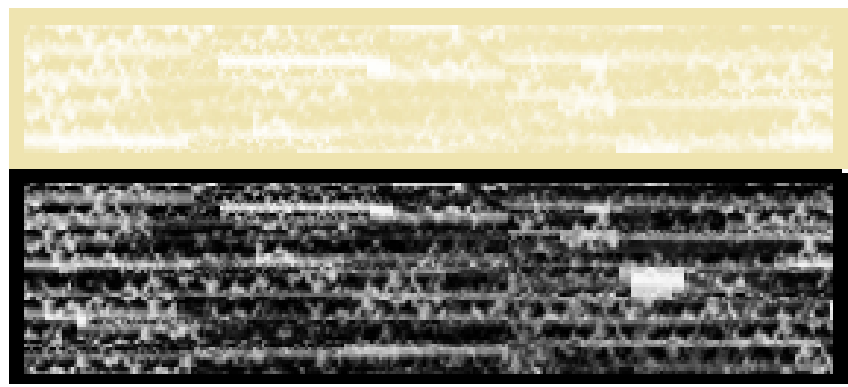

$R=1.05$

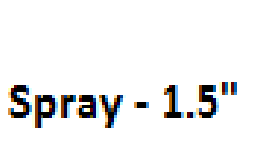

\section{Basement}

Figure 9 - Cross Section of Model House Roof and Basement

\subsection{Apparatus - Electrical Heating/Control Hardware}

The heating scheme designed for the model house is an electric-resistive, forced-air system with heating modules in each room. Each of these heating modules is comprised of a highpower $25 \Omega$ resistor running at $24 \mathrm{~V}$ and a small $12 \mathrm{~V}$ fan blowing directly on top of it to disperse the heat and simulate the air flow in a normal house's forced air system (see Figure 10). These are, in turn, mounted on top of an aluminum mounting plate and concrete ballast (whose purpose described later on). This module design was selected due 
to its relative ease of construction and control, low cost and high degree of reliability as compared to a centralized forced-air system which would require exotic controls and piping hardware. Furthermore, using resistors of a known value greatly simplifies the calculation of energy inputted into the system since the formulas for power/energy are trivial.

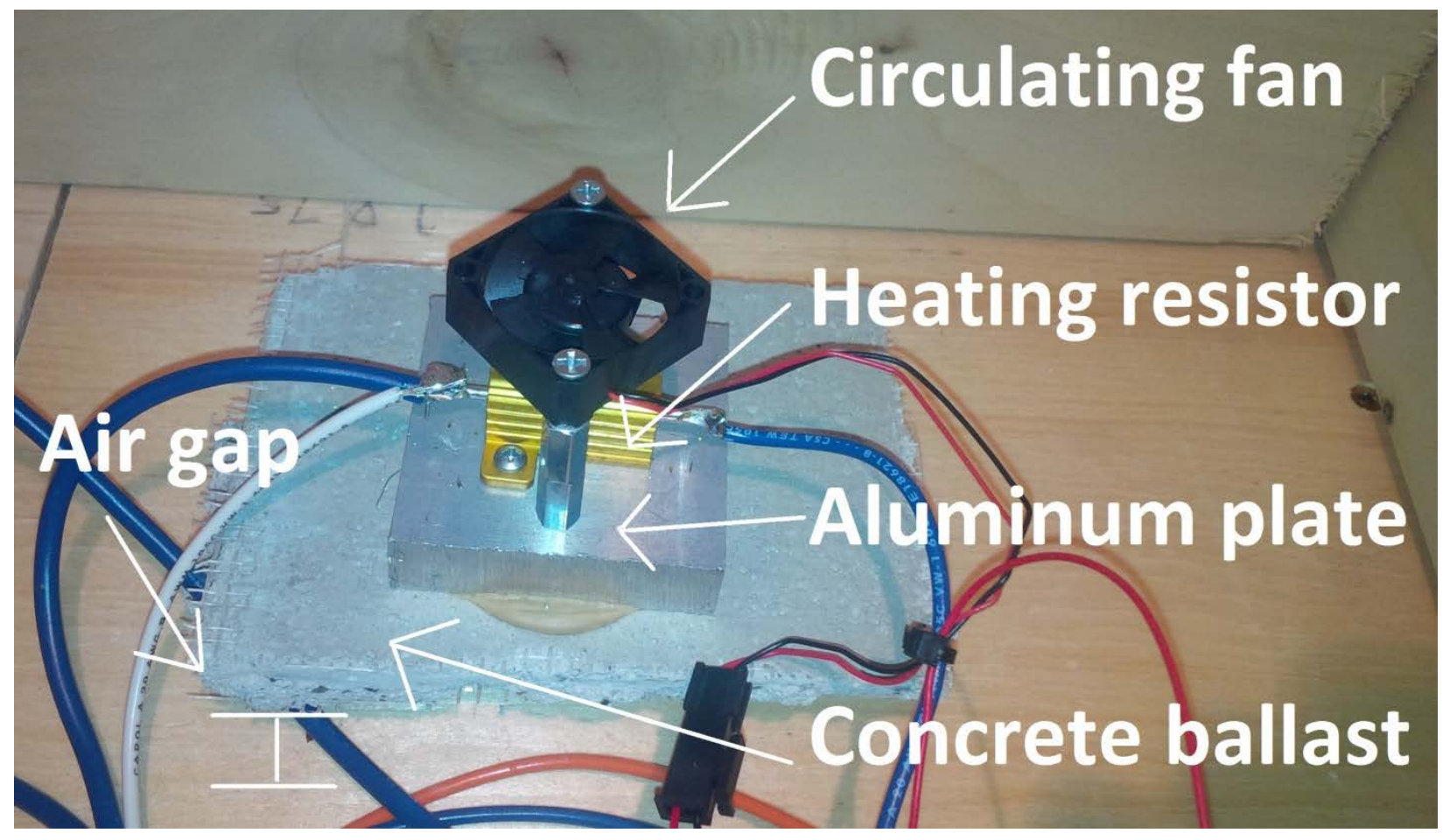

Figure 10 - Components of the Heating Modules Found Throughout the Model House

The thermistors and heating modules were mounted throughout the model house with a certain degree of randomness (see Figure 11) rather than in centralized locations. The hope with a random placement was to develop some discussion points after experimentation. 


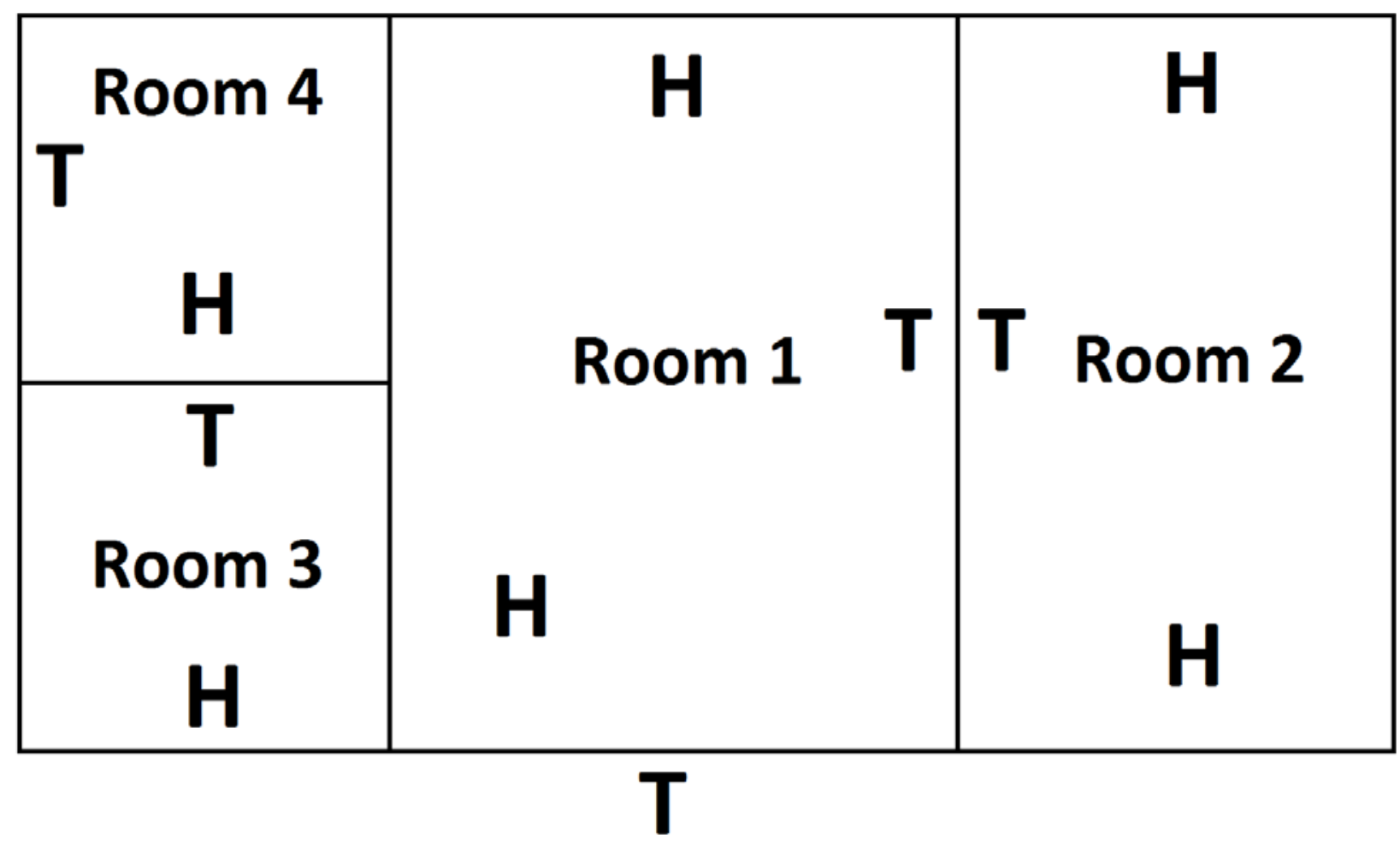

Figure 11 - Plan View of the Model House Showing the Location of Thermistors (T) and Heating Modules (H)

In the case of the larger rooms (1\&2), it makes sense to scatter the heating modules far away from each other such that the room can be heated in an even manner. The thermistors in those two rooms were mounted on the walls, rather than in the exact centre of the rooms in order to mimic the conventions used for thermostat mounting in today's homes. The layouts used in rooms $3 \& 4$ were selected in such a way that would hopefully provide some insight into factors that can affect heating performance (more on this in Chapter 5). It is reasonable to think that if the room layouts were identical (everything centrally mounted) that equal amounts of energy would be required to heat them. This is not interesting as rooms, in practice, are not designed in this manner.

The central nervous system of this home is based on the LabJack U3-HV data acquisition and control module with the CB-15 expansion board running in a LabView 7.1 environment over USB to a laptop shown in Figure 12 and Figure 13. 


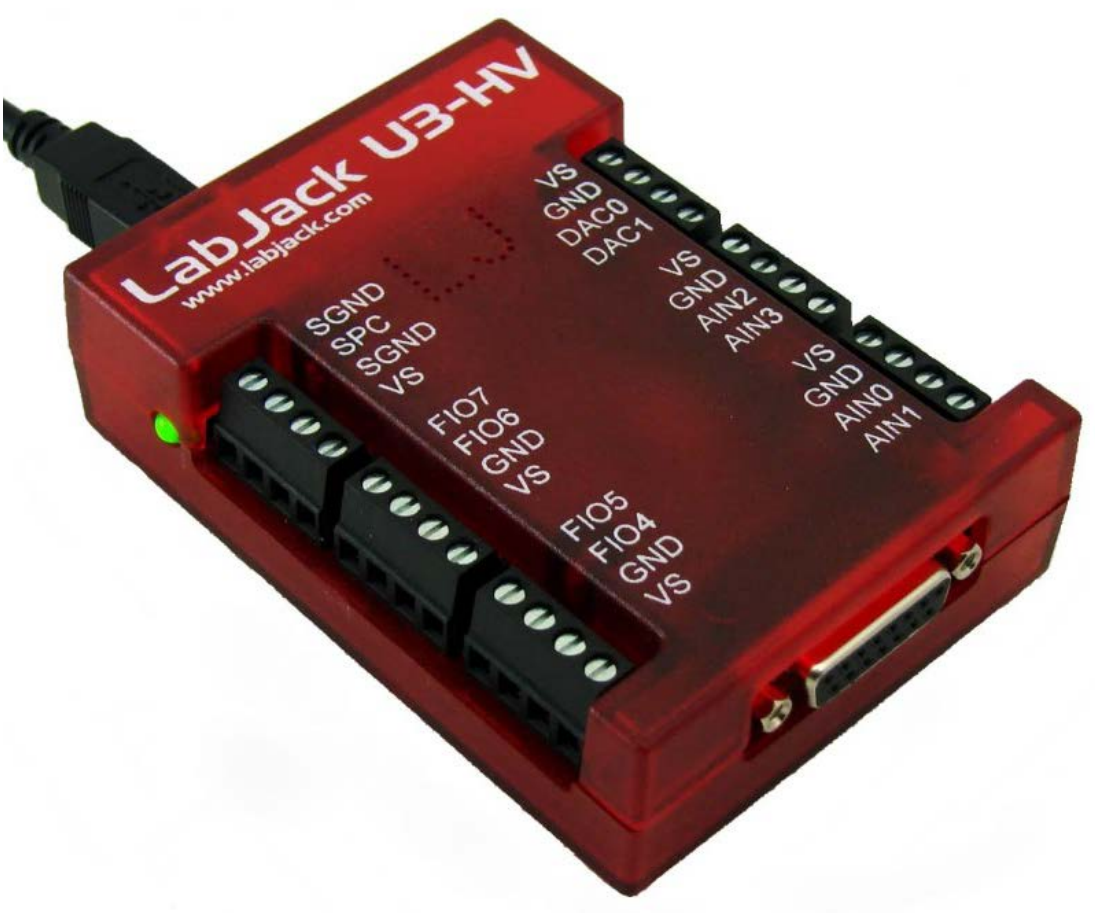

Figure 12 - LabJack U3-HV Interface

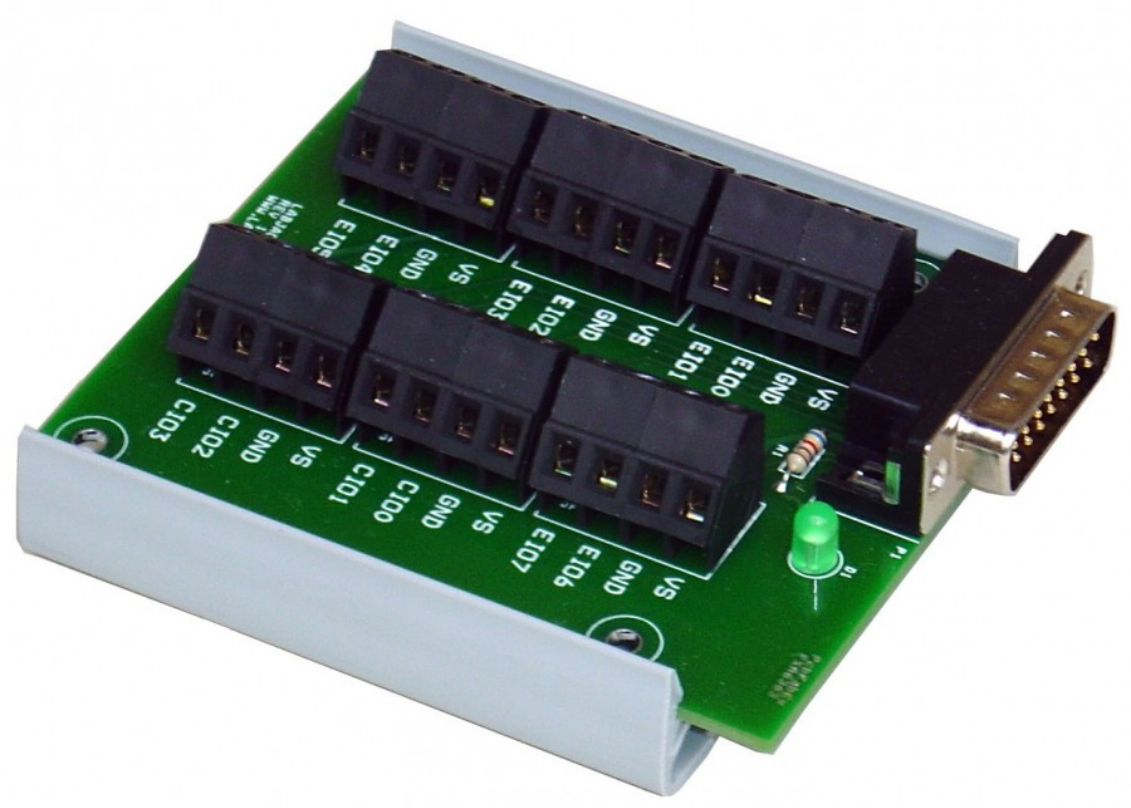

Figure 13 - LabJack CB-15 Expansion Board 
This particular controller has the advantage of being low-cost, offers a large number of digital/analog inputs and outputs and is relatively simple to program because of the company-supplied LabView drivers. The house is equipped with Semitec 103JT-75 negative temperature coefficient (NTC) thermistors which act as the temperature sensors/thermostats in each room (as well as one for outside temperature tracking) as seen in Figure 14. They are placed directly on the surface of the wall such that they are measuring ambient temperature on a per-room basis (inspired from [9]).

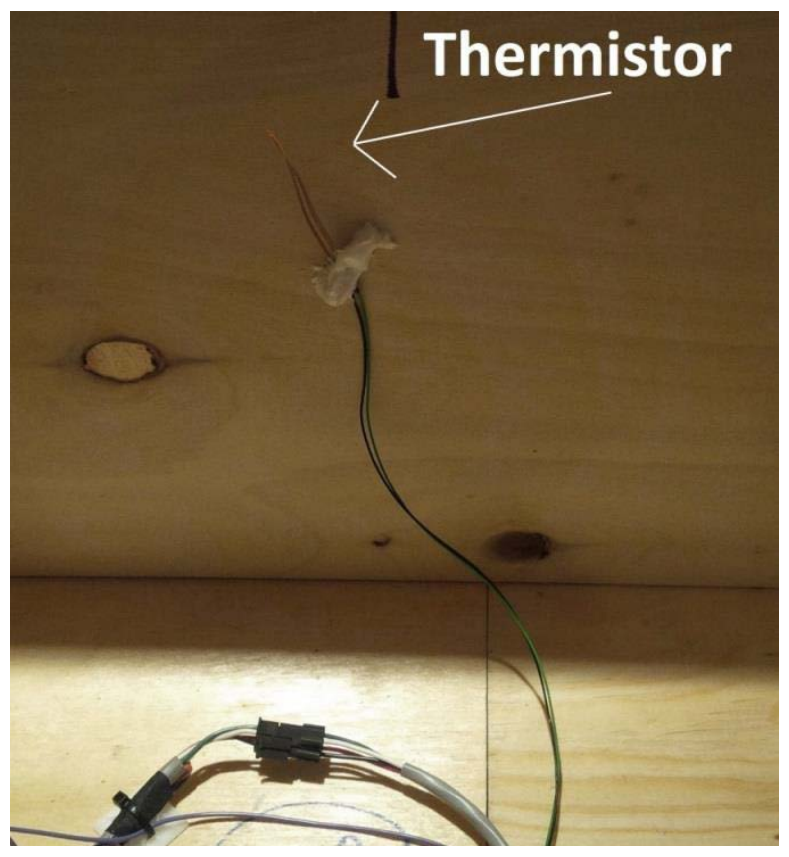

Figure 14 - Typical installation of thermistors throughout the model house

NTC Thermistors are a type of semiconducting device which exert the characteristic of decreasing their internal resistance as their temperature increases [10]. The manufacturer of this type of device supplies a characteristic chart of temperature versus resistance (see Table 1) and it is up to the designer to interpolate the resistance values to read a temperature during their implementation. The simplest way to read the temperature form a thermistor is with a voltage divider from rudimentary electrical engineering using the setup in Figure 15. 


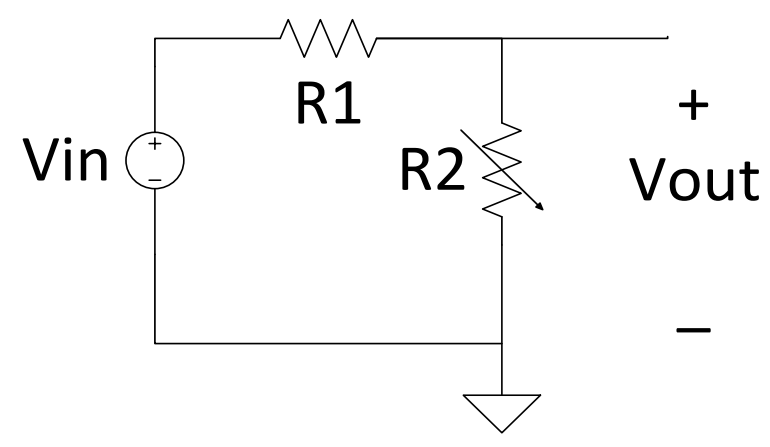

Figure 15 - Voltage Divider with R2 as a Thermistor

In this case, R2 is represented by the NTC thermistor and the output voltage (Vout) is given by the equation:

$$
V_{\text {out }}=V_{\text {in }} \frac{R 2}{R 1+R 2}
$$

\section{Equation 1 - Rudimentary Voltage Divider Equation}

As the temperature of the thermistor changes, so does its internal resistance. The change in voltage observed across the thermistor can be interpreted as a temperature change based on manufacturer data and captured for further use. One hang-up associated with thermistors is that their internal semiconducting materials tend to follow a non-linear trend, except within small ranges of temperature; see Figure 16. It is important to select a thermistor which exhibits a loosely linear trend in the range in which the application will operate. Having said that, the thermistor in question exhibited a very shallow parabolic trend within the desired temperature range and this had to be considered during the hardware implementation. 


\begin{tabular}{cc}
\hline Temperature (Celsius) & Resistance (kOhm) \\
-50 & 367.7 \\
-40 & 204.7 \\
-30 & 118.5 \\
-20 & 71.02 \\
-10 & 43.67 \\
$\mathbf{0}$ & 27.7 \\
$\mathbf{1 0}$ & 18.07 \\
$\mathbf{2 0}$ & 12.11 \\
$\mathbf{3 0}$ & 8.301 \\
$\mathbf{4 0}$ & 5.811 \\
$\mathbf{5 0}$ & 4.147 \\
$\mathbf{6 0}$ & 3.011 \\
$\mathbf{7 0}$ & 2.224 \\
$\mathbf{8 0}$ & 1.668 \\
$\mathbf{9 0}$ & 1.267 \\
$\mathbf{1 0 0}$ & 0.9753 \\
$\mathbf{1 1 0}$ & 0.7597 \\
$\mathbf{1 2 0}$ & 0.5981 \\
$\mathbf{1 2 5}$ & 0.5331 \\
\hline & \\
\hline
\end{tabular}

Table 1 - Raw Temperature and Resistance Data of 103JT-75 Thermistor 


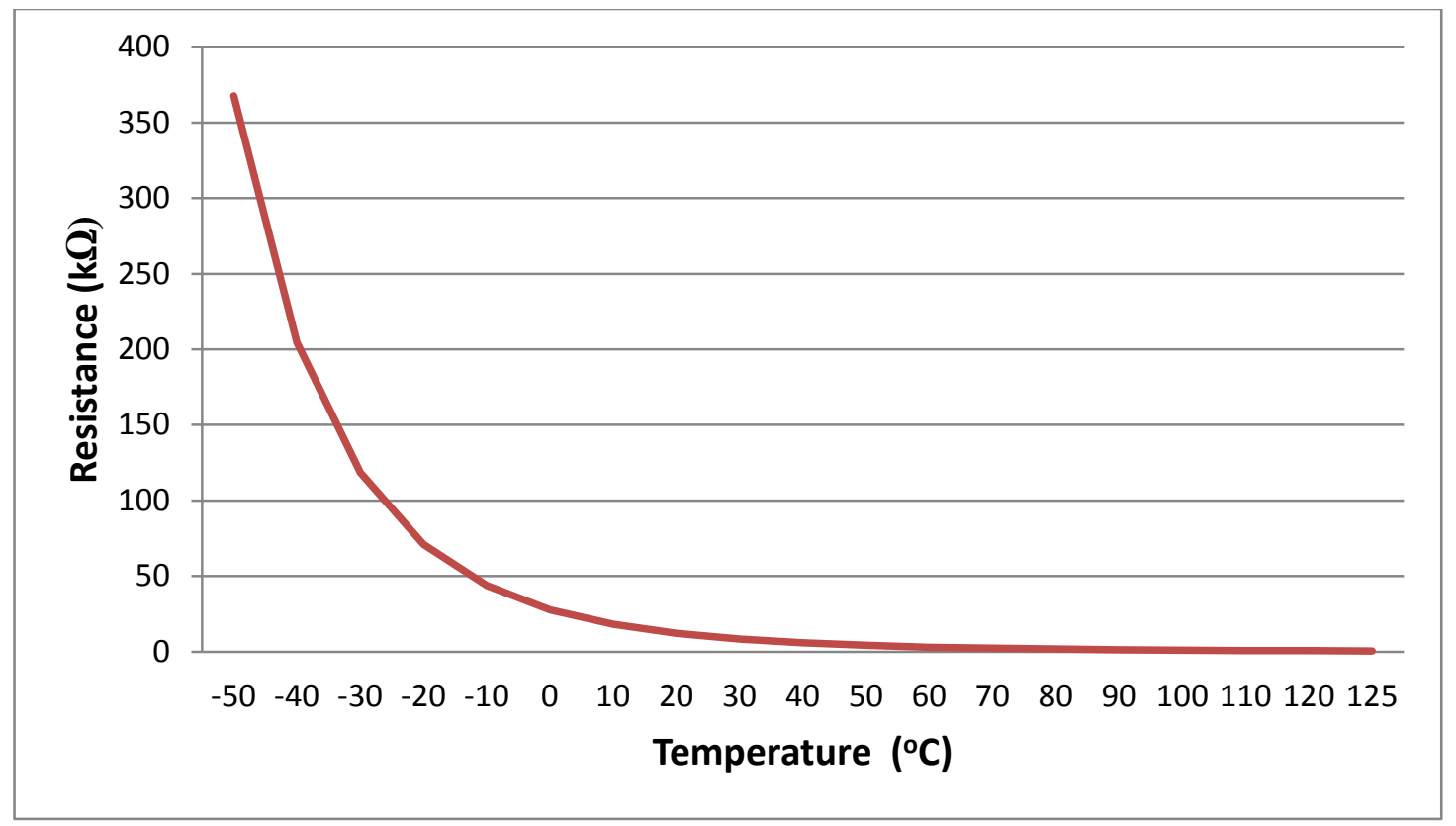

Figure 16 - Resistance-Temperature Trend of 103JT-75 Thermistor

In order to accurately use this thermistor, Table 2 and Figure 17 were created to give an indication of expected voltage values by solving the voltage divider equation at many temperature points.

\begin{tabular}{ccccc}
\hline Temperature & Vin & R1 & R2 & Vout \\
\hline $\mathbf{- 2 0}$ & 5 & 2200 & 71020 & 4.849768 \\
$\mathbf{- 1 0}$ & 5 & 2200 & 43670 & 4.760192 \\
$\mathbf{0}$ & 5 & 2200 & 27700 & 4.632107 \\
$\mathbf{1 0}$ & 5 & 2200 & 18070 & 4.457326 \\
$\mathbf{2 0}$ & 5 & 2200 & 12110 & 4.231307 \\
$\mathbf{3 0}$ & 5 & $\mathbf{2 2 0 0}$ & 8301 & 3.952481 \\
\hline
\end{tabular}

Table 2 - Thermistor Data in Voltage Divider Implementation (Vin =5V) 


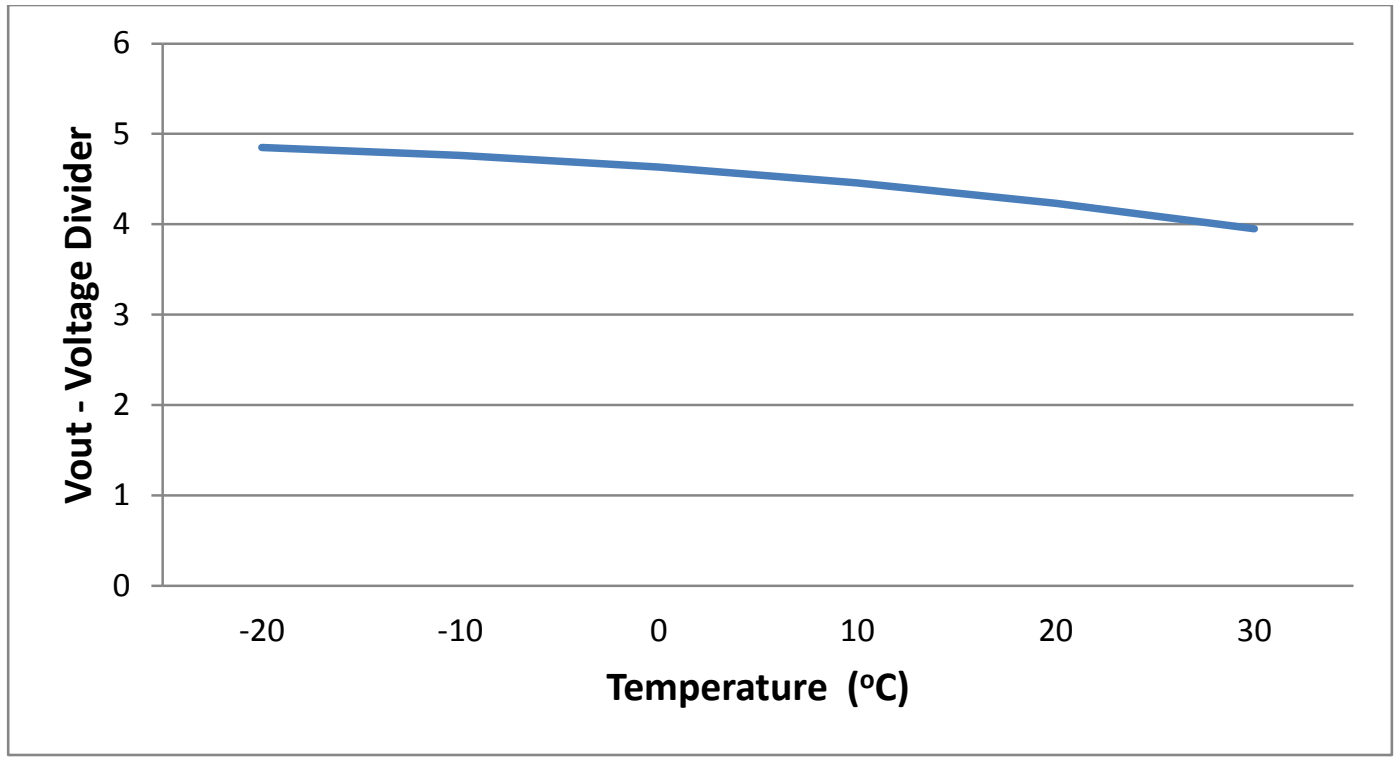

Figure 17 - Expected Voltage Values of Thermistor in Voltage Divider Setup (Vin = $5 \mathrm{~V}$ )

Knowing the anticipated voltage values at fixed temperatures allows parabolic curve fitting to occur. From rudimentary mathematics, we know that a parabola can be expressed in its standard form as:

$$
y=A x^{2}+B x+C
$$

In this case, voltage (v) can be taken as the input to the equation allowing the following representation:

$$
\text { Temperature }=A v^{2}+B v+C
$$

Using the projected voltage divider data from Table 2, three points representing voltage and temperature can be simultaneously solved in order to determine the three unknown coefficients, A, B and C. This now enables the LabJack controller to multiply and add together a simple batch of coefficients with the real-time voltage measurements to provide an accurate temperature which correlates to the thermistors' non-linear characteristic. In this particular case, A, B and C were found to be -27.027, 189.189 and -296.555 
respectively. This parabolic relation is plotted in Figure 18 and confirms that the operating range falls within the desired range.

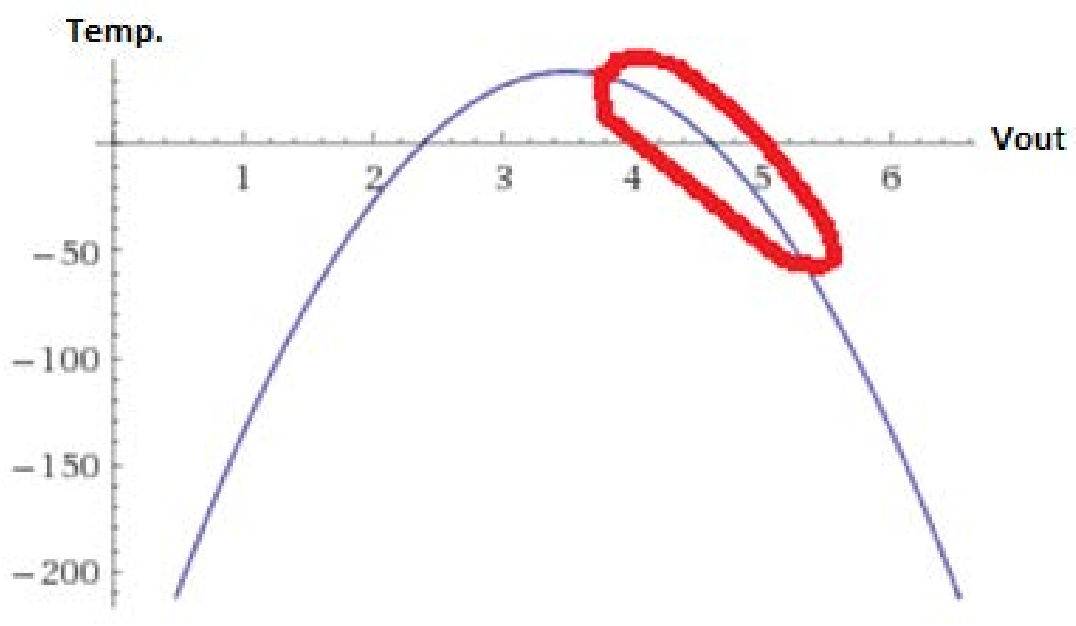

\section{Figure 18 - Plot of Parabola Obtained with Solved A, B and C Values Showing the Useable Region of Voltage (Generated Using Wolfram Online)}

It is important to note that the use of a parabolic relation dictates the need to keep temperature set-points within a relatively narrow range to avoid approaching the apex of the parabola. If the right voltages presented themselves, duplication of results could occur. Adjustment of this range can be accomplished with careful selection of the ballast resistor, $\mathrm{R} 1$. The value used in this study of $2.2 \mathrm{k} \Omega$ was selected in order to have the voltage values correspond to a useable range of temperature.

To be sure that the temperature, in fact, correlates to the 'real' temperature of the dwelling, it is necessary to calibrate the thermistors using known thermal reference points. Discrepancies in actual temperature-to-solved temperature can be caused by resistor tolerances and voltage drops on sensing wires. Calibration due to steady-state errors of this type mentioned above (ie., DC bias errors) can be corrected by modifying the value of $\mathbf{C}$ to provide the accurate offset. This process is performed simply by comparing the values of multiple known temperatures versus the output of the LabView gauges in Figure 32. In this case, a solution of ice water was used to verify that the thermistors read $0^{\circ} \mathrm{C}$ when 
immersed. To verify the upper threshold, an infrared thermometer was used to measure the surface temperature of the house walls where the thermistors were installed with a known reference temperature. Using this calibration method, the average disparity in readings from sensor-to-sensor was $0.5^{\circ} \mathrm{C}$. This was deemed acceptable due to the nature of analog circuitry which tends to have noise disturbances causing voltage fluctuations.

\subsection{Notes on Circuit Design and Implementation}

The electrical bill of materials and schematic for the model house can be seen in Table 15 and Figure 31 respectively. The control method is designed with simplicity in mind and utilizes $5 \mathrm{~V}$ (gate-source) MOSFETS to pull the coils of relays to neutral, thus turning them on. In this case, MOSFETS were preferred because of their low gate current requirement as opposed to sinking the full relay coil current directly through the LabJack. Found across the coil of every relay in the system is a standard diode in reverse bias. The purpose of this diode is to provide a path to neutral during transient switching events. The electrical engineers in the audience will remember that a relay coil looks like an inductor and switching such a device can cause voltage spikes governed by the equation:

$$
V=L \frac{d i}{d t}
$$

\section{Equation 2 - First Principles Voltage across an Inductor}

Even though the miniature $5 \mathrm{~V}$ relay is harmless on its own, it is more than capable of producing momentary spikes approaching a few hundred volts which can destroy the relay coil and any associated control circuitry attached to it [11].

Careful observers may have realized that three different DC sources (5V, 12V and 24V) were implemented in this circuit. Although a little redundant and unrefined, there were some valid reasons for this. First and foremost, the full heating power of the house equates 
to $150 \mathrm{~W}$ which is a fair-sized power supply for the hobbyist. Conveniently, the author had a $24 \mathrm{~V}(750 \mathrm{~W})$ power supply lying around, so it was determined that main heating power would come from this source. Once this selection was made, the first electrical hurdle was encountered. At the time of construction, it was difficult to source $24 \mathrm{~V}$ fans with a desirable flow rate (and price!!) to match up with the volumetric requirements. The decision was then made to add a $12 \mathrm{~V}$ power supply for the sole purpose of powering the fans. Once these two constraints were taken care of, $5 \mathrm{~V}$ relays were selected to turn on the heating resistors and circulation fans as they could easily be switched and powered from the supply rails of the USB power coming from the LabJack. This started off as a great idea, but turned into another large problem once the testing began. Taking a look at Equation 1, it takes no stretch of the imagination to observe that the output voltage measured across $\mathrm{R} 2$ is directly proportional to the network's source voltage, Vin. When relays began to click in and out during testing, large voltage fluctuations were noticed on the LabJack's $5 \mathrm{~V}$ supply rail. The resulting issue was grossly inaccurate temperature readings on the LabView gauge display. It was, therefore, decided to power the $5 \mathrm{~V}$ relays from a separate power supply. Again, the keen observers will notice that the use of a MOSFET to complete the relay circuits necessitates a common power supply neutral between the LabJack and $5 \mathrm{~V}$ power supply. Luckily, the LabJack is equipped with a pin named SGND whose sole purpose is to enable the connection of multiple floating DC power supplies' neutrals. Armed with these changes, the model house was rebooted and ran flawlessly.

The individual control boards were built on premade 'perf' boards to reduce development time, but aren't necessarily the prettiest solution as can be seen in Figure 19. This phase of the project was very much a hobbyist's implementation due to the time/financial constraints and much improvement could be made in further revisions. 


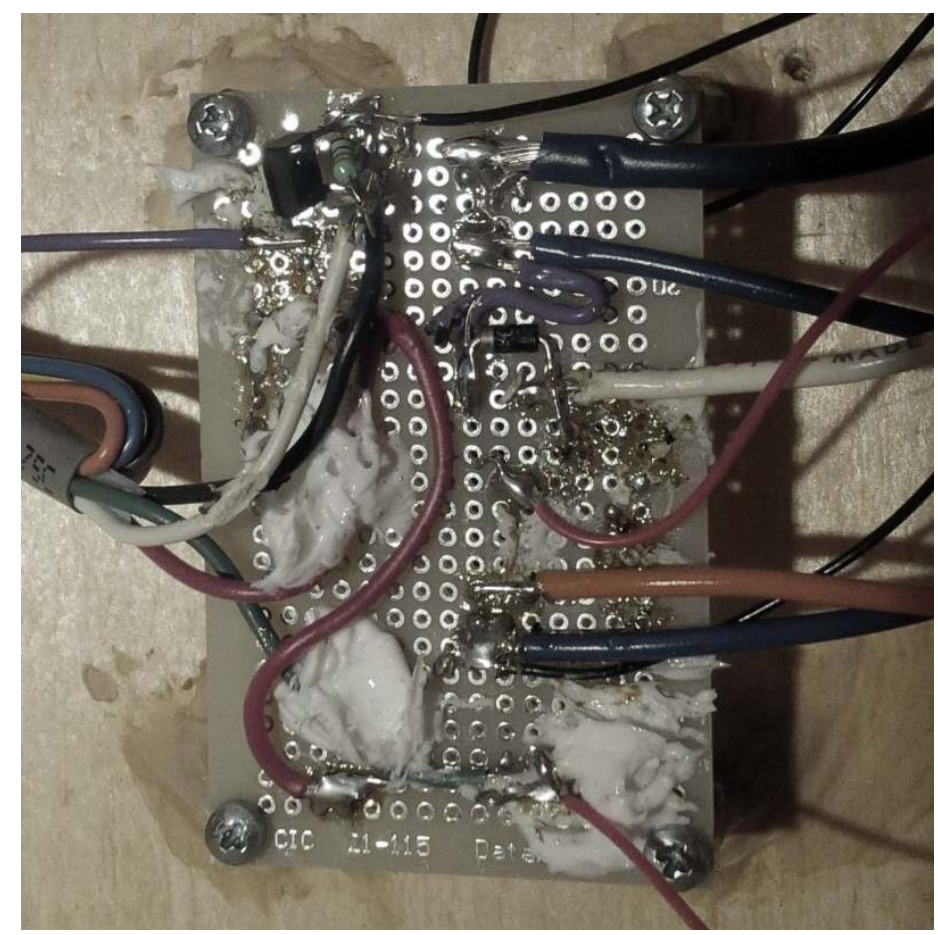

Figure 19 - Completed 'Perf' Board Used to Mount All Electronics (Relays on Bottom Side)

\subsection{The Surface Area : Volume Problem - 'Tuning' the house}

It was mentioned in Section 3.1 that the model house test-bed was scaled down by a linear scaling factor of 6.6667 from the Author's current place of residence. This scaling factor also corresponds to the model house lacking 44.44 times $\left(6.6667^{2}\right)$ the amount of surface area, as well as 296.30 times $\left(6.6667^{3}\right)$ the amount of volume. The specific thing to note is that the volume-to-surface area ratio between the real house and the model house are not equivalent as seen in Table 16 and Table 17. The vast majority of heat transfer in this configuration occurs by radiation of thermal masses (ambient air) through planar surfaces (the walls), so effort was required to ensure that the governing time constant of the room wasn't too quick. This would not be an issue if the scale-model house were conducting tests all on its own, but a secondary goal of building the model house was to demonstrate that it was possible to mimic the heating characteristics of a real house. 
In order to combat this undesired effect, the rooms in each house were ballasted with calculated thermal masses with the goal of acting as thermal storage 'capacitors.' The net result of doing this accounts for the equivalent missing air mass requiring heat and thus increases the time constant of the rooms. Without this exercise, the air in the room would heat up and cool down much too quickly which is not an accurate representation of real life houses.

The procedure for ballasting the rooms is as follows (using values from Table 17) :

- Calculate the volume of a full-size room:

$$
v_{\text {roomfull }}=6.18 * 5.50 * 2.032=69.11 \mathrm{~m}^{3}
$$

- The total wall surface area is calculated to be $81.49 \mathrm{~m}^{2}$

- Calculate the volume of a scaled-down room:

$$
v_{\text {roomscale }}=0.927 * 0.825 * 0.3048=0.233 \mathrm{~m}^{3}
$$

- The total wall surface area is calculated to be $1.833 \mathrm{~m}^{2}$

Now, it follows that the volume-to-surface ratios are:

0.848 for the full-sized room

and

\subsection{7 for the scaled-down room}

As was predicted, the scaled-down house lacks 6.667 times the amount of air mass to be heated as compared to the full size house. Extra thermal ballast must be, therefore, added to each room of the model house to ensure that an equivalent thermal mass is being heated. Continuing on, we can multiply the volume of the model house room by 6.6667 (the factor by which it lacks) to see what the volume of air should be in that room to meet the volumeto-surface area criteria:

$$
v_{\text {true }}=0.233 * 6.667=1.55 \mathrm{~m}^{3}
$$


Now, taking the difference between the required volume of air and the volume of air that is already the room can hold yields the excess volume of air required:

$$
v_{\text {air reqd }}=1.55 m^{3}-0.23 m^{3}=1.32 m^{3}
$$

And from this, we can calculate that the mass of air required:

$$
\begin{aligned}
& m_{\text {air reqd }}=\rho_{\text {air }} v_{\text {air reqd }} \\
& m_{\text {air reqd }}=1.619 \mathrm{~kg}
\end{aligned}
$$

Armed with this mass, we can calculate the amount of thermal mass that this represents using the specific heat of air:

$$
\begin{aligned}
& m_{\text {thermal air }}=m_{\text {air reqd }} c_{p \text { air }} \\
& m_{\text {thermal air }}=1615.67 \frac{\mathrm{J}}{\mathrm{K}}
\end{aligned}
$$

Unfortunately, a problem arises from this; the only way to add excess air mass to the house (assuming constant volume rooms) is by forcibly pressurizing it. To accomplish this, a source of compressed air would have to be connected to the house and the house would have to be perfectly sealed to avoid leakage of heated air. An arrangement like this is horribly impractical as was, therefore, decided against.

Using the specific heat of air and another substance, we can calculate the amount of thermal mass required to accomplish this with another material (preferably much denser). As was indicated earlier, concrete was selected due to its high density.

$$
m_{\text {thermal conc }}=\frac{C_{\text {pconc }}}{C_{\text {pair }}} m_{\text {thermal air }}=1554.519 \frac{\mathrm{J}}{\mathrm{K}}
$$

Using the specific heat of concrete, it is now possible to determine the mass of concrete required in room 1: 


$$
m_{\text {conc }}=\frac{m_{\text {thermal conc }}}{c_{\text {pconc }}}=0.576 \mathrm{~kg}
$$

This run-through represents one room of the house and was repeated for all four rooms as summarized in Table 17. The concrete was then acquired (in the form of concrete board) and cut to the appropriate size while checking mass on a precision scale. Next, the heating modules were mounted directly on top of the concrete to ensure that they would be the prime candidates to absorb generated heat. The use of the circulation fans on top, it was assumed, would ensure that the remaining air would be adequately heated.

\subsection{Model House Limitations and Chapter Summary}

From the above details of the model house construction methodology, it should be obvious that certain limitations exist. First off, the lack of windows and doors around the house provide a uniform and efficient structure. Glass tends to have an R-value substantially lower than that of insulation and is a major source of heat loss in structures. The net effect of eliminating windows from the model house will be one of decreased overall heat loss.

Second, this house can only apply to situations where the performance of wooden-frame houses is being studied. The dynamics of this house may, in fact, be completely different than that of one constructed entirely from concrete (similar to apartment buildings).

Third, the model house testing was run indoors and discounts any contributions from solar irradiation in the name of consistency from test-to-test. The sun has the ability to deliver vast amount of infrared radiation to structures and can, thus, heat isolated area of houses. 


\section{Chapter 4}

\section{THEORY AND COMPUTATION}

\section{Computational Setup}

As was stated in the introduction, one of the goals of this study was to investigate whether a simple model of heat transfer could be used to predict the behaviour of heating in a real house and the model house as well. The intent is not to be able to calculate actual numbers for temperature and heat loss, but rather to provide a ballpark guidance towards thermostat control schemes and the extent to which homes should be insulated. The results found here are likely to be very theoretical and the experiments in Chapter 5 are meant to provide credibility to these conclusions.

For the purposes of these calculations, some of the following information and assumptions will be used:

- We will model both houses as a single room of total actual room volume inside a box. Interior walls/floor decks will be neglected and, consequently, the volume of these models will be slightly larger than those that can be extracted from Table 16 and Table 17.

- Simplifying even further, the boxes will then be folded out into a single plane to allow the analysis to occur in one dimension. The R-value of the plane will be the weighted-average R-value of the whole house.

Having said that, the dimensions of model house box are as follows: 


\begin{tabular}{ccccccc}
\hline & $\mathbf{L}(\mathbf{m})$ & $\mathbf{W}(\mathbf{m})$ & $\mathbf{S A}\left(\mathbf{m}^{2}\right)$ & \%SA Tot & R-Value & R-Value Weighted \\
\hline Ceiling & 1.778 & 0.864 & 1.535 & 0.327 & 10.1 & 3.312 \\
Floor & 1.778 & 0.864 & 1.535 & 0.327 & 8.55 & 2.803 \\
Walls Major & 1.778 & 0.305 & 1.085 & 0.231 & 4.525 & 1.048 \\
Walls Minor & 0.864 & 0.305 & 0.527 & 0.112 & 4.525 & 0.509 \\
\hline
\end{tabular}

Table 3 - Dimensions Used to Calculate the Inner Surface Area of the Model House

With the associated surface area of the plane identified as being $4.682 \mathrm{~m}^{2}$ with an R-value of 7.673 and inner volume of $\left(0.469 \mathrm{~m}^{3} \times 6.667=3.124 \mathrm{~m}^{3}\right)$ to correct for ballasting issues. Continuing on with this theme, the dimensions of the full size house box are as follows:

\begin{tabular}{ccccccc}
\hline & $\mathbf{L}(\mathbf{m})$ & $\mathbf{W}(\mathbf{m})$ & $\mathbf{S A}\left(\mathbf{m}^{2}\right)$ & \%SA Tot & R-Value & R-Value Weighted \\
\hline Ceiling & 12.192 & 6.096 & 74.322 & 0.169 & 50 & 8.475 \\
Floor & 12.192 & 6.096 & 74.322 & 0.169 & 2 & 0.339 \\
Walls Major & 12.192 & 7.924 & 193.209 & 0.445 & 36 & 15.863 \\
Walls Minor & 6.096 & 7.924 & 96.605 & 0.220 & 36 & 7.931 \\
\hline
\end{tabular}

Table 4 - Dimensions Used to Calculate the Inner Surface Area of the Full-Sized House (Note: 3 Stories)

With the associated surface area of the plane identified as being $438.458 \mathrm{~m}^{2}$ with an R-value of 32.609 and an inner volume of $588 \mathrm{~m}^{3}$. Having gained both of these sets of values, the heat loss problems can now be turned into 1-D planar heat transfer problems. The simplest problems of this type are modeled as two sources of infinite heat (at different temperatures) on each side of the plane, with heat transferring through the plane. Since the assumption is made that the two sides of the wall have infinite thermal energy, heat transfer is assumed to be constant since both areas are able to maintain their temperature. 


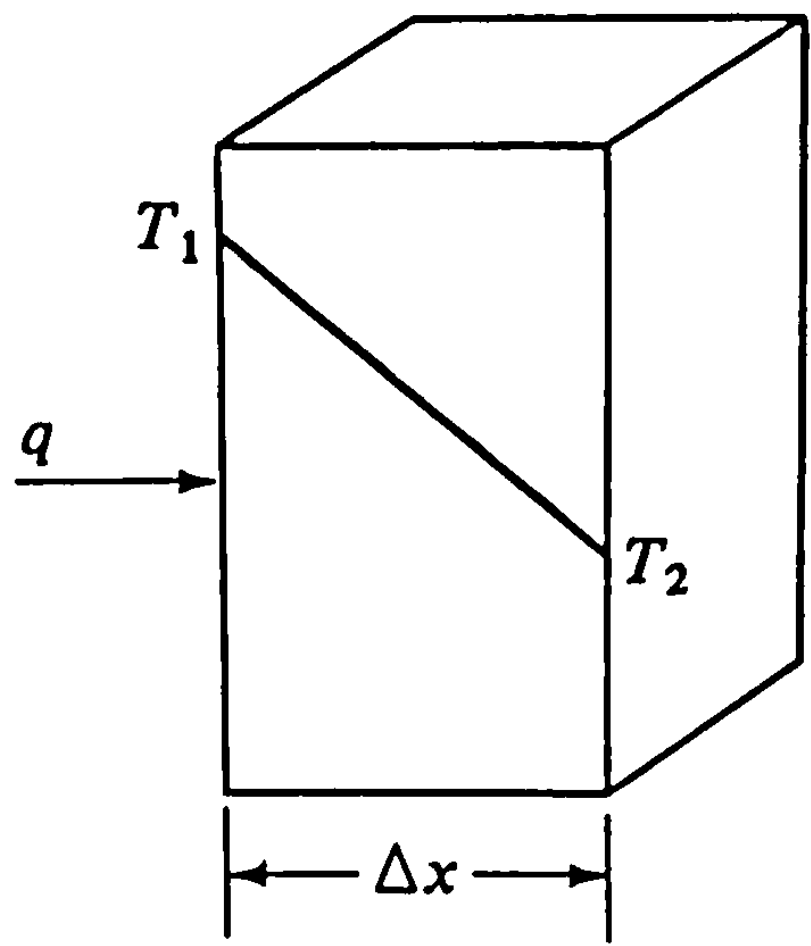

Figure 20 - Steady-State One-Dimensional Heat Transfer

Unfortunately for this study, this is not the case as we are generating heat to produce changes in temperature. Realistically, the house is not in steady state, but I wish to be a little adventurous to see if I can get close by iterating a steady state equation at very small segments of time (30 seconds each). Testing the limits of theory can be futile in some instances but vastly rewarding in other cases if the results can yield ballpark estimate with minimal work. The starting point for this analysis begins with the known model of the first principles heat equation in one dimension:

$$
\frac{d}{d x}\left(k \frac{d T}{d x}\right)=0
$$

Equation 3 - The One Dimensional Heat Equation 


\subsection{Conductive Model}

For this model, the representation of two thermal zones separated by a plane is still valid; however, generation will now be taken into consideration. This model assumes that temperature will remain constant on both sides of the wall for the 30 second time slot in which we are observing. Using Fourier's Law, we can establish the conduction heat transfer rate in watts:

$$
q_{\text {tot }}=\sum_{t=0,30 \text { s... }}^{8 h} \frac{k A}{L}\left(T_{\text {in }}(t)-T_{\text {out }}(t)\right)
$$

In this case, the term $\mathrm{kA} / \mathrm{L}$ is the thermal resistance associated with the surface area our plane. As we discussed in Chapter 3, the wall has a composite makeup all in series which means that all three terms (one per material) can be added up in series and averaged out to come up with a theoretical uniform R-value. The data from test \#4 in Chapter 5 was placed into a spreadsheet and the above equation was iterated each time heating was commanded. The theory in this approach was that the rising indoor temperature, Tin, could be used to mimic a momentary steady period of time and provide me with snapshots of wattage put into the building. Summing up the theoretical wattage generated during heat cycles should be able to yield results similar to those in the actual test, thus providing future work to be predicted pending validation.

After having run the iterated equation against my heating commanded data from test \#4, the conductive model indicated that $381.89 \mathrm{Wh}$ were 'generated' over the same period of time. In Chapter 5, you will notice that test \#4 only used 197.5Wh as indicated from the actual data logging. 


\subsection{Convective Model}

The convective model of steady-state heat transfer adds a few more terms the model to account for the increased rate at which heat transfers when the fluids on each side of the medium are being forcibly circulated around, which is the case in the model house (and to a degree, the environment in which the house was placed). As can be seen in Figure 21, the horizontal curve representing change in temperature as area is traversed drops quite significantly at the interfacing surfaces.

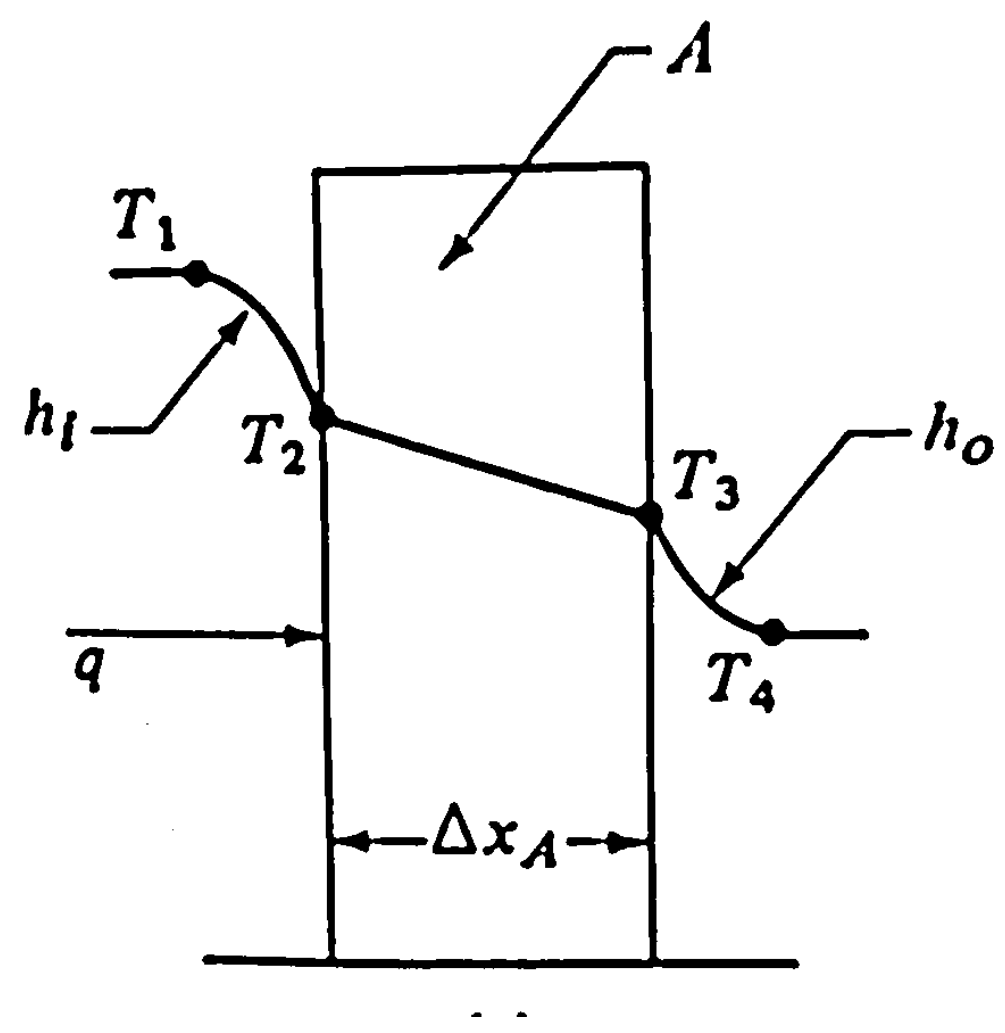

Figure 21 - Simplified Model of Convective Heat Transfer [12]

The more complete model which captures this effect is as follows:

$$
q_{\text {tot }}=\sum_{t=0,30 \text { s... }}^{8 h} R_{\text {convtot }}\left(T_{\text {in }}(t)-T_{\text {out }}(t)\right)
$$


Where $R_{\text {convtot }}$ is represented by:

$$
R_{\text {convtot }}=\frac{1}{h_{1} A}+\frac{L}{k A}+\frac{1}{h_{2} A}
$$

The additional terms containing the ' $h$ ' factors represent the added convective losses. More specifically, $\mathrm{h}$ is known as the convective heat transfer coefficient. Typical values for $\mathrm{h}$ in a forced-air situation can range from 5-200 and in this case, I selected 50 [6]. The hope in applying this model is that a more realistic setup should yield results that will more closely mimic the empirical results. In this case, the same rules were followed as with the conduction model; the equation was evaluated at 30 second intervals during periods of heat command from test 4.

Once again, there was a discrepancy from the actual obtained results when using this model. Interestingly enough, the results of the convective model were very close to that of the conductive model. A quick summary of the results is presented below. 


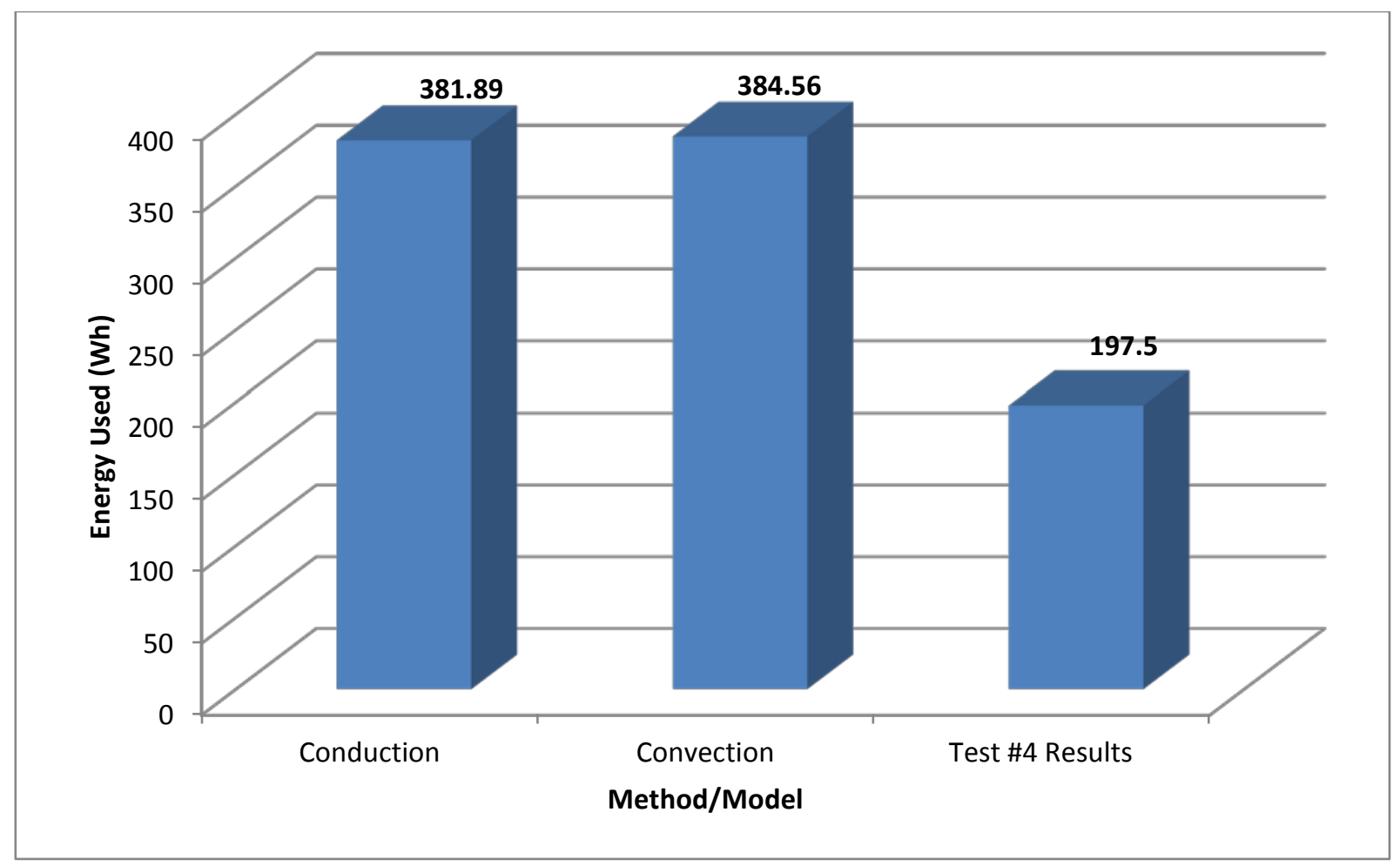

Figure 22 - Comparison of Energy Usage: Steady-State Models Versus Empirical Values

Seeing a pattern of this type points to one simple conclusion; when steady-state models are used to approximate transient heat transfer, you can count on overestimating your energy consumption by nearly double (based on these results). I would normally consider this a failure, but my inner aspiring Engineer says differently. In school, I was constantly taught to assume a 'safety factor of 2' when making engineering decisions. What has been proved here is that a very simplified model of heat transfer can be implemented in a piecewise fashion to yield a ballpark estimation of energy consumption. This would be a very helpful tool for quick analysis when only a limited data set is available, as in the case of sizing a heating unit for a customer with a tight deadline. 


\section{Chapter 5}

\section{EXPERIMENTAL VALIDATION}

\section{Model Home Experiments}

The desired tests to validate the hypotheses of the previous sections are explained in detail within this section. Four tests were organized to be run on the model house and two tests were organized on the full-size house as outlined in Table 5.

\begin{tabular}{|c|c|c|}
\hline Temperature Profile / Scheme & Zoned & Central \\
\hline Constant (w/Dead band) & Test $\mathbf{1}$ & Test $\mathbf{2}$ \\
\hline Occupancy Program & Test 3 & Test 4 \\
\hline
\end{tabular}

Table 5 - Organization of Model House Testing Plan

These tests combine all of the different heating/program possibilities that are available to the model house. To ensure accuracy across the board, each test began with an 8 hour period of constant temperature heating $\left(25^{\circ} \mathrm{C}\right.$ with $1^{0}$ dead band) thus ensuring that the house would be brought to a uniform temperature before test initiation. Each test was run for a period of 8 hours and took samples of data from each room and heating resistor at 30 second intervals. Keeping with the theme of consistency, the model house was placed in a room that was kept at a constant $20^{\circ} \mathrm{C}$ with no sunlight (thus eliminating solar irradiation as a parasitic source of heat). The obtained results, therefore, are as fair as I could physically make them given the capabilities at hand.

In order to run these 4 tests, two identical LabView environments were created allowing the control of all room heating based off of a central thermistor in one case, and 
individualized control on a room-by-room basis. The temperature ranges were easily set by the text boxes in Figure 32 with the help of a 2 hour long timer to notify me to change the set-points from $20^{\circ} \mathrm{C}->25^{\circ} \mathrm{C}$ in tests 3 and 4 .

\subsection{Test 1: Constant Temperature with Zoned Heating}

A 15 minute sample of the collected data for this test is shown in Figure 23. The desire is to show the reader the proper operation of the model house as advertised in the zoned configuration; for instance, a careful observation of on and off signals show a perfect match up with dips down to $24^{\circ} \mathrm{C}$ and falls from $25^{\circ} \mathrm{C}$ respectively. To show the whole 8-hour test data would be very messy and difficult to make observations on.

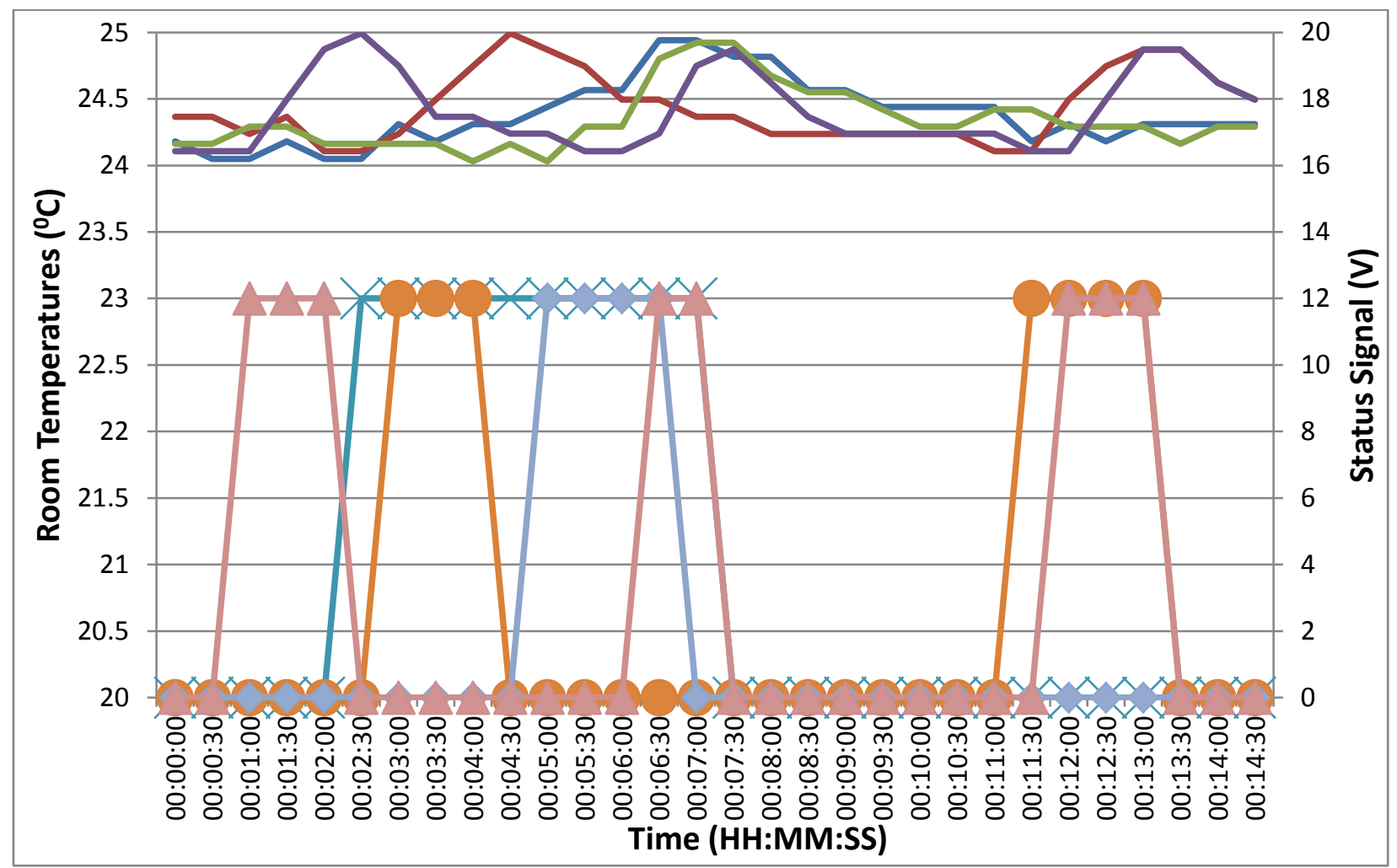

Figure 23 - Fifteen Minute Sample of Data from Test 1 
As can be seen, the rooms are free to be heated independently and the temperature fluctuation in each room is relatively minimal. A house with this type of implementation would provide uniform temperature throughout, minimizing hot and cold spots on different floors. In theory, this configuration would be one of the lower energy users in this test series since heat would only be supplied where required.

In Figure 24, a helpful representation of the average temperature recorded in each room, followed by the associated energy can be seen. In this case, the average difference in temperature across the house can be calculated to be $0.15^{\circ} \mathrm{C}$. This number tells us that the house proved to be uniform in temperature.

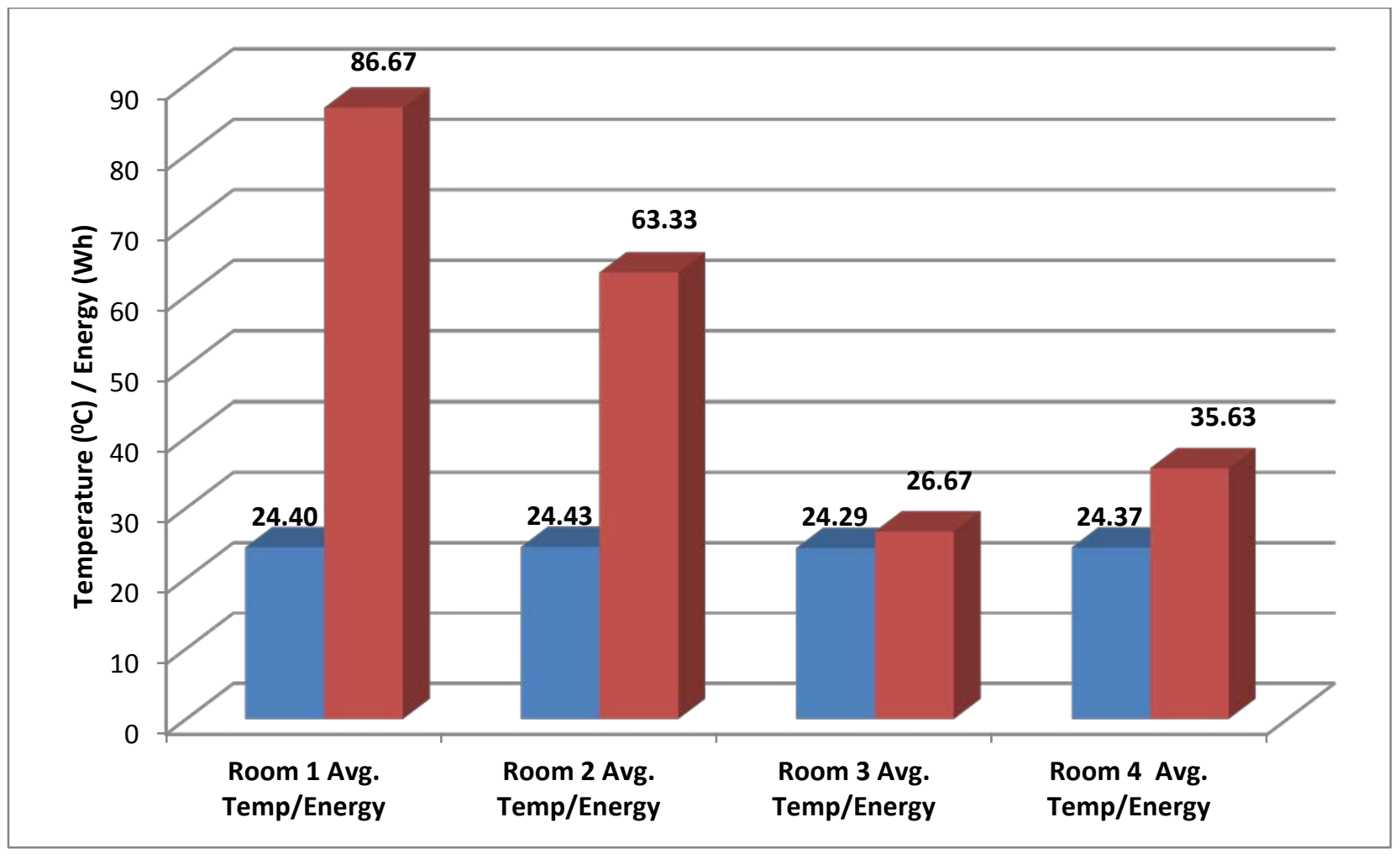

Figure 24 - Room-by-Room Analysis of Average Temperature and Energy Used in Test 1 


\subsection{Test 2: Constant Temperature with Central Heating Control}

Test 2, as can be seen in Figure 25 and Figure 26, utilized the central thermostat in the house to control all of the heating modules in the house. Temperatures can be seen to be rising while the status of the heat is 'on,' then promptly begin to fall at the 7:00:00 mark once the central large room reaches $25^{\circ} \mathrm{C}$. It is immediately obvious the first drawback of this configuration; uneven heating from room-to-room. By the time the control room reached the cut-off temperature, every other room in the house had far surpassed the desired temperature bounds, leading to hot spots all throughout. Some occupants might enjoy the increased temperature but, in reality, this most likely points towards an inefficient heating mechanism.

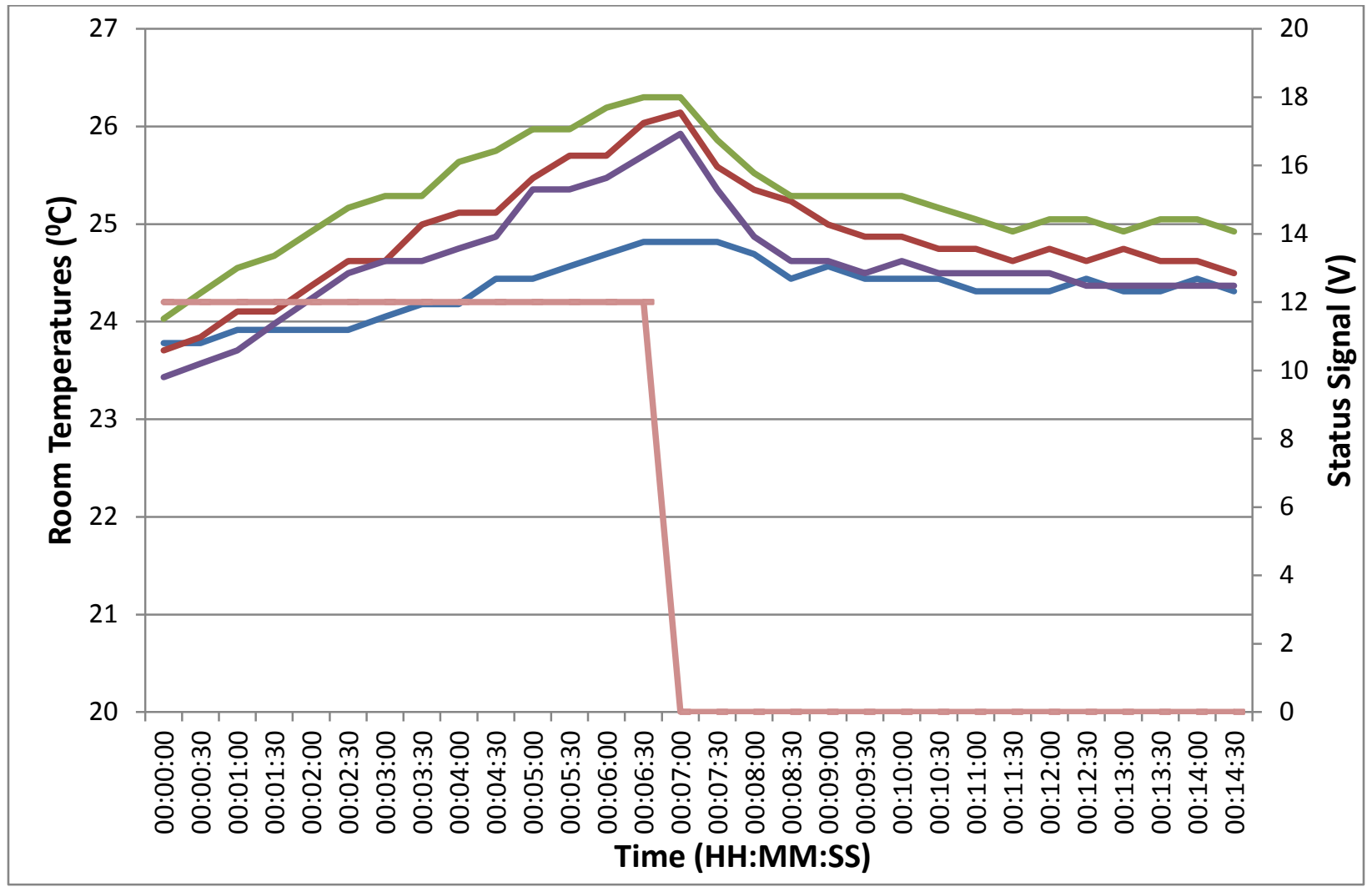

Figure 25 - Fifteen Minute Sample of Data from Test 2 Showing All Rooms Acting in Unison 


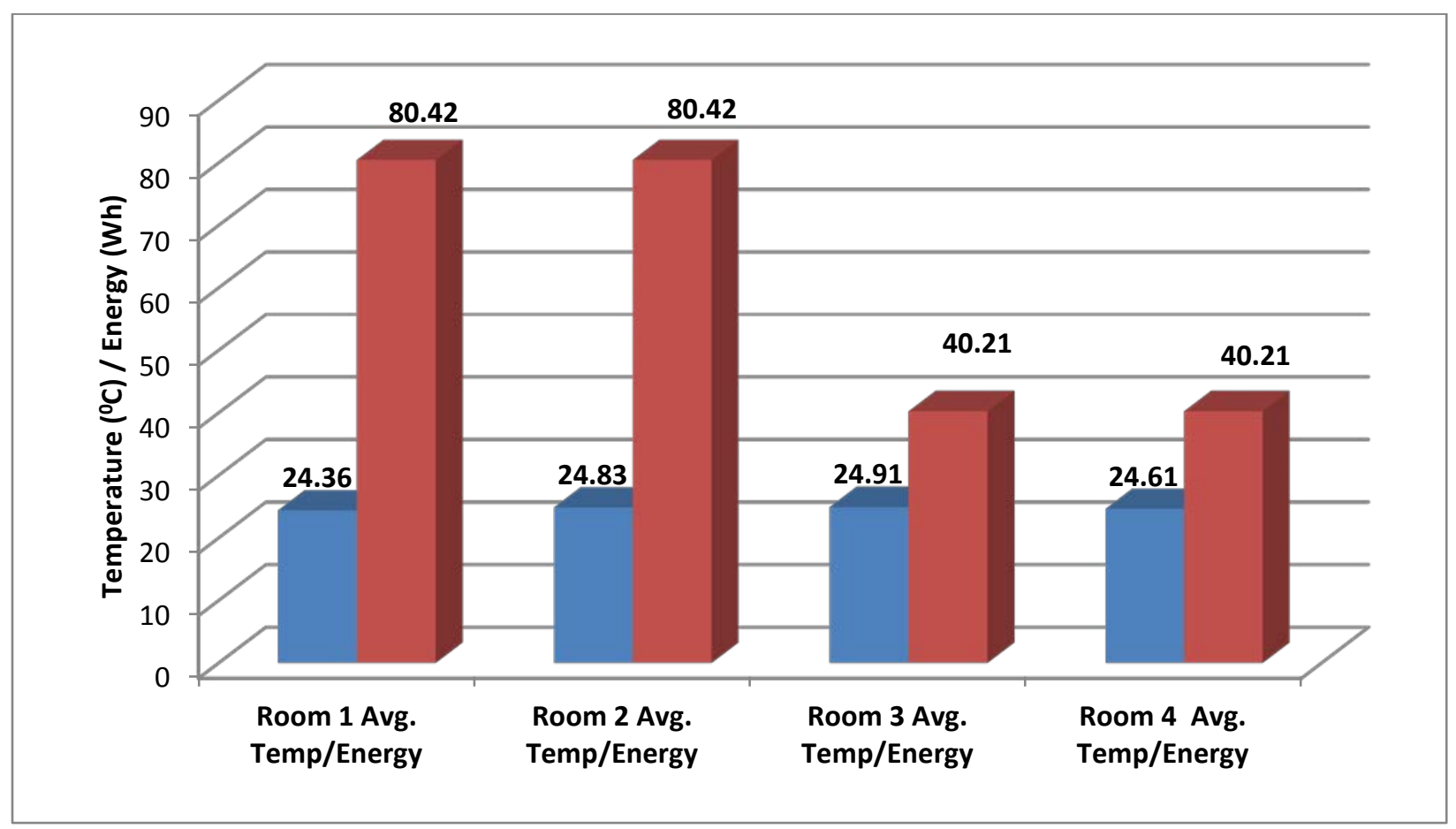

Figure 26 - Room-by-Room Analysis of Average Temperature and Energy Used in Test 2

\subsection{Test 3: Occupancy Program with Zoned Heating}

The results in this test showed some promise towards proving which control scheme is more efficient in the fixed temperature versus occupancy-based heating conundrum. As is easily seen in Figure 27, almost every room in the house used less energy than in tests 1 and 2 which should lead to an overall optimized solution. 


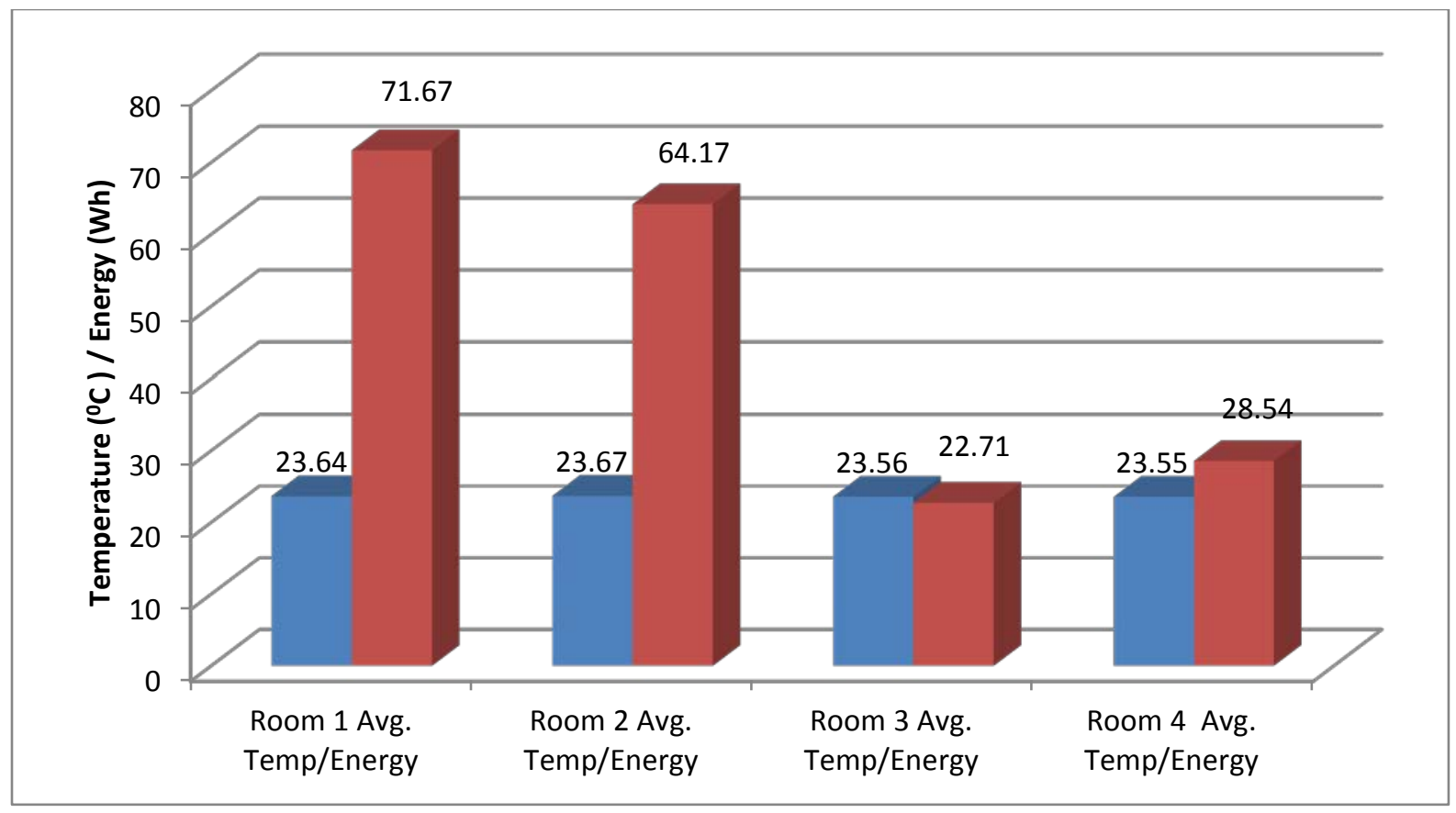

Figure 27 - Room-by-Room Analysis of Average Temperature and Energy Used in Test 3

Along with this gain in efficiency comes another added benefit; improved temperature regulation across the house. It can be calculated that the average difference in average temperature across the house was only $0.12^{\circ} \mathrm{C}$ which is a plus for uniformity. A house configured in this manner would feel very consistent from room-to-room with minimal hot and cold spots.

\subsection{Test 4: Occupancy Program with Central Heating Control}

Test 4 reverted back to centralized control and is the scheme which mimics as vast majority of North American homes. It can be seen that the average difference in temperature was $0.34^{\circ} \mathrm{C}$ which is a fairly reasonable range of temperature regulation. This scheme would hopefully be on the higher side of efficient since it's used so widely in North America. 


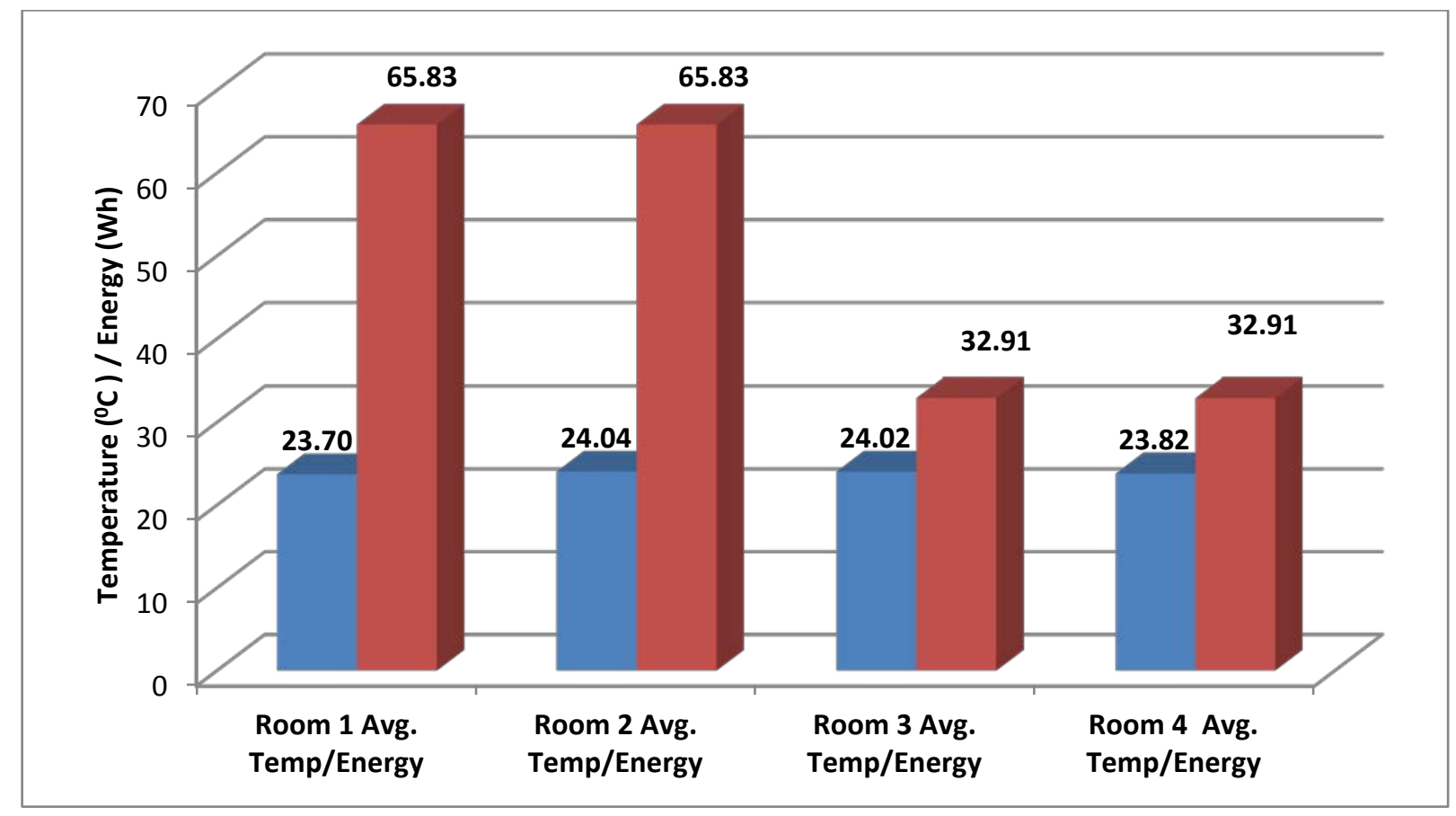

Figure 28 - Room-by-Room Analysis of Average Temperature and Energy Used in Test 4

\subsection{A Note on Thermostat Placement}

If you had been paying attention about the construction methods from the model house, you would've noticed that rooms 3 and 4 were of equal size and equal insulation schemes. It might be puzzling then why in every test, there was a difference in the energy used in rooms 3 and 4. One thing was that wasn't uniform about the construction of both these rooms was the placement of the thermistors in relation to their heating modules which can be seen in Figure 11. The thermistor in room 3 was located substantially closer to the heating module than in room 4 and was thus subject to higher average temperatures.

The reader should notice that in their own residence, thermostats are normally placed away from exterior doors and heating vents to reduce the adverse effects that can be caused by transient heating activity. For instance, if your thermostat were located adjacent to the main entrance door of your house, it is worth nothing that the cold air from outdoors 
in winter time would cause the thermostat to trip unnecessarily while open. This would waste energy and most likely cause the house to be a lot hotter than its set point. If your thermostat(s) is (are) mounted in such a way that these cases are true, then have them moved! You'll experience a higher level of comfort and efficiency.

\subsection{Model House - Conclusions}

Although the model did not have the exact same properties as a full-sized house, it is rewarding to see that concrete results were able to be harvested from this setup. A visual representation of the total energy used can be seen in Figure 36 and gives an immediate answer as to which method of heating is the most efficient. The model house platform was also able to provide a fair degree of independence from room-to-room with its novel zoning system and sealed-off areas. With this capability in mind, it makes sense to put a little effort into investigating whether or not some kind of transfer function can be applied to predict energy usage based on relative room size. The most obvious quantities to correlate to are volume and surface area. The room and energy data is summarized from test 1 in Table 6 below.

\begin{tabular}{cccccc}
\hline & E (Wh) & Vol. $(\mathbf{m} 3)$ & \% Total Vol & Total E*\%Vol & \% Error \\
\hline Room1 & 86.667 & 0.233 & 0.476 & 100.947 & 16.477 \\
Room2 & 63.333 & 0.129 & 0.263 & 55.889 & 11.754 \\
Room3 & 26.667 & 0.064 & 0.131 & 27.728 & 3.980 \\
Room4 & 35.625 & 0.064 & 0.131 & 27.728 & 22.167 \\
Total & $\mathbf{2 1 2 . 2 9 2}$ & - & - & - & - \\
\hline
\end{tabular}

Table 6 - Model House Data from Test 1 with Volume

By simply multiplying the total energy used in test 1 by the percentage of volume that each room occupies, it can be seen that a relatively accurate estimate towards representing energy usage per room. 
Another approach is to remember that heat transfer occurs through the walls of the surface in which the thermal mass is contained. Adapting this to the model house, Table 7 was created to summarize the surface area data and apply it accordingly.

\begin{tabular}{cccccc}
\hline & E (Wh) & S.A. & \% Tot. S.A. & Total E*\%S.A. & \% Error \\
\hline Room1 & 86.667 & 1.834 & 0.396 & 84.019 & 3.055 \\
Room2 & 63.333 & 1.268 & 0.274 & 58.089 & 8.280 \\
Room3 & 26.667 & 0.766 & 0.165 & 35.092 & 31.594 \\
Room4 & 35.625 & 0.766 & 0.165 & 35.092 & 1.497 \\
Total & $\mathbf{2 1 2 . 2 9 2}$ & - & - & - & - \\
\hline
\end{tabular}

Table 7 - Model House Data from Test 1 with Surface Area

Remarkably, results of even greater accuracy are produced when multiplying the total energy consumed during the test by the percentage of total surface area in which it's radiating through. For the reasons mentioned in Section 5.5, there is a large inconsistency between rooms 3 and 4 .

\subsection{Heating Scheme Tests - Full-Sized House}

Skeptics of the conclusions developed in this paper thus far might call the experiments performed on the model house invalid, due to the controlled nature of the circumstances surrounding its functionality. The decision, therefore, was made to utilize a real residential dwelling as a test bed for two empirical experiments (see Table 8), aiming to further support the conclusions obtained from the scale-model house. The author's dwelling was wired up to an HP 34970A data acquisition/data logger switch unit for the purposes of logging outdoor temperature, indoor temperature and the on/off state of the furnace. Two separate experiments were conducted over a period of 24 hours each to provide a realistic comparison to the model house tests. 


\begin{tabular}{|c|c|}
\hline Temperature Profile / Scheme & Central \\
\hline Constant (w/Dead band) & Test 5 \\
\hline Occupancy Program & Test 6 \\
\hline
\end{tabular}

\section{Table 8 - Organization of Full-Size House Testing Plan}

As an aside, the test dwelling is equipped with a gas-fired central air system operating on a centrally located thermostat. In this instance, when heat is commanded, the entire house is heated all at once. The timing of the tests-with regards to time of year-was selected during the Canadian spring to ensure a substantially large difference in indoor versus outdoor temperature. The aim in this experiment was to pick a time of year which would force the home's furnace to cycle frequently in the hopes of obtaining a large enough contrast between set-point schemes. The immediate goal was to observe a substantially large difference in energy inputted into the house from test-to-test in hopes of validating the trends observed with the model house.

\section{8. $\quad$ Test \#5 - Fixed Thermostat Set-Point}

The first test in this configuration was one in which the house's thermostat was set at a constant temperature regardless of occupancy and time of day. This particular set point was $23^{\circ} \mathrm{C}$ and an average outdoor temperature of $8.27^{\circ} \mathrm{C}$ was recorded over the 24 hour period. The results were gathered as can be seen in Figure 38 and provide a clear picture of indoor temperature, outdoor temperature and furnace operation.. After analyzing the data, it was observed that the furnace registered 1112 "on" points with a sampling time of 30 seconds. In other words, the furnace was on for a total of 9.27 hours in one 24 hour cycle in order to maintain an indoor temperature of $23^{\circ} \mathrm{C}$. 


\subsection{Test \#6 - Occupancy-Based Thermostat Program}

The second test in this series was modified from the first inasmuch that a temperature program based on occupancy was dialed into the thermostat. The scheme in question was programmed as follows:

- Thermostat set to $23^{\circ} \mathrm{C}$ beginning at 3:30am

- Thermostat set to $18^{\circ} \mathrm{C}$ beginning at 8:30am

- Thermostat set to $23^{\circ} \mathrm{C}$ beginning at $3: 30 \mathrm{pm}$

- Thermostat set to $18^{\circ} \mathrm{C}$ beginning at 7:30pm

The rationale behind this schedule is that the house should be reasonably comfortable for the building occupants for the duration of their time at home. This assumes, of course, a family where all of the occupants are away for the majority of the day. The results of this trial can be seen in Figure 39. Analysis of this data set tells us that 786 "on" points were registered, meaning that the furnace was on for a total of 6.55 hours over a 24-hour period. Clearly, we have found the more efficient solution.

\subsection{Tuning the Model House: How Did We Do?}

In Chapter 3, the details of model house construction and ballasting with known thermal masses was described. As was discussed, the ballasting was done in order to slow down the model house's heating response time with the hopes of providing more realistic heating figures. From [13], a slight variation of the Fourier heat model can be derived which is particularly useful for scenarios when you have experimental data. This model takes the form of exponential decay and is as follows:

$$
T_{\text {in }}=T_{\text {out }}+A e^{-\frac{b}{a} t}
$$

Equation 4 - Exponential Decay Formula Used to Calculate Heat Gain/Loss 
The ratio of $b / a$ is the decay factor of the house which will govern the rate at which heat is lost. This equation can be manipulated to show that:

$$
t=\frac{a}{b} \log \left[\frac{T_{\text {high }}-T_{\text {out }}}{T_{\text {low }}-T_{\text {out }}}\right]
$$

\section{Equation 5 - Expanded Formulation of equation 4 allowing for Initial and Final Conditions}

Once I discovered this derivation, I decided that I could gather some data from the model house (and later, a full-sized house) in order to empirically calculate the respective b/a. Armed with a data set from the model house and full-sized house, I would then be able to determine if I had constructed the house in a manner which modeled real life. The model house was programmed to run a series of temperature ramp-up/cool down sessions as can be seen in Figure 34 which allowed me to gather vital data to show the house's natural response during cool down periods (i.e,, no heat being generated equals no forcing function). I quickly rearranged the above equation to suit my data set:

$$
\frac{b}{a}=\log \left[\frac{T_{\text {high }}-T_{\text {out }}}{T_{\text {low }}-T_{\text {out }}}\right] t^{-1}
$$

\section{Equation 6 - Rearranged Representation of Equation 5}

After the trial ran, the data was plotted in Figure 34 and I began to grab data points. Unfortunately, the nature of the LabJack's circuitry created a lot of noise on readings, so I decided to analyze larger periods of time in the same range, average out ranges' values and use the midpoint in time as the applicable time marker. The results were inputted into Microsoft Excel for speed and solutions are presented in Table 9. 


\begin{tabular}{|c|c|c|c|c|c|c|c|}
\hline & $\begin{array}{c}\text { Time } \\
\text { Start }\end{array}$ & $\begin{array}{c}\text { Time } \\
\text { End }\end{array}$ & $\begin{array}{c}\text { Time } \\
\text { Marker }\end{array}$ & $\begin{array}{c}\text { Avg. Temp. } \\
\left({ }^{0} \mathrm{C}\right)\end{array}$ & Tout & $\boldsymbol{t}(\mathrm{h})$ & $\mathrm{b} / \mathrm{a}$ \\
\hline $\begin{array}{c}\text { Point } 1 \\
\left(\mathrm{~T}_{\text {high }}\right)\end{array}$ & $1: 21: 00$ & $1: 30: 00$ & $1: 25: 30$ & 24.11 & 20.00 & - & \multirow{2}{*}{0.09983} \\
\hline $\begin{array}{c}\text { Point } 2 \\
\left(\mathrm{~T}_{\text {low }}\right)\end{array}$ & $1: 57: 00$ & $2: 06: 00$ & $2: 01: 30$ & 23.58 & 20.00 & 0.6 & \\
\hline
\end{tabular}

Table 9 - Data Points Used to Solve for the Model House's b/a Factor

Continuing this theme, the same sort of data was gathered from the full-sized house occupancy trial due to the fact that it, too, contained decay data when the furnace was off. In order to deal with the noisy data obtained, the same averaging method was used to obtain some solid data points. The solutions for this can be seen in Table 10.

\begin{tabular}{|c|c|c|c|c|c|c|c|}
\hline & $\begin{array}{c}\text { Time } \\
\text { Start }\end{array}$ & $\begin{array}{c}\text { Time } \\
\text { End }\end{array}$ & $\begin{array}{c}\text { Time } \\
\text { Marker }\end{array}$ & $\begin{array}{c}\text { Avg. Temp. } \\
\left({ }^{\circ} \mathrm{C}\right)\end{array}$ & $\begin{array}{c}\text { Tout } \\
\left({ }^{\circ} \mathrm{C}\right)\end{array}$ & $\boldsymbol{t}(\mathrm{h})$ & $\mathrm{b} / \mathrm{a}$ \\
\hline $\begin{array}{c}\text { Point } 1 \\
\left(\mathrm{~T}_{\text {high }}\right)\end{array}$ & $9: 00: 10$ & $9: 10: 10$ & $9: 05: 10$ & 21.73 & 6.35 & - & \multirow{2}{*}{0.008174} \\
\hline $\begin{array}{c}\text { Point } 2 \\
\left(\mathrm{~T}_{\text {low }}\right)\end{array}$ & $13: 34: 10$ & $13: 44: 10$ & $13: 39: 10$ & 20.47 & 6.35 & 4.56 & \\
\hline
\end{tabular}

Table 10 - Data Points Used to Solve for the Full-Sized House's b/a Factor

According to this data, it appears that the model house was built in such a way that yielded a b/a approximately 10 times higher than that of the full-sized house. According to this result, I was partially successful in making the scale-model house as realistic as the fullsized house. But what does this disparity in b/a mean? It's more important that we go ahead and perform a quick analysis to determine what was wrong about the model house. 
Going back to Equation 5, we can use our calculated b/a values with an arbitrary outdoor temperature to verify how long it would take for the model and full size houses to decay from an initial point-to-a final resting temperature. In both cases, the global parameters were selected as follows:

- $\mathrm{T}_{\text {high }}=20^{\circ} \mathrm{C}$

- $\mathrm{T}_{\text {low }}=15^{\circ} \mathrm{C}$

- $\mathrm{T}_{\text {out }}=10^{\circ} \mathrm{C}$

Plugging in these values, it was found that it would take 3.02 hours for the model house to cool down from $20^{\circ} \mathrm{C}$-to- $15^{\circ} \mathrm{C}$. On the contrary, the same conditions yielded a time of 36.82 hours for the full-sized house to cool down. These results point to the obvious conclusion that the model house had too much heat loss through its walls as compared to the full-sized house. Seeing results like this now makes me wonder if I should have refrained from scaling down the thickness of the walls. Perhaps the model house endeavour requires more investigation in order to obtain more realistic values. This issue aside, the house still serves as a good platform on which to predict energy consumption trends.

\subsection{Full-Sized House - Conclusions}

As can be seen from these two tests, the occupancy-based heating profile proved to use approximately $28 \%$ less energy as compared to the constant temperature scheme. Another factor which speaks volumes to the savings to be had by modulating the temperature in this manner, is the fact that the savings were noted on a day where the average temperature over 24 hours was nearly $2^{\circ} \mathrm{C}$ lower than the 24 hour period selected for the constant temperature test. It is feasible to think that if the two days selected for these tests had been closer in temperature to one another, that further declines in energy use may have been observed. Unfortunately for me, the weather at that time of year did not lend itself to providing consistent daily weather patterns.

Something that should be taken into consideration as well is the fact that keeping the temperature constant required the furnace to operate frequently in very short bursts. Over 
time, short cycling of electromechanical systems can lead to premature failure of components which would cause an even larger cost to the homeowner. The advantage of modulating the temperature is that the furnace typically runs less frequently, but for longer durations. 


\section{Chapter 6}

\section{CONCLUSIONS AND FUTURE WORK}

\section{Conclusion}

This study has been able to prove - with a high degree of certainty — that keeping your home at a constant temperature is more energy intensive than allowing it to fall at night/day (based on theoretical occupancy). Although this sounds trivial in nature, it adds a definitive argument to this ongoing debate, which continues to rage on between property owners without any scientific backing. As was presented in Chapter 5, the savings to be had approached 30\% when performed on an actual residential dwelling. A simple conclusion like this could go onto save property owners hundreds of dollars every year (based on the author's average heating bill of $\$ 70.00$ per month).

After having seen the results of this endeavour, a definite physical reality becomes quite obvious to answer the question empirically; it must be realized that the materials in your house act as giant thermal capacitors (Figure 29) with the ability to store heat and release it in back into the building's interior air in order to lower the rate at which it loses heat.

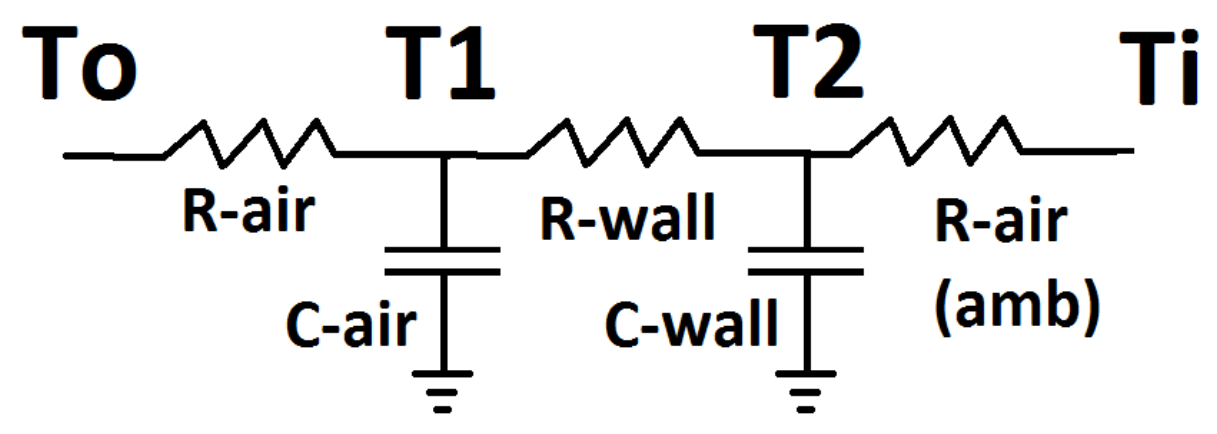

Figure 29 - Electrical Analogue of the Heat Loss Model (adapted from [14], [15]) 
This model becomes model for prediction when we look at the heat loss associated with the component of the house with the largest thermal capacity; the walls. The differential equation governing temperature loss across the wall is known to be [14]:

$$
C \frac{d T_{2}}{d \tau}=h A\left(T_{1}-T_{2}\right)+\frac{T_{1}-T_{2}}{R}
$$

\section{Equation 7 - Lumped Capacitance Model of Heat Transfer [6]}

Rearranging for $\mathrm{dT}_{2} / \mathrm{dt}$, we can see that large values of $\mathrm{C}$ will decrease the change in temperature over a unit of time. The moral of the story is, increase the thermal capacitance of your walls by installing as much insulation as is possible. Doing this will increase the ability of your home to store heat, thus allowing you to turn off your heating systems for longer periods of time when unoccupied.

$$
\frac{d T_{2}}{d \tau}=\frac{h A\left(T_{1}-T_{2}\right)+\frac{T_{1}-T_{2}}{R}}{C}
$$

\section{Equation 8 - Rearrangement of Equation 7}

Having provided a solution to the first major problem in this study, we move onto the next problem of determining whether there are gains to be made by equipping homes with heating systems capable of adjusting room temperature independently throughout the house. Due to the hardware and infrastructure required to simulate this in real life, it was not possible for the author to provide a data set from a full-sized house to prove this point. To answer this question, the study relied entirely on the tests run on the scale-model house 
described in Chapter 4. Although not as dramatic as the full-sized house test comparisons, energy gains of approximately $10 \%$ were observed by configuring the scale-model house with a room-by-room heating system as compared to a central heating system, which heats all rooms simultaneously.

Even though precautions and plans were put in place during the design/construction process of the scale-model house, the "b/a" time constants used in the heat-loss modelling equation calculated experimentally were quite different than those calculated for the fullsized house. Heating and heat-loss tended to occur at different rates from house-to-house (faster in the scale-model house) and this is the principle reason why energy gains were harder to identify with the scale-model house. What must be kept in perspective is that conclusions were drawn based on the 'same test bed,' in other words, 'apples-to-apples.' Experiments conducted on the same test bed can be compared relatively to each other to reach conclusions, but may not necessarily have to ability to be compared to other similar models in the real-world. It for these reasons why the results from the scale-model house were not compared with those from the full-sized house-that would be comparing 'apples-to-oranges.'

The reader must also realize that the underlying assumption for this whole study has been that the property occupants would be comfortable going on about their normal business with acceptable minimum and maximum temperature settings. Some people may find it comfortable to sleep within the National Sleep Foundation's temperature guidelines for proper sleep [16], while other occupants may prefer higher or lower temperature environments for sleeping or daily activities. For example, a fluctuating temperature scheme may not be acceptable for young infants, elderly people or rental units. In those cases, some temperature extremes may not be possible due to health, safety and legal concerns. For instance, the City of Mississauga, Ontario mandates that rental dwellings must be kept at a minimum of $20^{\circ} \mathrm{C}$ throughout select portions of the year [17]. As is the case with a lot of energy conservation ideas, the human factor typically dictates the degree of gains to be had. As an aside, if the reader wished to optimize their house's heating costs, the suggestion would be to run a series of tests on their house in order to characterize the temperature preferences of their particular occupants throughout the day. All that is 
required is a simple method of logging indoor/outdoor temperature and furnace operation. As long as the initial experimental conditions are identical then different schemes can be set and the results observed.

Regardless of the issues faced above, the ultimate goal of the study was met and that was to be able to draw definite conclusions on the optimal way to heat a house via experimental means.

\subsection{To Zone, or Not to Zone?}

In Chapter 2, zoned systems for real homes were introduced, but no conclusion was drawn on whether or not it makes economic sense to implement a zoned system in a house. The minimal bill of materials to required implement a 4-zone system is presented in Table 11.

\begin{tabular}{cccc}
\hline Device & Quantity & Max. Price EA. & Ext. Price \\
\hline MZP4 Control Panel & 1 & $\$ 604.00$ & $\$ 604.00$ \\
TDS Thermostat & 4 & $\$ 124.00$ & $\$ 496.00$ \\
SPRD - Static Pressure Regulating Damper & 1 & $\$ 172.00$ & $\$ 172.00$ \\
RDP - Zone Damper & 4 & $\$ 310.00$ & $\$ 1240.00$ \\
SPC - Static Pressure Control & 1 & $\$ 360.00$ & $\$ 360.00$ \\
\hline
\end{tabular}

Table 11 - Bill of Materials Required for a 4-Zone HVAC System [18]

The total cost of materials for this endeavour approaches $\$ 3000.00$ and does not even account for the labour component to have this installed by qualified professionals. Assuming a weekend's worth of work required to retrofit a system into an existing house would run $\$ 1500.00$, the total cost of a system would be approximately $\$ 4500.00$. ZoneFirst, a company which specializes in the manufacture of necessary components estimates that energy savings of $15-29 \%$ can be realized. Using my monthly heating bill of 
$\$ 70.00$ as an example, it would take almost 35 years to pay-off the added system cost using savings alone. That, or course, assumes that the costs associated with electricity and natural gas stay constant over that 35 year period (unlikely). The resulting conclusion is that property owners must be willing to take a rather large initial hit on cost to obtain said savings. Economically speaking, the suggestion would be 'No!', while environmentally speaking, 'Yes!' would be the appropriate feeling. The reader is free to draw their own conclusions, but based on my own personal feelings and some industry guidance against it [19], the general sentiment is to avoid zoning for now.

\subsection{Future Work}

In terms of continuing on this research exercise, there are numerous advancements and improvements that can be made in all of the following areas:

- Model home simulation and control

- Mathematical modelling used to predict heat loss

\subsection{Model Home Simulation and Control}

When it comes down to the scale-model home that was constructed for the purposes of simulating a house heating scheme, additional features could be implemented to increase the degree of accuracy towards real life;

- Control matrix for simulation

- Repeat for cooling to see if same conclusions can be reached

- Add contributions of windows and doors to overall heat-loss

To simulate the real-time occupancy of people in a dwelling, the LabView model could be provided 'control matrix' (see Table 12) in parallel to the fixed thermostat settings. 


\begin{tabular}{|c|c|c|c|c|c|c|c|c|}
\hline Time/Room & $\mathbf{1 2 : 0 0}$ & $\mathbf{1 2 : 1 0}$ & $\mathbf{1 2 : 2 0}$ & $\mathbf{1 2 : 3 0}$ & $\mathbf{1 2 : 4 0}$ & $\mathbf{1 2 : 5 0}$ & $\mathbf{1 : 0 0}$ & $\ldots \ldots$ \\
\hline Bed 1 & 1 & 1 & 1 & 1 & 1 & 1 & 1 & $\ldots \ldots$ \\
\hline Bed 2 & 0 & 0 & 0 & 0 & 0 & 0 & 0 & $\ldots \ldots$ \\
\hline Bed 3 & 1 & 1 & 1 & 1 & 1 & 1 & 1 & $\ldots \ldots$ \\
\hline Kitchen & 0 & 0 & 0 & 1 & 1 & 0 & 0 & $\ldots \ldots$ \\
\hline Basement & 0 & 0 & 0 & 0 & 0 & 0 & 0 & $\ldots \ldots$ \\
\hline Laundry & 0 & 0 & 0 & 0 & 0 & 0 & 0 & $\ldots \ldots$ \\
\hline$\ldots \ldots$ & $\ldots \ldots$ & $\ldots \ldots$ & $\ldots \ldots$ & $\ldots \ldots$ & $\ldots \ldots$ & $\ldots \ldots$ & $\ldots \ldots$ & $\ldots \ldots$ \\
\hline
\end{tabular}

\section{Table 12 - Sample Occupancy-Based Control Matrix as an Input}

The intent behind this control matrix is to simulate the dynamic presence of people in a dwelling without the need for a larger house equipped with occupancy sensors logging actual people. Alongside the room temperature schedules, these on/off commands would override the current state of heating and force the heating for that particular room to trip on for a predetermined duration of time, thus providing additional comfort to occupants while they are in a room. It is highly unlikely that this model would provide a costoptimized solution, but rather a comfort-optimized solution (as determined by real people in a real mock-up).

The idea of this control matrix stems from the Peak Saver Plus energy savings scheme developed by the Ontario Power Authority [20]. Local utilities have been given the ability to install hardware allowing remote control of people's thermostats to ease energy demands on the power grid. Peaksaver primarily focuses on cooling (electric air conditioning) versus heating, but the same sort of idea applies; the local utilities create a dynamic control matrix on a house-by-house basis (as opposed to room-by-room) which is sent across a power grid network in order to conserve energy during peak times.

Since the mention of cooling has been made, an interesting extension to this study would be the verification of similar results to the opposite problem: cooling a house. In theory, the governing equations would be identical to the ones used here; however, empirical ventures can sometimes end up surprising us. 
Finally, the model house certainly approached an ideal model for heat-loss given that there were no windows or doors whatsoever. Glass is known to have an R-value of roughly 0.14 (per inch), while the applied polystyrene insulation had an R-value of 3.75 (per inch). Combine this with the wood panelling on both sides of the insulation, and the total R-value comes to 4.525 (per inch) depicted in Figure 7. Adding glass panels and doors to simulate these contributions would represent the possibility of substantially more heat-loss and would provide very accurate prediction and simulation.

\subsection{Improved Mathematical Modelling}

The elementary mathematical models used to draw conclusions from the experimental results in sections $4 \& 5$ were conditional on a large amount of assumptions, the principle one being that heat transfer was from in steady state through a flat plane. It is worth nothing that this isn't the case in reality and a more accurate model could be applied with the aid of software packages. From [12], it can be seen that the complexity of heat transfer modelling goes up significantly when additional dimensions are taken into consideration. For instance, the finite difference model for the 2-D case can be represented by a series of divisional square blocks given in Figure 30. 


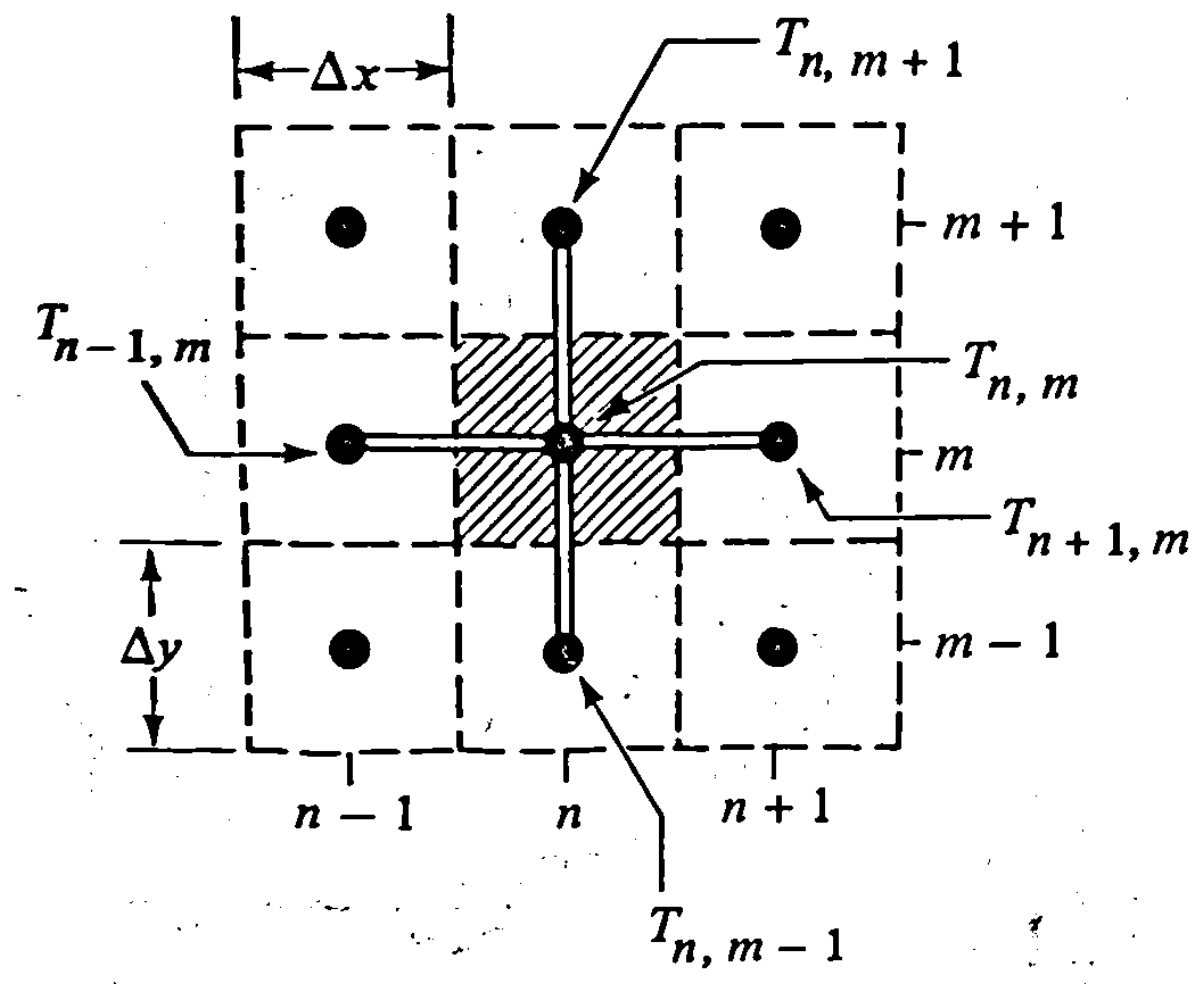

Figure 30 - Pictorial of the Finite Difference 2-D Heat Loss Model [12]

The theory behind this representation is that the heat transfer plane can be broken down into finite chunks with a point-source heater in each block. Using this analysis, heat transfer in two directions can now be considered and the results have the ability to be much more accurate than the 1-D planar model used in this study. The governing equation for this model is as follows:

$$
\frac{\delta^{2} T}{\delta y^{2}}=\frac{T_{n, m+1}-2 T_{n, m}+T_{n, m-1}}{\left(\Delta y^{2}\right)}
$$


The complexity associated with this model now dictates that solving must occur in a recursive method, best implemented in Matlab or similar software package for n,m sections of area. This would be applied to a full-sized house model to see, once again, if a reliable heat-transfer model could be produced. Ultimately, software packages from firms such as ANSYS are designed to solve computational fluid dynamics (CFD). The packages can also be used to generate mesh plots of heat transfer given an environment and material properties. 


\section{APPENDIX A - ASSORTED TABLES}

\begin{tabular}{cc}
\hline Substance & Density $\left(\mathbf{k g} / \mathbf{m}^{\mathbf{3}}\right)$ \\
\hline Air & 1.246 \\
Aluminum & 2707 \\
Concrete & 2370 \\
Mineral Based Insulation & 192 \\
Polystyrene & 16 \\
Water & 996 \\
Wood & 545 \\
\hline
\end{tabular}

Table 13 - Densities of Relevant Materials [21]

\begin{tabular}{cc}
\hline Substance & $\mathbf{C p}\left(\mathbf{J} / \mathbf{k g}^{\mathbf{0}} \mathbf{C}\right)$ \\
\hline Air & 1005 \\
Aluminum & 897 \\
Cellulose & $1300-1500$ \\
Concrete & 880 \\
Glass & 670 \\
Polystyrene & $1300-1500$ \\
Water & 4182 \\
Wood & 1700 \\
\hline
\end{tabular}

Table 14 - Specific Heat Capacities of Relevant Materials [22] 


\section{APPENDIX B - DETAILS OF MODEL HOUSE CONSTRUCTION}

In this study, the scaled-down model house used a custom electrical control system developed by the author. As was stated before, this thesis is meant to read like a recipe of sorts to aid the development of yet another scaled-down model house. It is for this reason that a great level of detail has been provided into house construction thus far. Continuing with this theme, a full system bill of materials and schematic are given in Table 15 and Figure 31. 


\begin{tabular}{|c|c|c|c|}
\hline Quantity & Part & Description & Part Number \\
\hline 6 & $\begin{array}{l}25 \Omega \text { Resistor, } \\
25 \mathrm{~W}\end{array}$ & Main heating resistors & Generic \\
\hline 4 & $\begin{array}{l}\text { Semtec 103JT- } \\
\quad 75\end{array}$ & $\begin{array}{l}\text { Thermistors for principal room } \\
\text { monitoring }\end{array}$ & 103JT-75 \\
\hline 1 & $\begin{array}{l}\text { Semtec 103JT- } \\
75\end{array}$ & Thermistor for near-door control & 103JT-75 \\
\hline 1 & $\begin{array}{l}\text { Semtec 103JT- } \\
75\end{array}$ & Thermistor for outdoor temp & 103JT-75 \\
\hline 4 & $\begin{array}{l}2.2 \mathrm{kOhm} \\
\text { resistor, } 1 / 4 \mathrm{~W}\end{array}$ & $\begin{array}{l}\text { R1 - Voltage divider resistor (AIN0- } \\
\text { AIN3) }\end{array}$ & Generic \\
\hline 2 & $\begin{array}{c}10 \mathrm{k} \Omega \text { resistor, } \\
1 / 4 \mathrm{~W}\end{array}$ & $\begin{array}{l}\text { R1 - Voltage divider resistor (FL04- } \\
\text { FL05) }\end{array}$ & Generic \\
\hline 4 & $\begin{array}{l}\text { Logic level N- } \\
\text { channel mosfet }\end{array}$ & Mosfet to turn on relay coils & Generic \\
\hline 4 & Relay - 5V coil & Main heater switch-on relays & Generic \\
\hline 4 & Relay - $24 \mathrm{~V}$ coil & Fan switch-on relays & Generic \\
\hline 8 & Diode & $\begin{array}{c}\text { Across all relay coils to discharge } \\
\text { back EMF }\end{array}$ & $1 \mathrm{~N} 4007$ \\
\hline 1 & $\begin{array}{l}\text { Power Supply - } \\
24 \mathrm{~V}\end{array}$ & To power heating resistors & $\begin{array}{l}\text { Generic - greater } \\
\text { than } 7.5 \mathrm{~A} \text { output }\end{array}$ \\
\hline 1 & $\begin{array}{l}\text { Power Supply - } \\
5 \mathrm{~V}\end{array}$ & To power $5 \mathrm{~V}$ relays separately & $\begin{array}{l}\text { Generic - greater } \\
\text { than } 2.0 \mathrm{~A} \text { output }\end{array}$ \\
\hline 1 & $\begin{array}{l}\text { Power Supply - } \\
12 \mathrm{~V}\end{array}$ & To power $12 \mathrm{~V}$ fans & $\begin{array}{l}\text { Generic - greater } \\
\text { than } 2.0 \mathrm{~A} \text { output }\end{array}$ \\
\hline
\end{tabular}

Table 15 - Electrical Control System Bill of Materials 


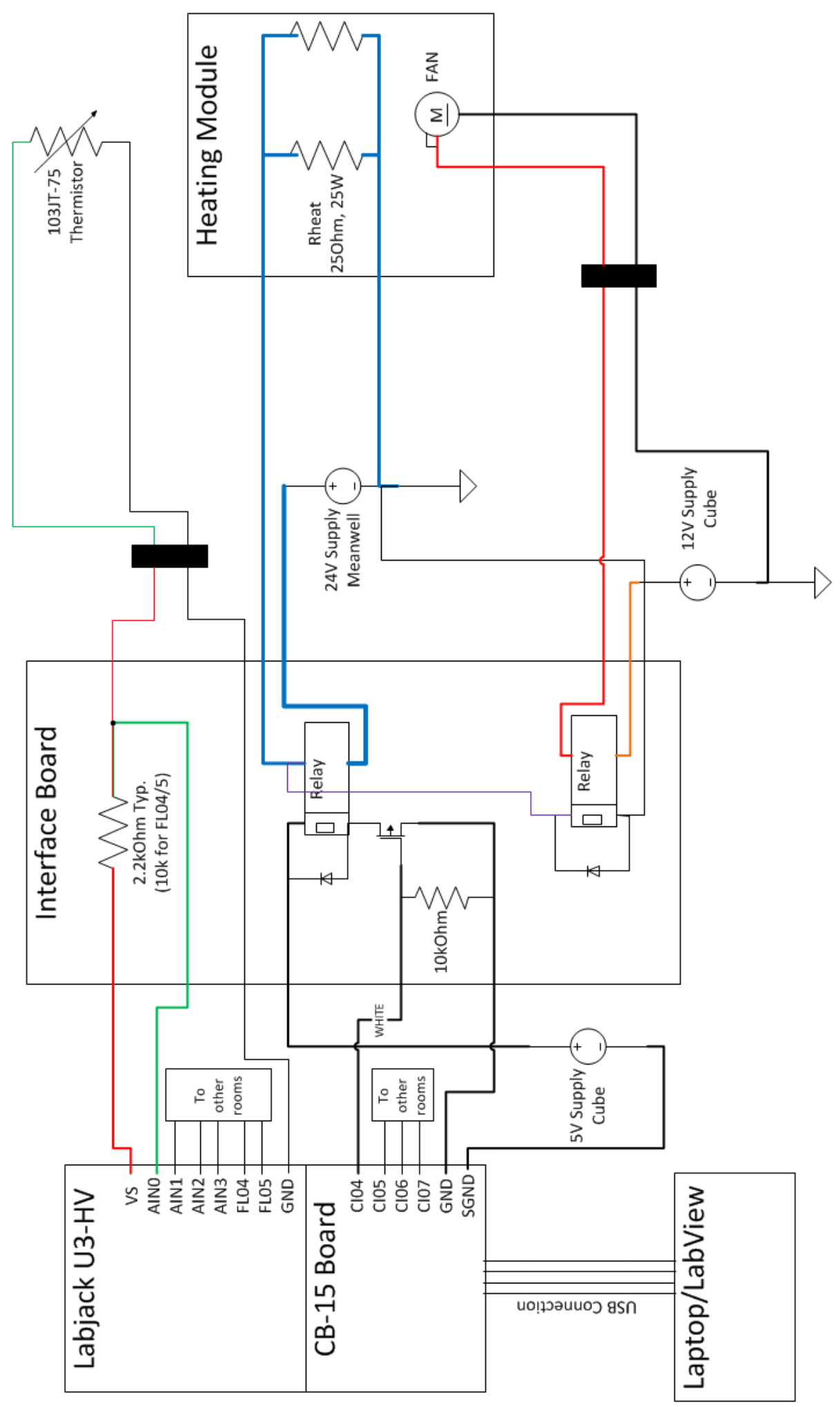

Figure 31 - Full Schematic of Model House Control/Heating System 


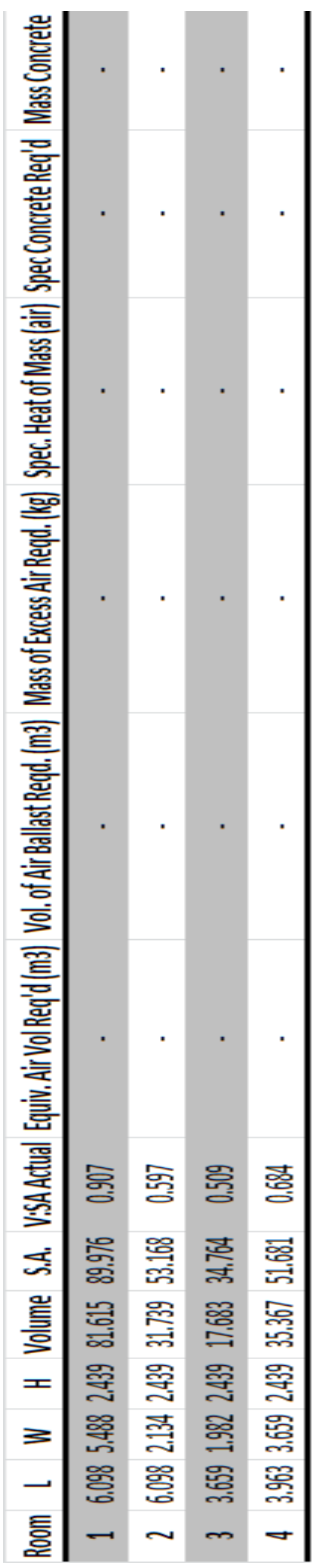

Table 16 - Dimensional Data of Full-Size House 


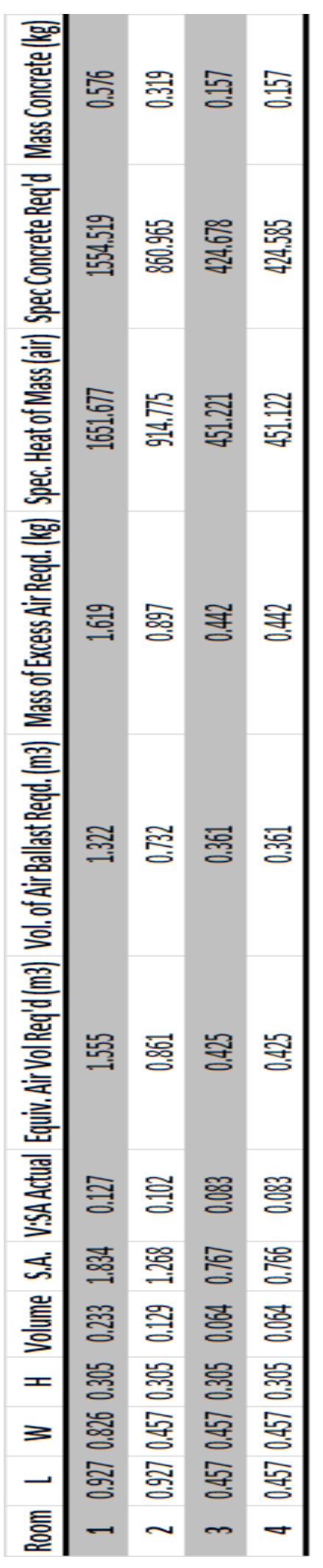

Table 17 - Dimensional Data of Model House with Calculated Concrete Ballasting Data 


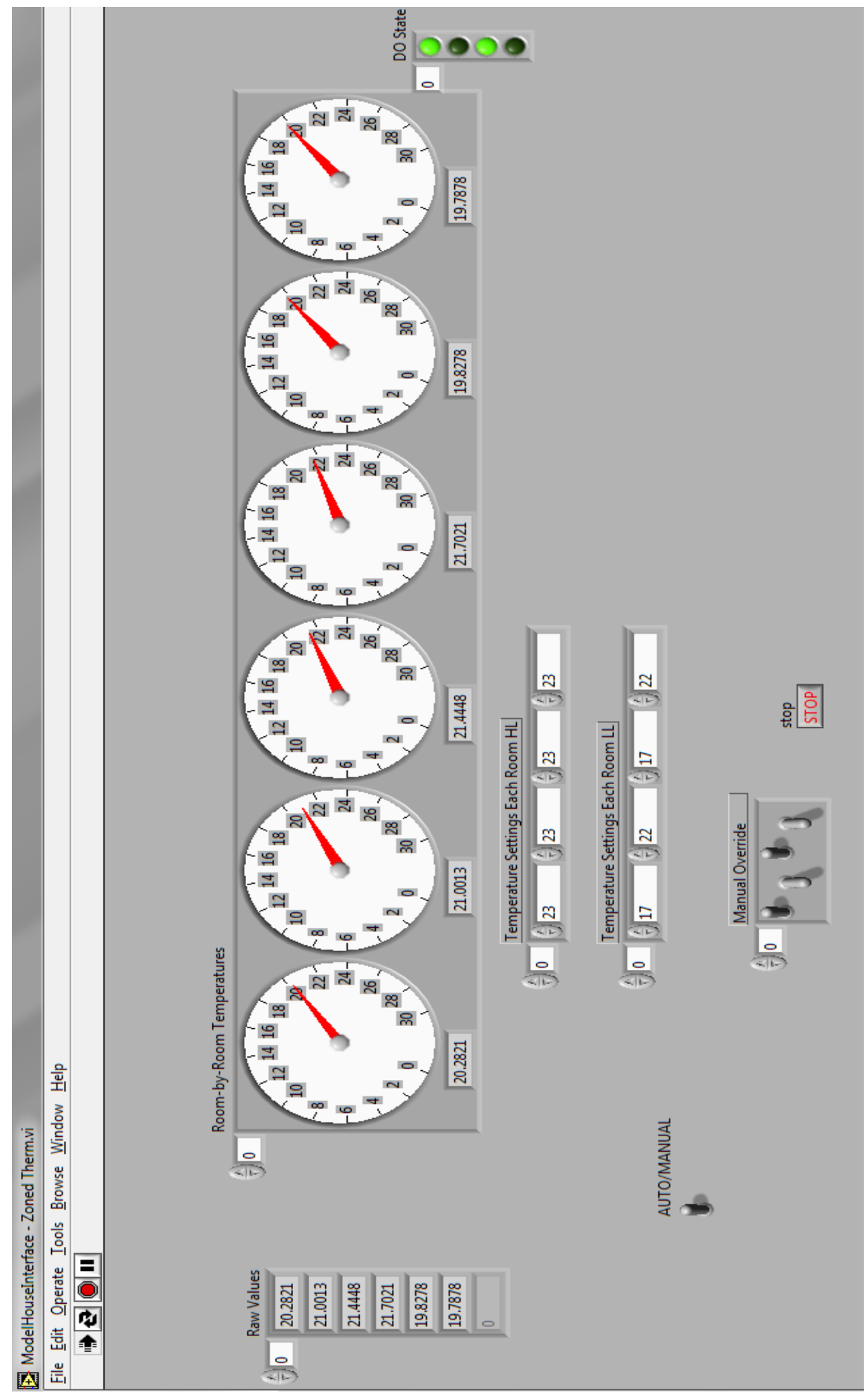

Figure 32 - The LabView Control Interface Showing Temperature Gauges, Thermostat High and Low Limit Set-Points 


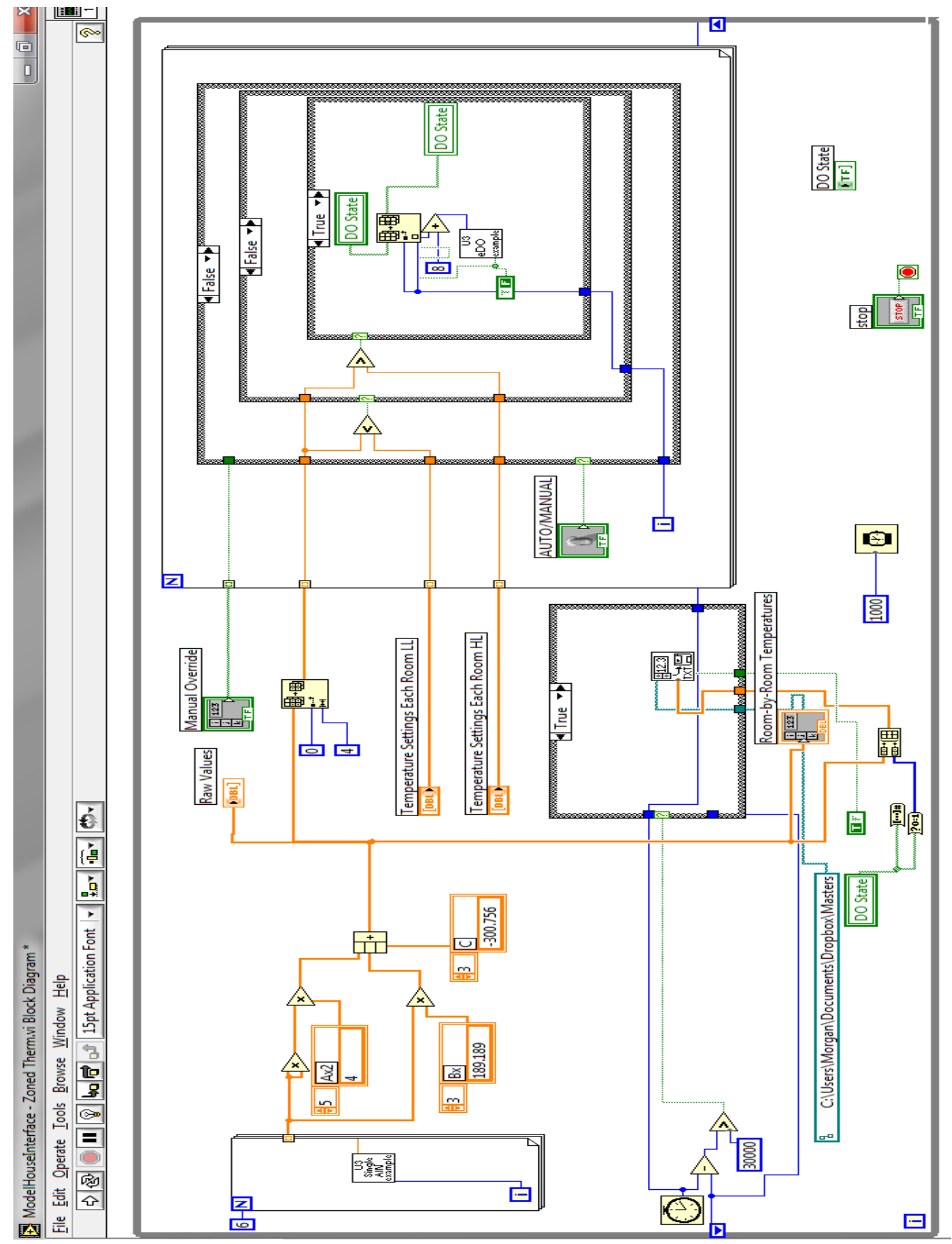

Figure 33 - One Version of the LabView Block Diagram Used to Automate the Model House 


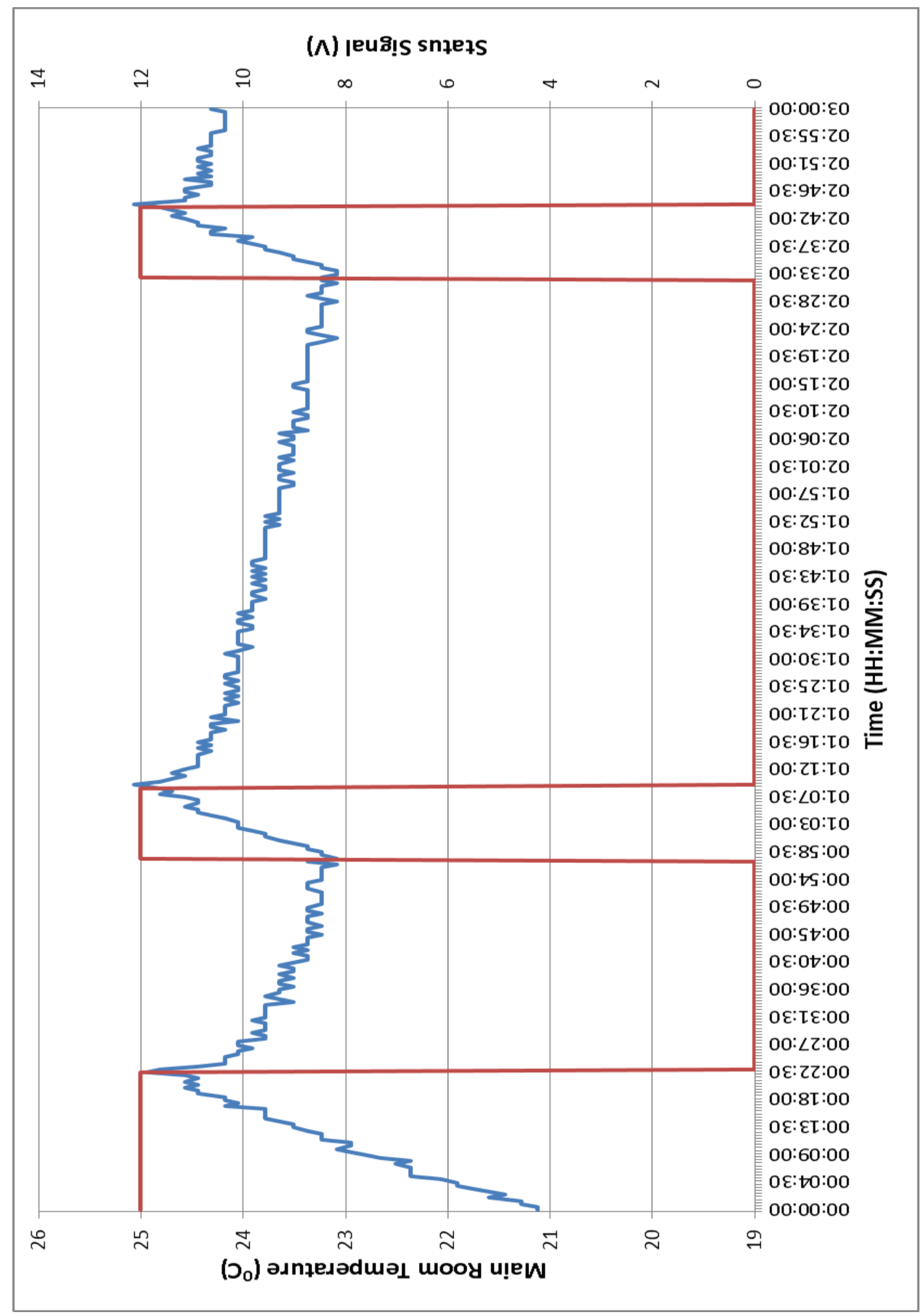

Figure 34 - Data Used to Calculate 'b/a' Constant for Model House 


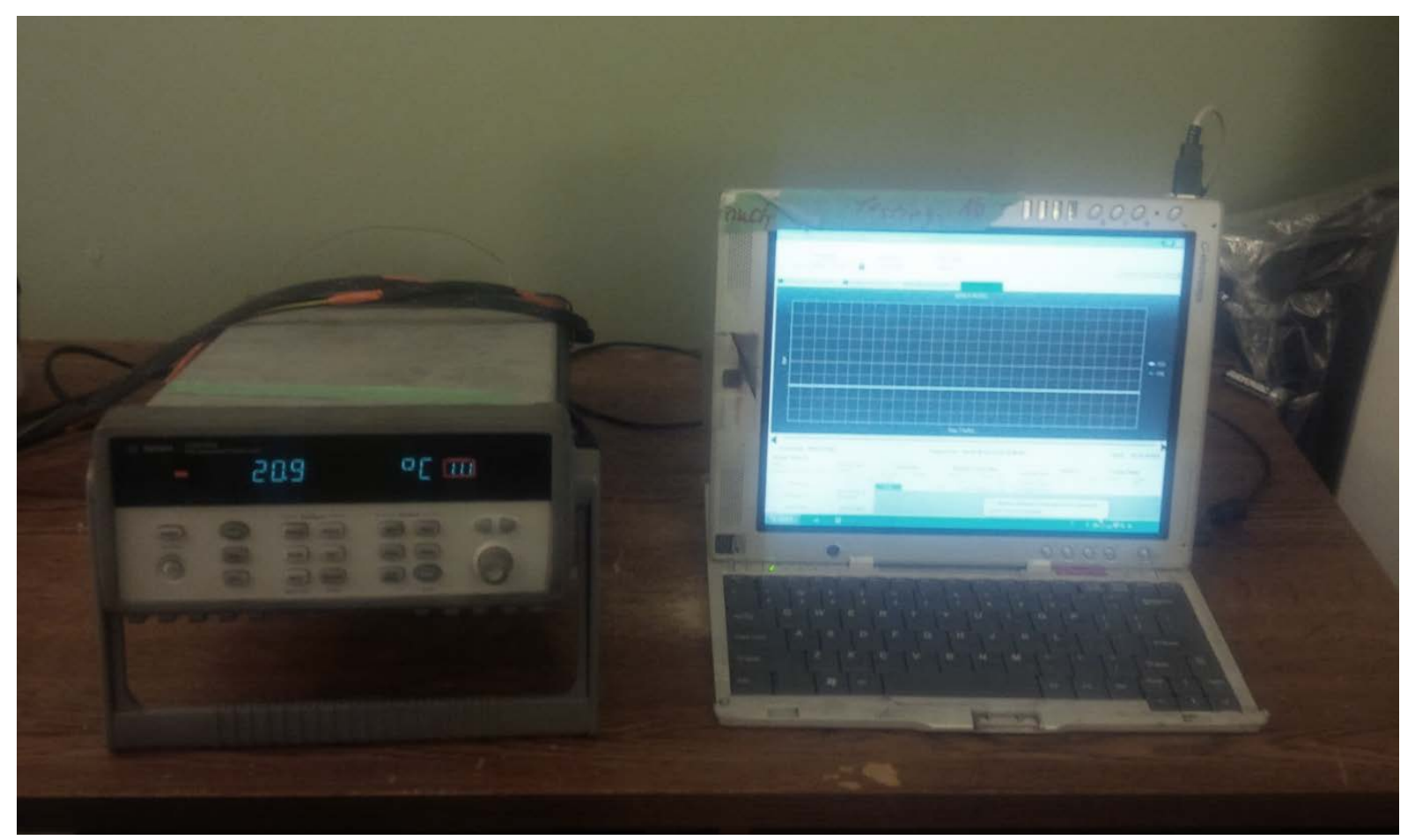

Figure 35 - HP 34970A and Data Logging Computer Setup Used for Full-Scale Testing 


\section{APPENDIX C - VISUAL PRESENTATION OF RESULTS}

The following appendix contains all of the charts of test data from the model house and fullsized house trials. The section is laid out in the following order:

- Summary of model house energy input results

- Individual plots of temperature trends and heating cycles for all test cases

- Summary of full-sized house energy input results

- Individual plots of temperature trends and heating cycles for all test cases

Please note that in Figure 38 and Figure 39, outdoor temperature is represented by the lower trend line while indoor temperature is represented by the upper trend line. It follows that in both cases, the furnace on/off status is represented by the perfectly square series of step functions. 


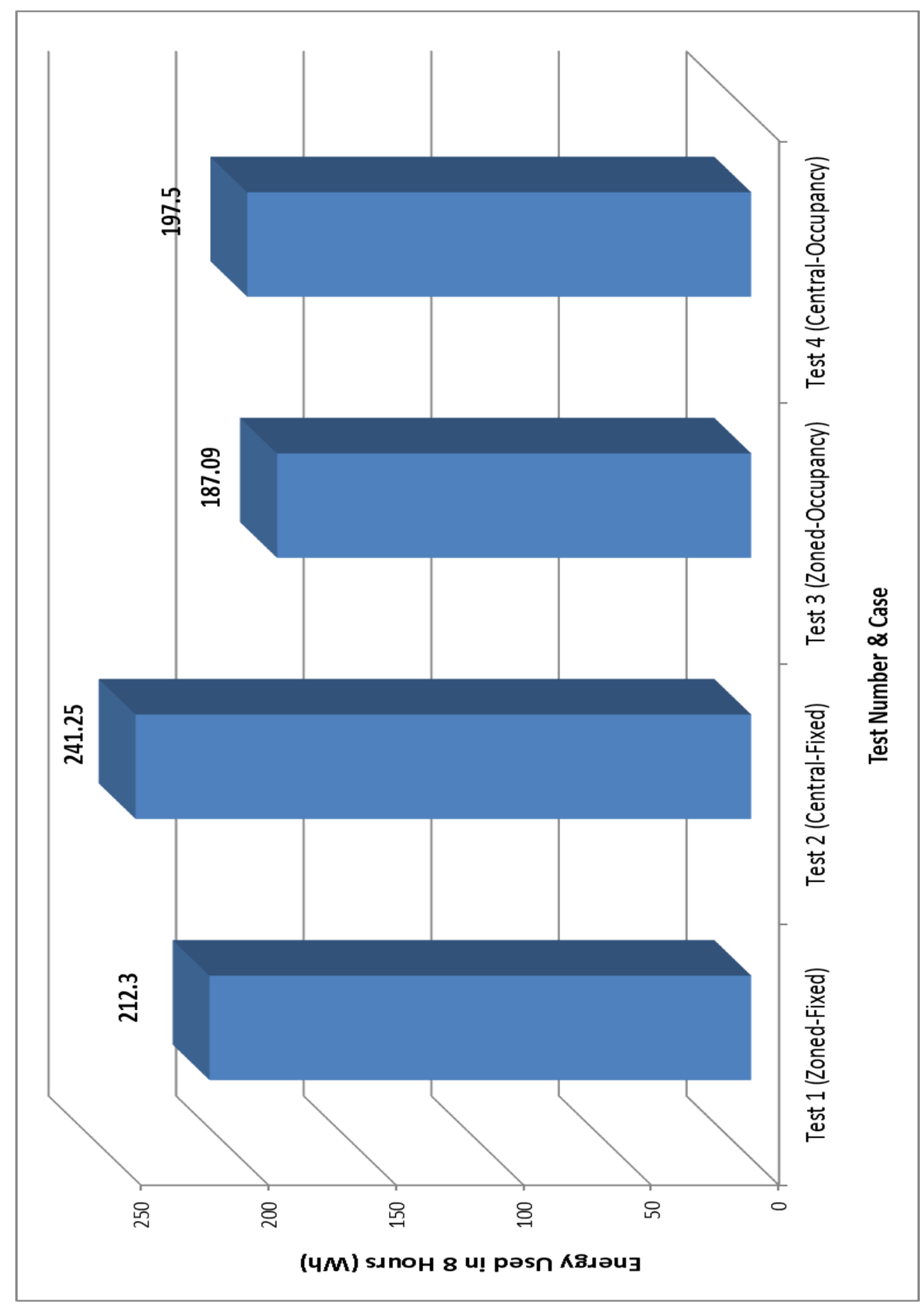

Figure 36 - Summary of Energy Input over 8-Hour Duration of All Model House Test Cases 


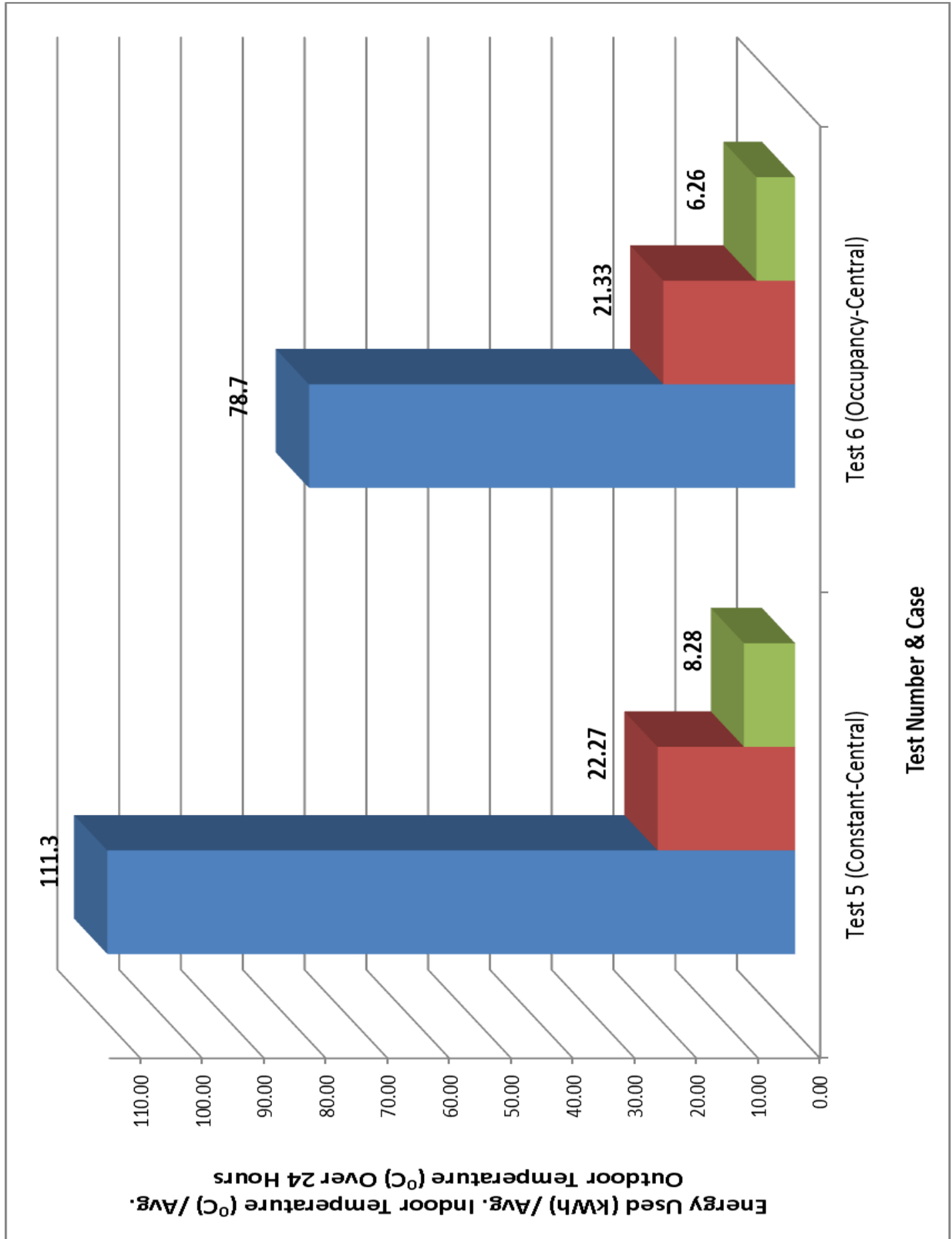

Figure 37 - Summary of Energy Input and Average Temperature Data over 24-Hour Duration of All Full-Sized House Test Cases (Note: BTU Converted to kWh) 


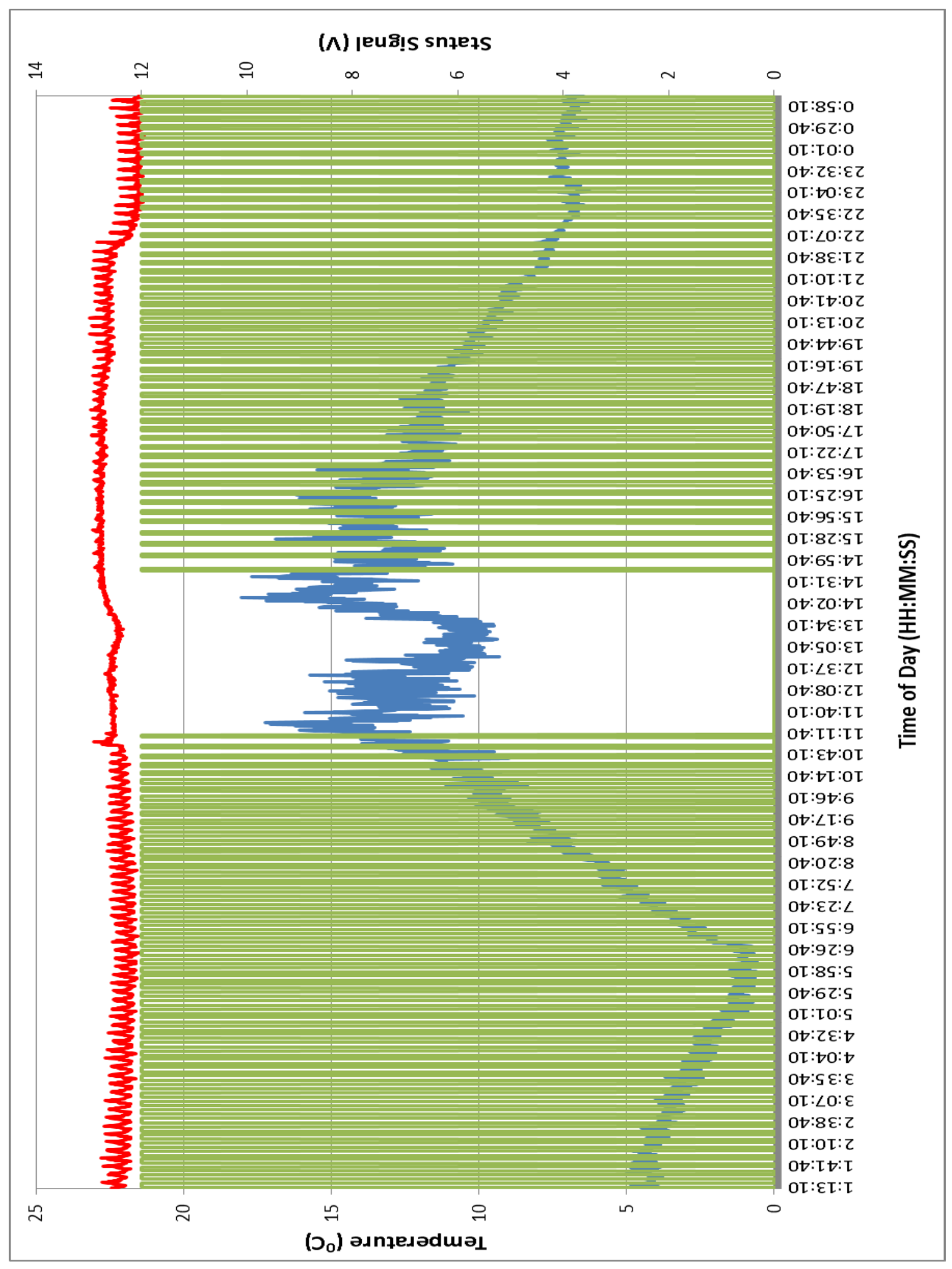

Figure 38 - Test 5: Temperature and Heating Data of the Full-Sized House (Constant Temperature Scheme) 


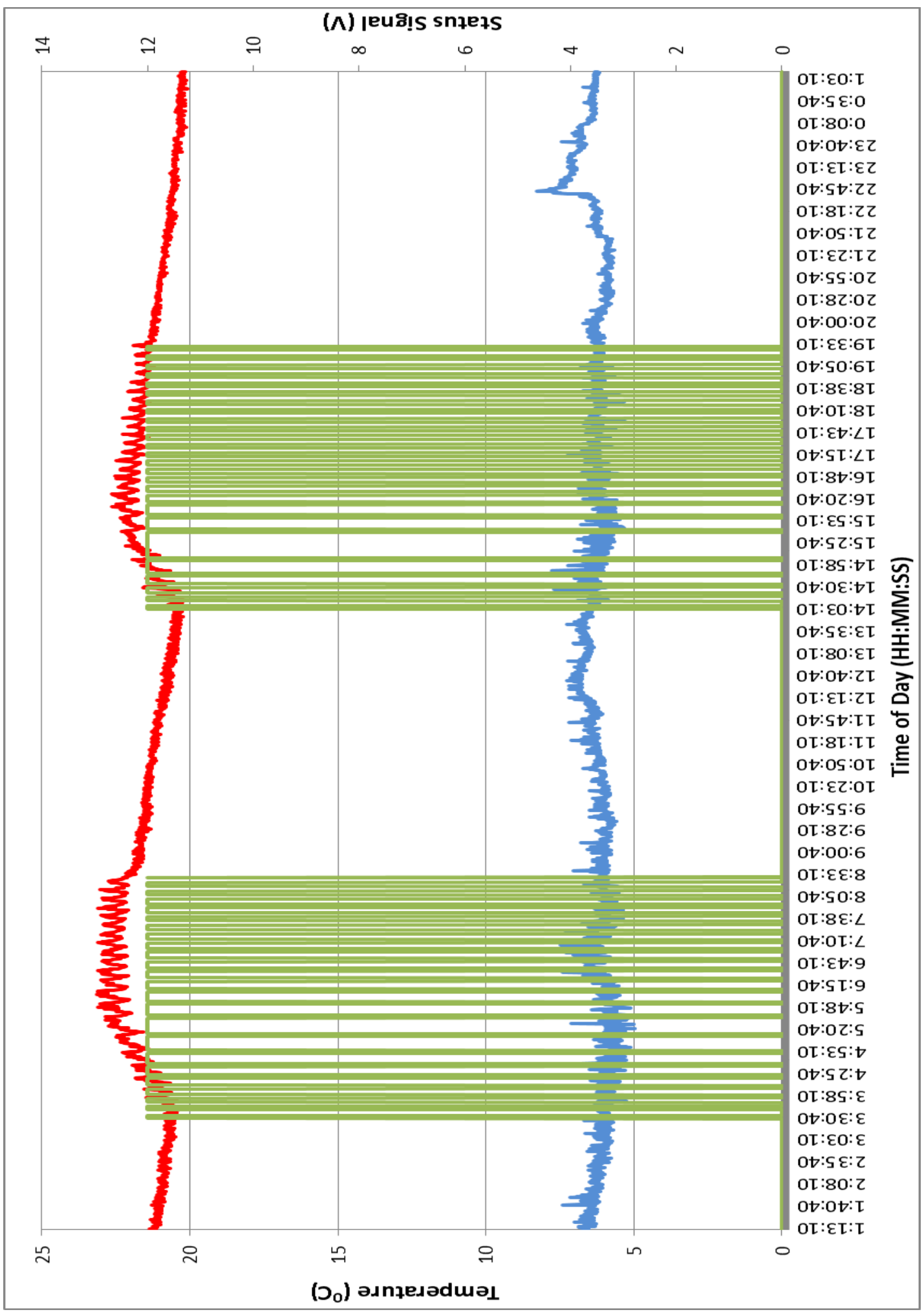

Figure 39 - Test 6: Temperature and Heating Data of the Full-Sized House (Occupancy-Based Temperature Scheme) 


\section{REFERENCES}

[1] Nest Labs, "White Paper: Nest Learning Thermostat Efficiency Simulation: Update Data from First Three Months," Nest Labs, Palo Alto, 2012.

[2] CanmetENERGY, "Zoned Heating \& Cooling Innovation," Natural Resources Canada, 19 November 2008. [Online]. Available:

http://198.103.48.154/eng/buildings_communities/hvac_energy_systems/publications/20 0815.html. [Accessed 25 May 2014].

[3] Smarthome Home Automation Superstore, "Residential Control System 2-Zone Controller," 2014. [Online]. Available: http://www.smarthome.com/3038A/Residential-ControlSystems-001-00242-ZC2S-HVAC-2-Zone-Controller/p.aspx. [Accessed 28 May 2014].

[4] T. Peffer, M. Pritoni, A. Meier, C. Aragon and D. Perry, "How People Use Thermostats in Homes: A Review," Elsevier Ltd., Davis, 2011.

[5] NRCAN, "Performance of Thermal Insulation on the Exterior of Basement Walls," Institute for Research in Construction, Ottawa, 1999.

[6] F. Incropera, D. DeWitt, T. Bergman and A. Lavine, "The Lumped Capacitance Model," in Introduction to Heat Transfer 5th Ed., Hoboken, Wiley, 2007, pp. 256-259.

[7] NRCAN, "Energy Savings Toolbox - An Energy Audit Manual and Tool," Canadian Industry Program for Energy Conservation, Ottawa, 2011.

[8] Energy Star Corporation, "Recommended Levels of Insulation," Energy Star Coporation, [Online]. Available:

http://www.energystar.gov/?c=home_sealing.hm_improvement_insulation_table. [Accessed 1 June 2014].

[9] A. Piot, M. Woloszyn, J. Brau and C. Abele, "Experimental Wooden Frame House for the Validation of Whole Building Heat and Moisture Transfer Numerical Methods," Energy and Buldings, vol. 43, no. 6, pp. 1322-1328, 2010.

[10] Semitec, "JT Thermistor, Ultimate Thinness," [Online]. Available: http://www.semitecusa.com/downloads/jtthermistor.pdf. [Accessed 23 February 2014].

[11] Tyco Electronics Corporation, "Coil Suppression Can Reduce Relay Life," [Online]. Available: http://www.te.com/commerce/DocumentDelivery/DDEController?Action=srchrtrv\&DocN m=13C3264_AppNote\&DocType=CS\&DocLang=EN. [Accessed 24 February 2014].

[12] C. J. Geankoplis, "Numercial Methods for Steady-State Conduction in Two Dimensions," in Transport Processes and Separation Process Principles, Upper Saddle River, Prentice Hall, 
2003, pp. 337-339.

[13] D. Rusin, "Heat Loss in House (Math Model)," 26 January 1994. [Online]. Available: http://www.math.niu.edu/ rusin/uses-math/heatloss/heatloss.01. [Accessed 18 April 2014].

[14] J. E. Seem, "Modeling of Heat Transfer in Buildings - Doctoral Dissertation," The University of Wisconsin, Madison, 1987.

[15] G. Platt, J. Li, R. Li, G. Poulton, G. James and J. Wall, "Adaptive HVAC Zone Modeling for Sustainable Buildings," Energy and Buildings, vol. 42, no. 4, pp. 412-421, 2009.

[16] National Sleep Foundation, "The Sleep Environment," 2014. [Online]. Available: http://sleepfoundation.org/sleep-news/the-sleep-environment. [Accessed 2 July 2014].

[17] The City of Mississauga, in Adequate Heat By-law 365-95.

[18] ZoneFirst, "Products," 2014. [Online]. Available: http://zonedampers.com/shop/. [Accessed 2 July 2014].

[19] D. R. Wulfinghoff, "Multiple-Zone HVAC: An Obsolete Template," Energy Engineering, vol. 108, no. 2, pp. 44-56, 2011.

[20] Ontario Power Authority, "Peaksaver Plus," 2014. [Online]. Available: www.peaksaver.com. [Accessed 17 April 2014].

[21] RF Cafe, "Density of Some Common Building Materials," [Online]. Available: http://www.rfcafe.com/references/general/density-building-materials.htm. [Accessed 18 January 2014].

[22] The Engineering Toolbox, "Specific Heat of Some Common Substances," 2014. [Online]. Available: http://www.engineeringtoolbox.com/specific-heat-capacity-d_391.html. [Accessed 15 January 2014].

[23] ZoneFirst, "Save up to 30\% on your energy bills with ZoneFirst Zone control systems," 2014. [Online]. Available: http://zonedampers.com/energy-savings/. [Accessed 27 May 2014].

[24] G. Hart, "Techs \& Specs - National Insulation Organization," Insulation.org, 2009. [Online]. Available: http://www.insulation.org/articles/article.cfm?id=I0090302. [Accessed 22 May 2014].

[25] M. Gross, "Conduction, Convection and Radiation Heat Transfer from a Solid Oxide Fuel Cell," Bucknell University, Lewisburg. 